TEXT Vol 17 Special Issue No 17 (October 2013)

Mud map: Australian women's experimental writing

\title{
Contents
}

- MTC Cronin, Prove love page 3

- Jill Martindale Farrar, Collector page 13

- joanne burns, corrida: a five poem suite page 19

- Jo Gardiner, The architect's dream page 23

- $\quad$ Loma Bridge, Casual, Diptych tourisms page 31

- Carolyn van Langenberg, Body parts page 34

- Jenna Sten, Supermarket page 40

- $\quad$ Pam Brown, Borrowed modifiers $\quad$ page 44

- Sal Brereton, excerpt from 'Treading water' page 47

- Sarah Holland-Batt, Littoral marginalia page 54

- Nour Dados, Lament on a postcard page 58

- Tiffany Hambley, Arrivals hall page 66

- Ashley Haywood, The wall reports (excerpt) page 70

- $\quad$ Teri Hoskin, The rectilinear case page 81

- Kate Lilley, Letters of caption page 87

- Maria Zajkowski, The specialist inbetweenery page 89

- Linda Marie Walker, Inconsolable: a film (extract) page 93

- Emma Ashmere, Portrait or landscape page 98

- Cath Davies, Milk glass (in conversation with Brooke Zeligman's Feast) page 107

- Virginia Barratt, She is a boy page 111

- Hoa Pham, Wave (novel extract) page 114

- Nasrin Matouhchi, The warmness of handling page 119

- Anne Brewster, Your mother's garden page 125 
- Jordie Albiston, Six black Saturday squares page 133

- Karina Barker, The inconsequence of offal page 137

- Barbara Holloway, Rockolalia, lithomania page 139

- $\quad$ Naomi Horridge, Flinders page 148

- Ella O'Keefe, Touching brick, Zone 1 page 151

- Jyanni N'Steffensen, Walking slowly wearing crimson page 154

- Gillian Barlow, Ruby page 163

- Robyn Ferrell, Whitefella worship page 170

- $\quad$ Gig Ryan, Rally, Central locking page 188

- Kathleen Mary Fallon, Spirit of France - a biography: Kaye Nine page 191

Note: This Special Issue of TEXT is non-refereed. 


\section{Independent author}

\section{T C Cronin}

\section{Extract from:}

\section{Prove love}

(by examining evidence of the imagination)

\section{Biographical note:}

MTC Cronin has written numerous collections of poetry (including several co-written with fellow-Australian poet, Peter Boyle) and a number of volumes of avant-garde cross-genre works. She currently lives, with her partner and three daughters, on an organic farm (specialising in fresh Spanish produce) in the hinterland of Queensland's Sunshine Coast, Australia. 


\section{defining terms}

\section{definition}

definition is how we fight off dream

how we make things certain

with whatever degree of certainty is above zero 


\section{imagination}

'when we imagine, we always imagine something'1

the unknown is known;

the hidden is visible;

the impossible, possible.

an enormous marine animal of serpent-like form,

frequently seen and described by credulous sailors,

imaginative landsmen, and common liars ${ }^{2}$

the future

the past

the present: you make what you can out of what's to hand.

your brain

imagining

your brain.

phantasia

imaginatio

that you are greek and latin.

ancient poets, philosophers, and psychologists consider imagination

a strong and diverse power, but unregulated it produces illusion, mental instability (often melancholy), bad art, or madness ${ }^{3}$

redly

chinesely

bigly

thinking about something contrary to fact

something novel

something not currently perceived

you, when we have not yet met

a sensible world rising and falling on the imagination

myself in love 
All the legal or illegal means, inclusive of mere argument, which tend to prove or disprove any matter of fact or fantasy, the truth or lie of which is submitted to judicial or poetic or any other kind of investigation or examination; as follows:

1. Oral: statements made by witnesses in this book.

2. Documentary: including public and private documents, and statements of relevant facts and fantasies made by persons in writing (includes writing done in any medium - eg, visible or invisible ink, blood etc; and writing done in any style - eg, poetry, official forms, last wills and testaments etc).

3. Conclusive: evidence of a fact or fantasy which the book must take as full proof of it, and which includes all evidence to disprove it.

4. Direct: evidence of a fact or fantasy actually in issue; evidence of a fact or fantasy perceived by a witness with the witness' own senses and senses not yet verified by science.

5. Circumstantial: evidence of a fact or fantasy not actually in issue, but legally or illegally relevant to a fact or fantasy in issue.

6. Real: evidence supplied by material or immaterial objects or subjects produced for the inspection of the book.

7. Extrinsic: oral evidence given in connection with written or unwritten documents.

8. Hearsay: what someone else has been heard to say or thought to think: 'what the soldier said or thought'; as contrasted with the direct evidence of the witness; oral or written statements made or thoughts had by persons not called as witnesses. Hearsay evidence is, in general, excluded, but the repetition of another person's statement (if executed poetically) is sometimes permissible, and there are express exceptions to the rule against hearsay (eg, anything sung).

9. Indirect: circumstantial or hearsay evidence; also any evidence gleaned by intuition.

10. Original: evidence which has an independent probative force of its own (eg., déjà vu).

11. Derivative: evidence which derives its force from some other source (eg, beliefs).

12. Parol: oral, extrinsic evidence (including any voices heard).

13. Prima facie: evidence of a fact or fantasy which the book must take as proof of such fact or fantasy, unless disproved by further evidence.

14. Primary evidence of a document is the document itself, or duplicate original.

15. Secondary: evidence other than the best or worst evidence, and which is rejected if primary evidence is available.

16. Dreams: had awake or asleep. 
17. Beauty.

18. Opinion.

Evidence must be given in open book viva voce, but for a book about love, provision is always made for witnesses to give evidence in any other form they choose. In love there is no choice so choice is provided in all other possible and impossible arenas. 
proof

Prove: To test. To experience. To suffer.

It is almost as if this transitive verb - a verb requiring a direct object - was created for the noun, the object, of love.

\section{Experience love. Test love.}

Suffer love.

Or do we simply imagine love?

Is love created by the imagination no less love?

How do you prove your love?

Can I spotcheck whether I'm in love? In the temporal lobe? In Anna Karenina? ${ }^{4}$

Proof is always disappointing precisely because it is not required. It is simply of something. As all our writings on love are not necessary being merely about.

Love is not about anything. Love may disappoint $u$ s but is not itself a disappointment. What is proved remains unchanged by its proof. So why do we act as if proof makes the real more real? (As if it makes anything, including a difference.)

What is the reality?

Love is. 


\section{what is evidence of the imagination?}

Merry-go-rounds. • Latin words and phrases. $\sim \bullet \sim$ What love does to the tips of your fingers. $\sim \bullet \sim$ The servant. $\sim \bullet \sim$ Arranging dances. $\sim \bullet \sim$ Dreams of followers. $\sim \bullet$ Ice drifting before the wind. $\sim \bullet \sim$ Pledge. $\sim \bullet \sim$ A drift-net. $\sim$ The sigh of an empty house. $\sim$ Absence of mind. $\sim \bullet \sim$ Your name the way you write it? $\sim \sim \sim$ Truth as it is constantly being alleged. $\sim \sim \sim$ Music and the revolution. $\sim \sim$ Great shows without reality. $\sim \bullet \sim$ The hand stirred. $\sim \bullet \sim$ Honoured. $\sim \bullet \sim$ Flying to the ground. $\sim \bullet \sim$ Compliance. $\sim \bullet \sim$ Plotting you. $\sim \bullet \sim$ A cross on the road. $\sim \bullet \sim$ The distance from what you hear. $\sim \sim$ A pea-shaped bone. $\sim \sim$ Aesthetic norms. $\sim \sim \sim$ A body of secret intriguers. $\sim \sim$ (Camarilla.) $\sim \bullet \sim$ Adoring reason. $\sim \sim \sim$ Companion of the lie. $\sim \bullet \sim$ Credibility. $\sim \sim$ The philosophy of diamonds. $\sim \sim$ Interference with time. $\sim \sim$ Willpower. $\sim \sim$ Inventing the raisin. $\sim \sim$ Luminous conversation of blood as it roars above the earth. $\sim \bullet \sim$ Nerines. $\sim \sim$ Being satisfied. $\sim \bullet \sim$ Bladder gently filled with sterilized water. $\sim \sim$ The glimpse stretched out. $\sim \sim$ More and more iffy. • Journeying. $\sim$ To face from where you have come and smile. 


\section{love \& definition}

Love definable. Not too narrow. Not too broad. Nor circular. The defining expression exactly matching the degree of vagueness or precision of the expression being defined. How inaccurate every judgment. How accurate loving. Even a love thinned down. Becoming more and more naked. Necessary. Unnecessary. Nothing changes it if it is. Though definitions fall into at least the following kinds:

analytical a love true in all possible worlds as well as a love necessarily true. They could love though. Conditions all cleared. Fate is nowhere near as certain.

contextual $\sim$ expression as it occurs in a larger expression. They love in summer. The love is such-and-such. Like a warm day that falls into the night's cool arms.

coordinative $\sim$ theoretical love as felt by non-theoretical lovers. Vice-versa. Love experienced in stories. Love retold and felt again.

definition by genus \& species brief love is love. Forbidden love is love. Love that falls short is love. What is not love is defined purely by self-interest.

definition in use as it is impossible for love not to always be.

explicit definition clearly love means the moment you spent as what you are not. Love is only love if you forgot yourself.

implicit definition love is not something to worry about.

metaphorical definition heavenly, heavenly, stones, teeth, hate, morality, and ships, even flowers and balancing on what will not hold us ... I love you like multiple possibilities. Like trying.

nominal definition typically in terms of macrosensible characteristics, as in, 'butterflies in my stomach' for love or 'a fat new moose of a lover in his boney head'. 5 Though it is possible to ask what butterflies would be doing there; if 'bony' here is meant to have the 'e' in it; and whether anything to do with love makes sense. (Fortunately 'Locke spoke of nominal essence and contrasted it with real essence'. ${ }^{6}$

lexical definition love appropriate for the dictionary and able to be looked up under every word.

ostensive definition apparently love needs to be pointed to. This is the only case in which the movement (indicating the thing being defined) is judged upon the style of the gesture rather than on the alignment of the definition with the thing that is being pointed to. Similarly,

persuasive definition there have been few who have needed to be persuaded however it does seem true that over time persuasion becomes more and more necessary. Persuasion rarely convinces. 
precising definition $\sim$ definition of a vague expression - love - intended to reduce its vagueness, as in 'in pieces or entire; its presence veneers over want; in all its moving parts, it could be something else' ${ }^{7}$ (line breaks removed).

prescriptive definition love giving a new meaning to love? Baudelaire knew well of this with his little flea-bag wife with a halo. The impossibility of it and the way it occurs to us that our own love always does this impossible thing.

real definition $\sim$ specification of the metaphysically necessary and sufficient condition for being the kind of thing a love designates:

Our bodies fall.

Our wills fall.

Our virtues fall.

Our happiness falls.

When I know your 'oneself'

we rise up

higher than all

these things.

We do anything.

And all it may lead to.

stipulative definition regardless of what love usually or ordinarily is love is always something different. 'By 'zoobeedoobah' we shall mean 'vain millionaire who is addicted to alcohol'. ${ }^{8}$ Love might mean much the same thing.

synonymous definition for example, 'god for love'; 'obligation for love'; 'pain for love'; 'madness for love', etc., etc. Love has more synonyms than any other known word. Love is anonymous. Love's pseudonym is your name. There is only one antonym to love and it is not known. (Though the antonym's meaning is that love has no antonyms.)

syntactical definition $\sim$ when we know what we stand for.

tautologic definition despite reality, what is true, and including the consequences of truth:

(There is no question.

- $\quad$ 'What is love? Any type of love?

- $\quad$ The best definition is simply: Love is love.

- $\quad$ Have you suffered much for love?

- $\quad$ I am prepared to suffer even more.') $)^{9}$

working definition love allows

$\sim$ what follows. [Consequences is

the name of 'a game describing the meeting of a lady and a gentleman and its consequences, each player writing a part of the story, not knowing what the others have written'. ${ }^{10}$ ] 


\section{Endnotes}

1 Audi, Robert (gen ed) 1999 The Cambridge dictionary of philosophy, second edition, 1995, Cambridge: Cambridge University Press, 417

2 Macdonald, A M (ed) Chambers twentieth century dictionary, new edition, 1972, Edinburgh: W \& R Chambers Ltd, 1221

3 Preminger, Alex and Brogan, TVF (eds) 1993 The new Princeton encyclopedia of poetry and poetics, Princeton: Princeton University Press, 567

4 Waldrop, Rosmarie 2003 Love, like pronouns, Richmond, California: Omnidawn, 35

5 Davis, Olena Kalytiak 2003 'poem for my \#* birthday', Shattered sonnets love cards and other off and back handed importunities, New York: A Bloomsbury/Tin House Book, 83.s

6 Audi, Robert (gen ed) 1999 The Cambridge dictionary of philosophy, second edition, 1995, Cambridge: Cambridge University Press, 214

7 Swensen, Cole 2004 'Two', Goest, Farmington, Maine: Alice James Books, 11

8 Audi, Robert (gen ed) 1999 The Cambridge dictionary of philosophy, second edition, 1995,

Cambridge: Cambridge University Press, 214

9 Lispector, Clarice 1992 'Lightning interview with Pablo Neruada (II)', in Giovanni Pontiero (trans) Selected cronicas, New York: New Directions, 66

10 Macdonald, A M (ed) Chambers twentieth century dictionary, new edition, 1972, Edinburgh: W \& R Chambers Ltd, 276 


\section{Independent author}

\section{Jill Martindale Farrar}

\section{Collector}

Bibliographical note:

Jill Martindale Farrar is a poet, journalist, academic and fiction writer. She has had a long career in journalism researching and writing for mainstream magazines (Vogue, Mode, Cleo, HQ, Elle, New woman), metropolitan daily newspapers (Sydney morning herald, The daily telegraph, Australian financial review) and national radio (ABC Radio National, AWA Radio Network). Jill's poetry has appeared in Meanjin, Overland, Aspect, Your friendly fascist and Womanspeak. Her PhD (UWS) thesis examined fictocriticism through a work entitled 'The glossary' and its novel 'Through glass'. 
I am a collector.

\section{Contemplative.}

A collector of words.

Calabash. Nougat.

Say them over to yourself. Run them round your mouth. Con-tem-pla-tive. A flamenco tirade interrupted by 'pla' - a 'who cares' light as poof. Ca-la-bash. A word I just want to sink my teeth into. And Nou-gat. So dense one's jaw gets stuck half way through.

I know they are just words, as my Ex would say. Yet words at times seem all I have, seem all I'm made of.

They protect me and comfort me. They lull me to sleep at night and cast a spell on me as I gaze out at the Gardens at lunch Words are the black and white of a nun's robes, with all the shades and feelings contained within the habit, pun intended, of common usage. Though I realise most words, ultimately, need to go together to generate meaning. There is something spare and arresting about certain singular words.

Oberon - They don't - Opulent - go in any - Ostrich - specific order. But I play with different combinations, as a thief at a locked safe.

Oberon, oberon, ostrich, etiquette

Vellum, dumpling, taboo.

They are song lyrics, they are polaroids. They are chess pieces, worrybeads and dice.

Nonsense, my Ex would say, they are just words.

My Ex is my former husband - an expression I find myself trotting out more and more as if to justify whole swathes of misdemeanours. He would have made this pronouncement, just words, as though they were two distinct entities: Just. Words. 'Just' as in merely, never 'just' as in mot juste. He would have thrown the phrase up, the way people throw up their palm, speak to the hand, after I had let slip my enthusiasm for some new moniker like a kid who finds a birds nest on the way home from school.

Parasol. I might have said to him across the dinner table. With a deep breath I might have exhaled adamantine, or, glitter. Just saying them would bring a smile to my lips and the corners of his mouth would draw in. His shoulders would do a small upturned semi-circle to show me he was trying to be patient. Trying not to sigh. The size of the semi-circle would be in direct proportion to my enthusiasm. The greater my birds nest, the tighter his coil. It would take huckleberries or etiolated for him to look at his watch and push his plate away, suggest we move to the living room. Being a words person in his estimation put me on a par with next to useless. They wouldn't 
help in an emergency, he would patiently point out paring his toenails; they won't change anything.

Patient, I said, is an interesting word.

Each day I take my sandwich into the Gardens at the bottom of the sandstone cliff, and take off my shoes to feel the cool grass under my feet.

\section{Talisman. Marzipan. Date.}

No matter if I take an early or late lunch, there are always joggers plying back and forth in counterpoint to the ferries on the harbour. I have no objections to conversation and company, but mostly what I crave in the middle of a working day is some middle distance to stare into. A neutral backdrop on which to page through my collection of words. Not just any words. Not just empty words. Words that seem to promise something - something always tantalizingly just out of reach.

\section{Casbar. Cantilever. Cadeaux.}

It is often a wrench to take myself back to the office and temporarily leave my words and the Gardens behind.

At work it is all about parties. As in, 'the relationship between the parties', and, 'the parties expressly excluded' subject to and hitherto aforementioned. The parties have agreements, arrangements and termination dates. They have voidable terms, they have waivers and most of all entitlements. In my book, 'entitlements' would be small things passed on trays at Friday night drinks. Another entitlement with your martini, madam?

In reality they're bulleted lists printed without thought for aesthetics, tonality, nor shape, nor form. They are like very badly (I almost wrote 'baldly') choreographed sequences. They are bulkily put together. They move in ungainly ways from hyperextended clauses defining what they are not, to accusatory statements of fatuousness. My editing hand hovers in despair over a page that has neither the momentum of a pirouetting ballerina nor the definitive gesture of a work of Noh. These pages are like watching someone uncoordinated jog.

Sometimes I would have liked to have been a painter. Or a dancer. Or a bird. Something more succinct, more defensible than a words person. Because there are always words one should have said and ones one shouldn't have. And yet I am paid to be a words person. Paid to what they call wordsmith things - pieces of other people's text, other people's poorly thought out meanings. 'Just go away and wordsmith this for us would you,' they say and I obediently shuffle back to my cubicle.

Individual words have for me a beauty and melody to them which resonate outward, like rings in a pool. 
People are always looking for explanations for things. I want to confront the reader by which I mean the world - with the single, isolate word. (Without prescribed explanations). I want them to feel their muscularity, their poetry. Their cool, solitary existence, that doesn't promise anything beyond.

As a child I would sit on the train going home from school and try to listen to the other peoples' conversations as though they were speaking in a foreign language. The idea was to re-experience my own language as though I had just arrived from Kalamazoo. It takes effort to produce this effect through one's ordinary, everyday ears. But the process is a little like squinting to get a better look at a painting.

Take 'fell'. A beautiful specimen. It seems to me it should be something verdant and mossy green. I'm probably thinking of 'fen' but I won't look it up in the dictionary or else I will lose my image of something dark and damp, but delicious - the crease between a woman's breasts, the join between buttock and thigh, the dip between hillocks, the damp earth smell of under the veranda. Fell. And yet in its most common, obvious meaning it is also superb. Fell. It is a ballet. It is a succinct history of something damaged. We fell apart, if you need the longer version. Or, even longer: we fell in love then, we fell out. But should anyone ask for my life story and say, 'but give me the brief version, I have a plane to catch', I would just say, 'Fell'.

We are all given a word at birth. And then other words crowd in and some words are called nonsense. We must hide some words and only display others. Soon we have whole legions of the things sloshing around inside us and we wonder that no one understands us.

Though one sees words and hears words, it is the saying that really counts. Say you love me. Say we elope. The love of them is fundamentally a fusion of these other senses - seeing, hearing - and wanting to mouth them. Which is also tactile. Some words like balm or milk, melt on the tongue, thrilling the surfaces of the skin. There are those which must not be used around or close to the eyes, the lips, the mucosa: like cruel intentions or acid tongues. Those which must not be ingested or swallowed: caustic wit or withering sarcasm. The mouth is the exploratory orifice and the first point of entry to the body where we are told 'Don't': 'Don't put that thing in your mouth'. There are certain words that can only be held in the mouth in private.

If I imagine my life I think of the sadness that descends on me in a hotel room, on day two, when the room has been cleaned and all trace of me has been expunged, like evidence from a crime scene, bar a few items of clothing and a toothbrush.

I waited in a hotel like this once for a lover who said she would meet me there. There is something sad about a television turned down so low it sounds like the people are quietly heaving or clearing their throats. 
No one really looks at the words or where they come from. And they always think they can do better.

Though I recite them like rosary, in my mind where I really see them - or really perform them - I can't get enough space around these words.

I want them in a gallery, writ large or small, roman, capitalised or italic, but with vast areas of white around them.

\section{RENDEZVOUS}

\section{REQUIEM}

Hope.

I want my words - and I think of them as my words - to command attention. I want each to be an utterance like a Rothko painting - a whole room full of Rothkos. This seems grandiose as I write it down, but it is the words which wield the power which is what I want to release.

In this supposed gallery - which is more like a cloud - I want the words to have free rein. Each reader generates links between the words, creating individual story lines coalescing like raindrops or, briefly glimpsed, like rainbows, but without the pressure of having to be anything. Without being typecast.

I want them proliferating various contexts - not spelled out or enclosed in the strictures of syntax (though syntax is another favourite word).

I recognise the irony that my fascination with words does not necessarily make me a successful communicator. Though my Ex in the middle of an argument used to say, 'It's easy for you, you're a words person', I think he exaggerated the benefits of a facility with words.

I mentioned the sadness of my life if I imagine it, as I picture it, as it is. My emergent life on the other - my life as it could be, my 'cloud gallery' life if you like, where my words are suspended and yet to be yoked to a narrative - is more that of a pointed toe drawing an arc in the sand.

These two lives - the as-is and the emergent - meet at the arc in the sand, the beginning of a gesture, a movement, and its erasure ... The moment I can't see forward any further - the impossibility. Yet this so-called impossibility, the moment when the dancers' bodies are suspended in mid-air - this is also the great escape. This is what I'm after with my words. In this frozen in mid-air moment - where the movement's intensity is released, and also releases a kind of well-spring in the heart of the observer: my 'self'. I'm not able to explain all this very well, but just as a gorgeous sight makes one catch one's breath - is it the sheer impossibility of it or, is it, the 
reality of its materialization - this 'impossibility', what the dance world calls balon (a quality of elevation like a bouncing ball, which cannot be taught) is what I want to capture in words. In some new form of expression.

And I am trying hard not to ask a question.

Life seems to pose imponderables and I am tired of that whiny tone and messy appearance of a whole pile of questions. They never come as one neat Q and A. Nothing that can be laundered, ironed and stowed in a drawer.

\section{What am I trying to express?}

Each word is a drama ... and yet ... focussing on the words not the sequences of events, I can fondle and shuffle them, polish and improve on what might have been. Everything I fall in love with is impossible ... what therapists call magical thinking.

I realise I am being contradictory. On the one hand I complain about these, I hesitate to call them, documents on which I labour from 9 to 5 to drag them kicking and screaming into some semblance of eloquence, and then in the context of my own words I want the reader to simply appreciate them, to be struck by their justness. Why can musicians play with notes and I must make sense?

There I've asked another question. The fairy door is open and I'm falling down the dell, the well, into the fell and all the questions have come tumbling out.

Why didn't you show up? Why did you hang up? Why don't you love me? And Why am I not surprised?

But if I write 'why' and leave it without its accompanying punctuation mark '?' then it regains a pleasant musicality. It becomes a firm down beat - WHY - with a slight twang at the end - why - the visual coiled tail of the ' $y$ ' on the end of the script satisfyingly echoing the way the jaw and tongue retract in the enunciation of it. It is no longer the querulous, persistent annoying little creature, 'why?'

I want my gallery to be a place of refuge for the perplexed, the discombobulated, the etiolated. People sick of being told they have a communication problem. I want my words to screw the 'reader's' patronising smile and savage their right to remain silent. I want to puncture their pallid obfuscation with some sharp, pungent words.

But between the entreaty and the articulation, between the dancer's jetée and arrival en pointe, there is the impossibility of ever knowing what was meant or said.

Fabric.

Collector.

Balloon. 


\title{
Independent author
}

\author{
joanne burns
}

\section{corrida: a five poem suite}

\section{Biographical note:}

joanne burns is a Sydney poet. Over a dozen collections of her writing have been published. Her most recent book is amphora (Giramondo Publishing 2011). kept busy, a CD of joanne burns reading a selection of her work, was released by River Road Press in 2007. She is working on a new collection brush. 


\section{i. business as usual}

it's war, the meat pie bonus staff were arrested offended and intact that's what you get with the arms-length approach to the corrida's history although bakers have more control over their pies people want to see real chunks; still the platinum diversification code means it's not all meat, ravenous fans have been seen romancing fish and vegetables in the hybrid blood spas so surprise surprise

the jaguar threw a lavish party on a host of solar panels i'm a bit nervous doing my sums in the steel mill foyer the thought of that green halo eloping - the window would only wind down just an inch stone walls are still a feature of a head

\section{ii. manifest/er}

the surprise decision on the bumpy road to grammar, a coup in the diary covenant well received; trapped in its own web the vacant chair diverse as an emotive phrase restructured the backyard; and who would have imagined a bus driver to return like a prodigal sun from the versailles exploration thesis, the arrival party at the tower of london was acute and taciturn - some still believed it was best to trim the hedges some were tight lipped about the rosey picture - and this could wipe out any benefit from the plan to divide the good from the bad everyone was happy though about the 19 billion sound rescue package the final comment 'we misjudged how quickly syllables could turn around' one of the best sellers was the seamless camisole someone suddenly declared 


\section{ii. tough love}

it's the city of optimists

the bulls are roaring

over the leftovers shining

like gift cards there

are pizzas so new the

olives are still on the trees

here are pavements lined

with almonds myth solid

as guides to the holy land

and spiced lamb on tooth picks

to sample while the chefs

get on with cooking the books

and the patient ocean so

energetic in the titanium lobbies

no shortage of people to count

\section{iii.lotional}

portafiled in waterproof snaplock plastic share portfolios will bide their time like projected family weddings you ought to be congratulated mums and dads for feathering your nests intoned the presidential spectacle/s from a harbour newsroom it's all ship shape my friends leave the old pacific chunder of tin coins and the crested carpet that pokie spew is for the mugs shares can be your shoreline or think of it as share farming, as our pastoral heritage - he ploughed her and she cropped - the pumpkin will be golden blue or butternut -

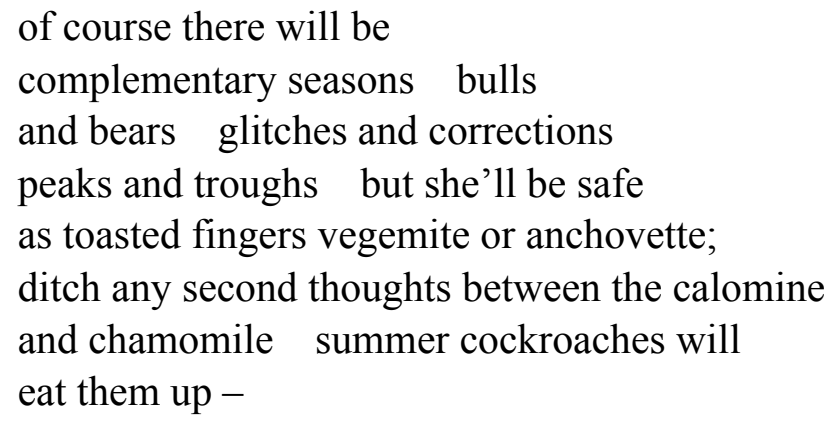

\section{iv. hilt}

the giveaway dead flowers boom:

sprawling mines contemplating 
entertainments: the grass pallets slide: niche profits on a global dive, you pitch my pool into a passing buck and i'll ride you into bank-ruptcy: equine woodchips pulse for pulse; pretty forecast, sleep easy on the oil rig bud while the internet circum ambulates the rampant hedge like a stylebook parent naked in autumn toxic bones defend the tight rope with choc aholic con-fidence have you recruited yet that winner, jitterbug! 


\section{University of Western Sydney}

\section{Jo Gardiner}

\section{The architect's dream}

\section{Biographical note:}

Jo Gardiner is a poet and novelist who lives in the Blue Mountains. The concerto inn was published by UWA Press in 2006. 


\section{Brief}

The opening phrases of a prelude arise as the architect retrieves a letter from the post, rubs her thumb across the envelope, the texture of the translucent paper. Seeking some sign of its origin, she flips it over and reads the name of her new client, an aging writer who first contacted her a month ago requesting her services. She saves the letter to read later in the evening and it tucks itself in the back of her mind, remaining there like a half-remembered fragment of music.

As darkness falls, pianissimo, the architect drifts through the other rooms of her house to the place she calls her drawing room. The drafting table is arranged under the window by the fireplace. On this table, beside her T-square, lies a copy of the client's novel which she has been reading in the evenings. It carries the title of a lost concerto.

An overture of wind is fluting through the eaves. The architect bends to the fireplace to set a fire. She strikes a match and holds it quite still until, with a little burst of flame, it catches the paper. She stretches out her hands to the warmth, then sits at the table and adjusts the light so that the letter is fully illuminated. As she opens it, she senses her own excitement. It's as if it were, somehow, a love letter.

Upon reading the opening lines, she sees that the letter is written by someone who is passionate about architecture, about the possibilities that lie in the arrangement and rearrangement of space. The letter possesses the attractions of a close-woven story inscribed upon leaves of silk in an ancient manuscript. Its distinctive handwriting appears as a graceful calligraphy. She stokes the fire before addressing the brief.

'I'm seeking an interpreter, asking you to design a sensation, to construct a shelter for the words I have collected over my lifetime. I wish to have a house for my books, my manuscripts, papers and dictionaries. I want a place of repose where I can work at a desk that looks out over the valley down to the hanging swamp. My wish is to bring the landscape into the structure, so that mists move into its rooms and birds fly through the overhanging eaves, mistaking them for branches.'

As the architect sits before the fire with the letter in her hand, ideas sift through the night. She thinks of the building as a small cathedral dedicated to language, a place from which the music of words will float. She contemplates the construction in her mind, engaged by a chimera, a passegiato of ideas, seeking a visual coherence. Her task will be to awaken the music within the building and make it eloquent. Intent upon marrying form with air she engages in a choreography, an experimentation in performance and form. She travels through the winding dark to the realm of dreams.

In the territory of sleep she takes the old writer's words and makes her own shape. She will build a space to house ideas where writing has materiality in text, the architecture attempts an analog in space and light. From the novel she understands, deeply, the architectural skin and tissue of the writer's work and discerns that once a space is loosened, the dual questions of how to construct a work, and how to construct a life, emerge.

She seeks to build a shape from ideas in close response to concerns of light and proportion. She will give ideas rooms to speak in, move across, doors to pass through and windows to gaze from. 
She dreams of a shimmering building made of rich, woven glass and the rarest fragrant foreign woods. It has gateways to the east, the north and south and is arranged in two storeys with a flight of stairs linking the upper and lower chambers. The rooms are furnished with lamps of gold, bowls of hydrangeas, Japanese wash paintings and separated by fine veils. From each room drifts the scents of honey and oil.

Surrounded by gums standing like slender columns, the building is a complex structure designed to withstand the blight of winter, and like a wooden pagoda, to give shelter from the sun. There is movement in the closing of a shutter, the opening of a window to allow entry to birdsong. The eloquence of the building lies in the way it responds to the light and in the rhythms and harmonies of its construction. As a thing heard, it resembles a stringed instrument - a cello, a violin - and produces a new musical language of languid ascending and descending notes.

\section{Site}

The first movement opens with the architect visiting the proposed site on the eastern side of a harsh and barren valley. Here she finds feather-shaped grasses concealing tiny florets of thought. The land speaks an ancient language of geological disruption and upheaval of the different layers of the earth's crust: lava flows, basalt domes, soft shale, sandstone embedded with lizard skins, fossil seashells and beds of granite and quartzite. High cliffs are enveloped in cloud. The ground is figured. As she stands there, a site emerges from the landscape. She notices that it's already occupied by an old shed. Rather than demolishing it, she plans to take possession of it and make the new building a renovation of an existing storey, a surface alongside this other surface so they coexist with their contiguous stories, one set in the footprint of the other.

The architect sits and observes the way the light moves throughout the day across the site, imagining the texture of the building among the trees. A trail of dust appears up the road and snatches of music disturb her train of thought. She looks up from her site notes, as the builder arrives with his apprentice in a ute loaded with plumb lines, float levels and carpenters' squares. In the tray a blue cattle dog stands delicately balanced on a stack of off-cuts. The ute draws to a stop, and the builder emerges from inside, slamming the door behind him. The dog leaps from the back, and with the apprentice - a young woman in grey overalls - follows him down to the site. The radio continues to sing operatic music and voices enter the site by a stairway of fifths, rising through higher octaves, until there is a polyphony of voices, each located within the other.

The architect soon learns that the builder is a blowhard. He holds one eye closed to the sun as he offers his experience in making materials and structures perform to their limits. He reveals a mind geometric in its construction, and like his hero, the architect Dave Hickey, he is wary of theory and opts for 'palace architecture'. His voice grows low. She can smell the scent of sweat and wood shavings floating from his shirt. $\mathrm{He}$ smiles to himself, his face flushed with self-importance. 
'Dave says Vegas is like Venice in that it's a continuous architectural environment and a slut. It loves you whether you like it or not. It gives you everything it has and breakfast, for $\$ 2.98 . '$

The apprentice looks away from the builder. Her gaze finds the cliffs at the edge of the site. The architect is uneasy. She frowns. She dislikes what she hears but she has seen the way the lines of his buildings fold into their landscapes. Her attention is caught by the apprentice who stands a little way off, detached, watchful. Over the coming months it is the apprentice whose misreading and mistakes will cause both the builder and the architect perturbations and prove invaluable. It is this silent young woman who will show them both that in essence, life is what is capable of error. Without a word the architect turns away and starts setting out stones on the ground, making the first marks of the map her plan will become.

\section{Plan}

With sudden leaps of intuition the architect plots some internal elements and on a plan specifically designed for instability, sketches an ambiguous play of volume and space. She dwells in it, and as the night deepens and the building unfolds from east to west, she organises the space around a central room - the existing shed. In a reconfiguration of multiple stories, each of which succumbs to the desire for repetition, she constructs strongly figural forms out of a thick assemblage of scrawling, scratching-out. Each part performs a specific structural role. She seeks a synthesis of rhythm in her temporal order, and geometry in her spatial order. There is soon a density of additions and subtractions, an interplay between atmospheric zones and strict geometries. The inherent beauty of the construction lies in the gathering of its parts, in the converging of its lines, the alternation of materials. She creates a structure woven from a gently rhythmic unfolding of ideas. The emphasis is upon the horizon and the horizontal, bringing the mountainous landscape into the structure. She collects ideas from her boneyard - the journals and notebooks where for years she has kept diagrams and shapes in soft residues of ink, to be dug up when required.

Seeking a harmony of elements she works slowly through the night, weaving solid and space together, designing from the inside out, with each opening expressing the entrance to a new interlocking interior space. When she is finished the plan, she determines that it will be read as a musical score. She composes an ornamental concerto of fast, repeated notes and structures them temporally in a complex of recurrences until the main melody returns again and again in decorated form.

\section{Section}

In her dreaming sleep, the architect hears a wistful, foreign music, a recurring passage varied in length and by transposition into other keys.

The strata of the construction resemble geographical layers or layered textures of musical planes in a concerto created by coalescing differing tempos and rhythm patterns. 
She finds herself spending more time at the site than she would normally allow, and when not present, believes she can hear the sounds of the hammering of secret nails. One evening she visits the site and becomes aware of the building's stillness. The sense of a temple is present. The roof glistens in moonlight. A thick skin of marine varnish over the wood adds a layer of luminosity. As she renders the plan in section she can see a network of brushstrokes.

She hears a small sound and comes across the apprentice rousing from sleep in the half-constructed library, the builder's dog at her side, its head upon its paws. It seems that the apprentice is occupying the site. The architect sits down beside her, spreads out the section and elevation drawings and, deciphering multiple perspectives, they examine the plans together.

\section{Glass}

As the night shifts and the dream deepens, the library evolves in a movement that is a nocturne, a night song. It emerges from the site rich and harmonious. Following the architect's design, the builder constructs an elegant pavilion, a summer palace. The treatment of the elliptical curved roof objectifies its presence. It floats above the body of the building now cleared of anything superfluous, and sheathed in glass. From within, the windows construct the landscape outside.

The architect invites her client to taste the sweet, crumbling cake of memory. Step outside memory, to accompany her on an inspection of the work-in-progress at the site. The apprentice follows them closely. The old writer shows her stories inscribed on the exterior of the lofty walls of the library. Her voice is soft. The apprentice hears an incantatory song. When she lifts her head she sees that the building culminates in the floating roof that envelops the whole construction. It resembles a curving, floating wing. She does not blink.

Each room resounds with their voices, their footsteps and the sound of their breathing. They pass along walls into corridors, up steps, past niches. They imagine they see a glass staircase. They follow the fluctuations in light until they come to an idea that is offered like an extended hand.

The library is constructed almost entirely from glass which gives multiple interpretations. Here the glimpse of an illuminated hand reaching for a teapot floats in the garden. A lamp, unattached to its wall, appears in the darkness. Theses overlays, superimpositions are created in the reflections of the glass, like the drafts of a novel. These reflections involve the client in a process of turning, folding back. The glass invites her to fix her thoughts on a meditation, a remembrance, a recollection.

\section{Interior}

The music begins again - a long elegiac, slow movement that ends in a silence ushered in by the beating of wings. You can feel the breeze made by these wings. The architect leads her client deep into the interior of the library until they come to a locked door, the entrance to what was originally the shed. Thus the building conceals 
a hidden interior structure, a covert narrative.

The client pauses a moment before entering and the apprentice detects in her a shiver of desire or fear. She is watching her carefully. Her face is grave; she seems older, vulnerable, as if ill-health or adversity will carry her off. The architect produces a glass key from her pocket and they enter the interior room where language lies in wait in a strange diffuse light. This part of the building is like a walled village in the heart of a large city. Here, nothing is as it seems. It's a construction full of mazes that seem to offer a way out but box one in instead. The subtle gradations of light and dark confuse. Everything here is at the level of symbol, emblem, sign.

\section{Passage}

A short musical passage links the darker mood of the previous movement with the full-throated response of the next one. As the piano's right hand is followed by a calming passage of tremolando, then a gentle counter melody, the air becomes the colour of manganese violet. The sharp, metallic smell of rain comes. The room darkens as a storm rises and breaks over the building. The rain sets up a pattern on the gently sloping roof which collects the cold water in gutters shaped like cups, and conducts it into pipes and away from the roof. The wood creaks as it shivers and contracts in spasms. The rain slides across the darkened glass.

The three women pause, waiting. Suddenly there is a rapid sequence of notes, and a narrow seam of light appears at the top of the roof. The sun emerges and the washed glass glistens in the light. It is here in this passage that a transition from one state to another occurs, for it is via the passageway that together they escape the prison room of language, leave the gendered space of the locked room, and enter the writing room.

\section{Writing room}

The composition unfolds in a rich, musical language. It is clear that for the client, writing is life itself. The apprentice watches her move quickly, smiling, into the light and airy scriptorium, a place she will remake herself through writing. She glances around. It is an awareness of the importance of this process that informs the undercurrent present in everything the architect has created. For the client, language is a doorway. When she steps across the threshold she finds herself free from the practices of expert knowledge. It will be in this room that the meaning she makes will constitute her life. She pauses at the entrance, entranced by the power of possibilities here on the edge of meaning, each limned with a new thought. It is in the writing room that the client apprentices herself to a richly illuminated manuscript inscribed upon velvety smooth vellum. The text is bordered with gold chiaroscuro scrolls, cameos, pearls, and images of musical instruments. The frontispiece is designed as an architectural entrance into the book. As the pages are turned there is the graphic unfolding of a journey far across the reaches of a world. Inscribed there is the Chinese character for poetry composed of the character for temple and that for word. 


\section{Garden}

Towards evening the architect and the client hear the simplicity of a pastoral movement as they enter the garden. As she follows them, the apprentice feels her hair lightly brushed by the wings of a low-flying bird.

A secluded, exterior room, the garden offers stillness. Animated by light, it is the most open of rooms. Here, engaged in the production of her own life, the writer will become other than who she is and, transformed by memory and desire, slip out of the story that self is.

The building is grateful to the garden in which it rests. It stands burnished and gleaming after the rain shower. The pond appears as a large basin of polished silver like those used by alchemists to collect and condense moonlight. It offers its face to the sky.

A breeze arises and they hear the movement of trees and see petals falling or birds dropping from the white limbs of ghost gums. They glance at each other, their faces so warmly lit they appear like lamps in the dim. The light moves. The evening star appears. Darkness will soon come, and long after the music of it unfolds, when night arrives like an animal settling down upon its nest, the apprentice will remain in the garden navigating the night by the stars like a mariner.

\section{Completion}

The final cadence of her dream finds the architect still at her drafting table amid a synthesis of form, line and colour. Surrounded by blueprints, specifications, scale drawings, elevations, sections, she is contemplating the illusion of completion. The library can only be conceived of as being completed when it has had bestowed upon it the texture of difference and incompleteness. In the end, her building stands like an unsolved enigma, an unheard piece of a concerto with an inclination to suggest something other than what it is - a shed.

In her dream the night is steeping, and the air is growing colder. The fire has died down. Just at the point of revelation of the confluence of the geometry of architecture and the structure of writing, there is a slippage in meaning. The architect rouses from her reverie a little and turns towards the fire for warmth. She becomes aware that the plans of her unbuilt ideas are slipping from her knees onto the embers. As the possibilities of meaning drift away from her, she knows that her dream has stirred her consciousness with infinite possibilities by approaching the brink of meaning, yet never falling over it. In sudden combinations, she has glimpsed a melange of images in the laceration, the slaughter of sentences. She smells paper burning. She senses the disintegration of the figures in her mind and before she can wake herself fully, the plan catches alight. Its secret cohesiveness is revealed and continues on as a line of thought that disintegrates. The distressed surface of language bubbles and cracks in the heat of the flames. A strange mood passes through her. As an endnote to her dream she hears the concerto commence a long, slow decay into inaudibility. Fire overcomes the building. Words spark above the bonfire and writing at last becomes possible. In just a few seconds the architect's plans burn and exist only as an 
afterimage. They disintegrate and will be interred in Hejduk's cemetery for the ashes of thought. 


\section{Independent author}

\section{Loma Bridge}

\section{Two poems}

\section{Biographical note:}

Loma Bridge is a part-time writer, editor and visual artist. She lives in Sydney. 


\section{Casual}

Landscape as an escalator. Down the down river. The river is not flat.

In Mathematics $1+1=2$.

In the soul it is possible that

$1-1=2$.

Kandinsky

Gaining the escarpment she pushed on through paddocks full of steel woolled sheep. The ridges they made in the earth zig-zagged down the hill like a parliament. She saw below the river that had been gouged out by the giant Kauri tree. It looked treacherous, thick. This was not a sunburnt country. A mutter of passengers in a green bus reminded her that public transport was possible. But she's not ready for the easy life yet. There's a body in the way - a sweating male torso. Growing bigger like a plant. Plants can shoot OK - but not kill themselves. Over near the Horizon Hotel a group of men in red, pointing their rifles straight down at the earth. Then the mountain. Little screams float up as the bullets go in. She gets on the bus after all. It stops outside the Hollywood Shoetique, next to a bruised fountain. She lights a cigarette. Might as well burn something.

\section{Diptych tourisms}

\section{1}

in the aeroplane there is no sunlight

[but] there's a sound of jazz

just over

the violent road

narrowly missing a mystery tour

we watch the rocks

appear alive and looming

rubber bodies blow up

on the boats before crashing

time for meditation, or medication

don't go into the sunlight

the packet warns

a storm breaks: 'my name is Ty Phoon' jokes our guide roaring at a happy parrot scooting by drenched in rain perched on a table

propped on the heads of two girls

Ty turns left - his favourite direction -

towards the revolutionary museum where

a pink horse hides shyly

in a corridor 
by the time we get to the tombs $\mathrm{i}$

can't open my mouth

that night

i dream of Picasso

making live sculptures now

2

you can tell how animism

came about - you eat the beast and the beast rewards you

with an iron hit - he must be a god to bless you so

and so - you create

the Superbeast and kill

drink the godblood

dance

a lot later a sandaled malacologist

collects a jar of dirty water

from a pond on Lord Howe for Rosemary

to dig her tweezers

in the leaf mould [in the sunlit room]

down the microscope she stares

trash keeps her busy in the sunlit room

all day until she gets it - a mollusk

big as a full stop

it's like looking for a plane that has gone out of sight

and now you can see the cyber-tour-sits

clutching maps

like prayerbooks

to their chests

how their eyes are dazzled

by the shell 


\section{Independent author}

\section{Carolyn van Langenberg}

\section{Body parts}

\section{Biographical note:}

Carolyn van Langenberg's first book, Sybil's stories (Pascoe Publishing), was praised as a treasure of a book in which the stories blend content, form and language into a unity that is expected only of poetry (Alan Myers, Flight deck). In 2000, fish lips, the first novel in the fish lips trilogy (fishlips, the teetotaller's wake, blue moon) was short-listed for the David T K Wong Fellowship, East Anglia University, UK. Carolyn lives with her husband in the Blue Mountains, west of Sydney, where she is indulging her love of gardening. 
Light angles through gaps where red curtains meet. Light angles up the ceiling to stars imitating heaven. A mirror mirrors the white walls and fails to catch the light of cerulean bliss within its flamboyant glassy frame.

The orange coverlet on the bed bunches over the drooping yellow blanket, all of this reflected in the tear drops of the chandelier. Dust furls in corners. Plaster cracks. The elaborately carved dresser creaks. A drawer in one of the bedside cupboards drops.

A vase decorated with a bird on lattice, a plaster prettiness balanced on a rickety stand, throws a shadow up the blank wall. The mirror fails to repeat the shadow above a drying rack draped with socks and underpants.

Vapour melts like breath on glass.

It was hot when they arrived in Bologna.

Ellie collapsed in the apartment they rented and peeled off the clammy clothes sticking to her flesh. She had packed for autumn. She wanted to wear her coat and scarf, thick socks and gloves. But she made do with jeans, a thin shirt and orange crocs.

Her crocs made her feet look like Daisy Duck paddles.

At the twin towers, a young woman stared in horror at Ellie's bright crocs. The embarrassed Ellie told Oliver that her orange feet were offensive to Italian sensibilities. He said that he must eat tripe before leaving Bologna. She said she thought crocs worked to keep feet comfy on cobbles. He said that tripe was a must. He added that Italians would be offended by the synthetic material and chunky design of her crocs, not by the orange.

Ellie's eyes searched for food.

Around them, exuberance, coiffed.

Ellie announced that at least her orange shirt matched her orange crocs, that she was properly colour-coded, not decked out in primitive gaudiness or functionally attired in beige.

Oliver said, 'What?'

Oliver and Ellie are slow tourists. They rented an apartment in the old ghetto where in the $16^{\text {th }}$ century the city's professional middle-class Jews and tradesmen and craftsmen with their families were walled in. During the second inquisition, they clustered in the narrow streets, paying the city exorbitant prices for fresh water, sanitation services, food and the tools for their various trades. After 25 years of being fleeced, when they were penniless, the bishop evicted them. The survivors went to Turkey where the Ottoman tolerated them rather than persecute them.

If Islam had at the centre of its theology a dead body, would it equal Christianity for physical persecution? 
Ellie thought it would, but for different reasons also associated with attitudes about the body.

Oliver opined that Christianity is all about body parts and the dead one at the centre of redeeming thought. 'Its history flings bits of disbelievers' viscera and gore here and there to ensure the dead body at the centre is honoured by more dead bits', he said.

At the Capella Santa Cecilia, they listen to music played by Davida Rebuffa, a specialist in medieval guitars and lutes. He is their first experience of Italian concerts. Neither was prepared for the disquisition between each bracket and neither knew enough Italian to really follow what was being said. But they got the idea that walking and listening to music predates walkmans and ipods.

David Rebuffa flips hair over his shoulder, his round face beaming like the full moon on a cloudless night.

Oliver comments that Rebuffa had studied the medieval lute players very closely, so closely he imitated their hair, mannerisms, even clothes, until their style became his own.

Ellie observes that Europeans were often like that, '... reminding tourists, even the slow ones, that the people in the old paintings have a lot of descendants who bear immediate resemblance to them'.

A young man wearing long curling hair looks over his shoulder at Ellie. His insolent mouth surprises her.

Oliver says he wants tripa, a plate of tripe served in a rich Italian sauce, a sauce from the north, not a Neopolitan sauce, but a la Bolognaise or Ravenese. That kind of sauce.

In this city of religion, city of music, city of science and invention where there lies the body, many dead bodies, all their bones decorated in jewels, Oliver wants innards steeped in rich sauce, celebrated on a plate.

A woman holding a doll under her armpit bends too close to Ellie's elbow. Ellie jumps like a teevee cop, hands free, legs astride, back straight. The woman's fingertips kiss her lips, round eyes focussed on her as if her intention is to mesmerise her.

A zombie begging for food.

Ellie walks quickly to the corner of the street to ask the shop owner about the woman. Before she formulates her question in Italian, she is startled to see she has gone.

Vapour. Yes, vapour. A graveyard wisp evaporated. 
In duomo after duomo, bodies recline, anorexic cadavers, ribs protruding, dead faces fixed in speechless agony. Fingers trail, toes curl. One dead body with holes in its hands and feet and chest rises above the adoration of others.

... hair flowing down a young man's back. Tresses of light auburn hair. Black wavy hair caught in a chignon on the crown of a man's head. Thick brown hair clasped by a tortoise shell and silver comb on the back of a man's head. Black auburn red brown hair buckled rolled gripped. 'Men celebrating hair,' she says to Oliver. 'That's different.' He hadn't noticed.

photograph
one breast
and the
memory
of a breast
fingers
where scars
shrink skin
opposite
the poised nipple

... down Castilglioni, to Queen Marguerita's Garden ... a bird swoops over Ellie's head.

Pescherie Vecchie, past Archiginassio Hall, a shopping mall to surprise New World people. Not that many know Giosue Carducci often shopped at the bookstore Zanichelli.

Carducci: Ellie struggles to find out who he is. A poet, a politician, d'Anunzio was his student, Nobel Prize 1906, anti-cleric and Professor of Italian at the University of Bologna. She writes notes about him, imagining the period he walked the streets of Bologna when Italy was in the process of becoming a nation-state.

At a concert, the woman sitting next to Ellie fusses with her handbag, until she retrieves her lipstick and small mirror. Her hand is a prosthetic. She balances the mirror between her senseless thumb and forefinger, manipulates the lid off the tube of lipstick, then carefully applies it. Replacing the lid onto the tube is a time-consuming fumbling of the senseless with the sensate. After she succeeds, she props the mirror again between her fixed thumb and forefinger and neatens her smeared lips with a tissue.

In Bologna one wet night, chocolate coats the inside of a white cup. Ellie, happy in her coat and scarf, boots and thick socks, hugs chocolaty warmth. 
Laundry flags from chimney pot to chimney pot on the top of a four storey building near the two towers.

Oliver repeats that he wants to eat tripe. Ellie conjures up images of white muscle, '... striated and rough surfaced tissue resembling a cunjevoi and designed to suck in nutrients and spurt out toxins bathed on a white plate in white sauce'. 'No!' says Oliver. 'Tripe cooked in tomato sauce with fists full of basil. And garlic.'

'Like a blood-soaked stomach. A bloodied stomach arranged on a white plate for your cannibalistic apprehension.'

... long dark porticos. They close over a history of romance and intrigue. There is a story of a bomb falling into rising dough, of Italian fascists who carefully removed it and took it to a field on the outskirts of the city to explode, of Nazis at the war's end who hauled one out of the dough and blew it up on the street outside the bakery. The moral of the story? Some fascists love a good bakery and others love a big bang.

'Tripa,' says Oliver. 'I want to eat tripe.'

Ellie laughs that there was plenty shrivelled under a gold leaf or two back there under the altar.

Being ex-Catholic, Oliver winces.

Ellie crawls into pages of print with pictures, her sensitivity challenged. She hears the teevee talk about President Obama. Oliver flicks to a jazz channel from the Netherlands and opens his laptop. She nods off over a page of long legged girls with hair extensions. They all wear purple see-through dresses with extremely high-heeled shoes. Oliver says, 'Found it. Where to go for tripe in Bologna'. He turns to tell her that the sauce isn't as tomato-based as the one he remembered from years ago, but before he could begin to say anything, she snores very loudly.

Ellie writes: What I like is the food. I like the bread and the cheeses. I like the shoes. I like the university students who wear strange boots and thongs with contraptions around the ankles as if the thong is a boot. I like the jackets. I like the age of the city.

... lips pout, she speaks to the priest at San Dominica. She tells him that she respects the way the Catholic church involves itself in International Jurisprudence through Amnesty International, representing the interests of people who fall foul of their regimes. She respects those Catholics who believe in social justice and the muscularity of the church that endures many changes to meet the needs of the people in the $21^{\text {st }}$ century, people displaced by political and economic and environmental havoc. But she continues in this dream in which she talks without drawing breath. She 
says when she walks through these Bolognese churches, peering at the wracked body of Christ and the remnants of St Sebastian, at the bones, gold and lace behind altars and in crypts, she is proud her ancestry leans towards the Reformation. 'My ancestors probably lopped off a Catholic head or two', she tells the white-robed priest who may be a monk. 'And when I see all this domination of the people, these high ceilings, this wealth displayed to intimidate, my blood boils for the lack of justice in historic time. It had to be. The Reformation had to be.'

Ellie, alarmed by her dream, wakes in a sweat.

A doorknocker in the shape of an old woman's screaming mouth. The keyhole is the devil, the knocker an incubus.

Oliver searches for a small trattoria in a very ordinary street and he orders tripe.

Ellie chooses tortella with sage sauce.

She falls asleep in the golden light the room effuses. Periodically laughing students and music disturb her sleep. The students party all night, their loud laughter and talk echoing down the cobblestoned streets, up the long dark porticos and she turns in her sleep, finds herself in a candlelit room, the smell awful. Men with coarse skin, the pores on their noses large and black, their hair hidden under greasy caps, seem to be at some kind of work. Their hands manipulate knives. A wooden wrack is at an angle, a priest intones when intestines fall on the floor. A man screams as the expressionless men disembowel him.

Horrified, Ellie floats to the outer edges of her dream, but not so far that she avoids the deep sad voice of a man calling out, 'What is that foul smell that will deny me the company of women forever?'.

Ellie wakes, the smell of viscera and gore somehow clinging to the walls of the room. She sits up in bed, wondering what history has taken place between these walls. After all, the flat is in the old ghetto. Heavy boots would have pounded the steps, heavy fists would have bashed the heavy doors where Oliver stands. 'Wow!' he says. 'I don't know what was in that tripe dish, but it went through like an avalanche!'

And the stench of medieval nightmares dissolves, overpowered by the smells of deodorants and perfume, scented detergents and toilet paper, aromas of concealment preferred in the 21 st century, no corpses to be seen. 


\section{Independent author}

\section{Jenna Sten}

\section{Supermarket}

\section{Biographical note:}

Jenna works in arts administration in Melbourne, and is an alumni of the Voiceworks Editorial Committee. She has a Bachelor of Arts in Writing and Cultural Studies, and sporadically writes reviews, literary fiction, and non-fiction. You can read more of her work at jennasten.wordpress.com. 
I've got Angus and Julia Stone playing in the background ('I'm wasted, so wasted on you') and Daria is on the TV ('You're standing on my neck, la, la, la'). Earlier it was the I.T. crowd ('I feel trapped. Like a moth. In a bath') and even earlier than that it was The L Word ('everybody's a liar, dear'). Earlier still it was The Mighty Boosh and Juno and The Rage in Placid Lake. Before that it was Amelie ('Scowling at them is Joseph...All he likes is popping bubble wrap').

(I'm putting something off.)

Before that I wasn't watching TV. Before that I was reading. I was reading about Alice's Adventures in Wonderland ('What for?" said Alice'), but I found her too intrusive. So I read Rosie Little's Cautionary Tales for Girls ('The wolf has teeth'), and bit my fingernails. Before that I read Charlotte's Web, and developed a fondness for sketches of spiders. Before that it was Essays in Love, and I discovered a fleeting interest in theory.

Before all this though I was reading Beloved ('She was my best thing'), and feeling sick over something I couldn't understand. Before that it was The Bride Stripped Bare, and I felt sick over something I could understand. Before that it was The Rachel Papers ('She's not pretty enough and she wets the bed'). Before that I was reading PostSecret, and becoming increasingly terrified. Before that it was Landscape with Animals, and I've never felt so sickened and intrigued. Before that I drank two cups of tea and removed lint from a jumper with one of those hand held machines.

(I can't put it off any longer.)

Grocery.

Shopping.

Grocery shopping.

I have to go grocery shopping.

The glass double doors don't look very inviting. I grab a trolley, look down at my list.

My list/my budget/my box/my ... all I can afford for a fortnight:

bananas
apples
mushrooms
apathy
carrots
cucumber
candles
cereal
corn
anxiety
yearning
strawberries, if they have them

The checkouts are whirring and buzzing as people complain about mismatching prices and the checkout operators call for their supervisors. The floor is matted with roots and dirt, and every few meters weeds flourish in a damp spot. All the fixtures are made of wood and everything smells like flowers. 
I push my trolley along, wending my way through the hordes of people. It trundles over roots and twigs, locking into bits and pieces every now and then. I look up at the sign hanging from the roof, its thin wooden form swaying in the draft of the air-conditioning. Bananas are ... aisle seven. I turn and narrowly avoid two school-age boys having a trolley war. Splintered bits of wood fly into the air as the front of one of the trolleys is busted and a woman, probably their mother, pelts their backsides with a discarded branch

The bananas are next to the fertility. A teenage couple is dismantling a box and peeking inside it, looking guilty. Further down a staff member is blotting a spill of indignation, and a woman is examining a packet of zeal. I slip between them to get to the bananas and give the lust a stealthy glance. I'm a little tempted, but there are some dodgy-looking men hovering there, evidently trying to find someone to take it with. They look a bit like rapists, but then if they were they'd probably be in aisle six. I move along. Aisle eight is mostly for adolescents, but that's where I get the apples, apathy and anxiety. In aisle nine I pick up some corn on the cob.

I'm trailing behind a man when he drops his list and wheels himself into the next aisle. I glance either side of me. The only person to be seen is distracted and ten meters away (an elderly lady fondling a bag of peaches). My heart skips a beat. I collect lists.

a hot water bottle
sounds of the ocean CD
raw sugar
mittens
love

$A$ bit needy, I think, and pocket it anyway. It will make an off-putting addition to the pile at home. I pick them up, torn and wrinkled from the supermarket floor, then take them home and pin their soft bellies to a corkboard on the wall.

I once took a list from a woman's back pocket, folded neatly along frequently pressed seams. In felt tip pen with clean lines she had written:
scotch
loneliness
rope

But her trolley was filled with other things. Perhaps it was for someone else. Thinking of it that way makes me feel better for saying nothing to her. But what could I have said? Excuse me, ma'am, but a moment ago I picked your pocket and I think the idea of you committing suicide is just frightful.

A glass jar of shame falls from the topmost shelf and smashes over large root on the ground. I sigh and shift some of the glass with my shoe. A pebble of shame rolls down the aisle and into the cold section. It nestles itself beneath the mince.

I don't like this place. It tells you what you should buy. The things you shouldn't buy evade you sometimes and change aisles without warning. But if you're desperate for them you can usually track them down. It is, after all, still about making a profit. If you really want to waste your money on things you don't need it'll let you. But it does like to put up a feeble for-your-own-good fight first for some reason. A high pitch beeping erupts from the 
floor near the jar and another staff member rushes along to clean up the shards. I step around them.

I wheel the trolley back to the first aisle and pick up the other food items. I don't get the strawberries because they're sitting next to a cracked bottle of envy and have started to rot. I turn down the second aisle and pass the man who dropped his list. He's patting down his pockets, looking for it. I smile. I won't be giving it back. It's too hilarious to be returned, and will contrast nicely with the woefully depressing lists that make up my collection. Like last week's gem:

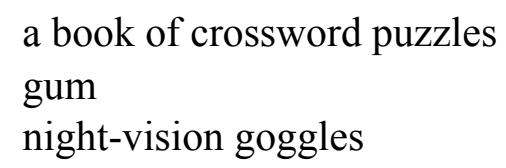

I scan the aisle. I can see a tall display of yearning down the end, but a box of resilience edges toward me on its shelf. I shove it back with my elbow as I pass. Nice try. I know what it wants me to get over, but I want to yearn. Realising this, I run hastily towards the yearning. My hands close roughly around a box before the others disappear. They flicker back into place as they register that I've already caught one. The other boxes show no change, but I can feel their frosty stares radiating from the logo on their faces. Time to leave, I think.

I forget about the candles. 


\section{Independent author}

\section{Pam Brown}

\section{Borrowed modifiers}

\section{Biographical note:}

Pam Brown's most recent title is Home by Dark (Shearsman Books, 2013). She has published many books, chapbooks, and an e-book, over four decades. Pam is a peer reviewer for online journals Polari and Rubric and an associate editor of Jacket2. She lives in Alexandria in Sydney and blogs intermittently at http://thedeletions.blogspot.com. 
Administered Capitalism

Advanced Capitalism

Affective Capitalism

Anarcho Capitalism

Bio Capitalism

Bureaucratic Capitalism

Cartel Capitalism

Casino Capitalism

Cognitive Capitalism

Communicative Capitalism

Comprador Capitalism

Consumer Capitalism

Corporate Capitalism

Creative Capitalism

Crisis Capitalism

Crony Capitalism

Cultural Capitalism

Cyber Capitalism

Disaster Capitalism

Finance Capitalism

Fordist Capitalism

Free-market Capitalism

Gangster Capitalism

Global Capitalism

Hyper Capitalism

Imperialist Capitalism

Industrial Capitalism

Informal Capitalism

Informational Capitalism

Laissez-faire Capitalism

Late Capitalism

Liberal Capitalism

Liquid Capitalism

Managerial Capitalism

Mercantile Capitalism

Monopoly Capitalism

Neo-Liberal Capitalism

Pan Capitalism

Post Capitalism

Primitive Capitalism

Proto Capitalism

Rentier Capitalism

Schizo Capitalism

Semio Capitalism

Spectacular Capitalism 
State Capitalism

Turbo Capitalism

Venture Capitalism

Vulture Capitalism

Thank You

McKenzie Wark

Evangelical Capitalism

Guru Capitalism

Crisis Capitalism

Teleological Capitalism

Pro-Market Non-Capitalism

Quasi Capitalism - A Joke

Viral Capitalism! We Have A Winner! 


\section{Independent author}

\section{Sal Brereton}

\section{excerpt from 'Treading water'}

\section{Biographical note:}

Sal Brereton helped establish the early 1980s Sydney Women Writers' workshop. She was for a time co-editor of Magic Sam magazine and, as well as having written scripts for experimental film, has published the prose sequences: Ideal conditions (Experimental Art Foundation), Sitting rigid (Little Esther Press) and Taking stock (Jelly Tongue Press). Unpublished work includes 'Treading water' and two novels, 'The Vau tree' and 'Above the clouds'. She lives in Sydney and is currently researching her sequel to 'Above the clouds'. 
I open my eyes - a red-and-white-dotted radio pole in the hills ahead; round grey clouds above and a sign by a park saying $1 \mathrm{~km}$ to the turn-off to the pool.

We stop and get out. While we eat, Lil is telling me about a recent love affair. I find myself looking at an old lady in the caravan park at the same time. (Dressed in a nightdress, she sets a sprinkler by a back patch of sun near the camper-caravan she lives in.) I want to be able to see the weekend around us. I want to feel that my mind doesn't wander but, on the contrary, that I'm guiding it finally the right way.

As we sit by the car drinking coffee a small truck pulls up on the dirt track beside us. A man asks if we've seen cows running in the oval 'just now'. We say no. He says he's been phoned about some. We all look up at the empty green field.

Perhaps, since I feel detached, I turn and say: 'Well, hope they weren't referring to us'. For the first time since coming back to Sydney I feel satisfyingly 'Australian' in the setting. He takes his hat off and appreciates the joke by not laughing. He will say something more deadpan to please us. He says, 'Well, catch yous later ...', then, pleased with himself, he drives off and, in the back of his truck in a cage, a small pup jumps madly up and down as he leaves.

I imagined I could write my way through the weekend - as if any fact, or even misfortune, could at least be part of a small, positive, end result.

Into the piece I could wind myself as well. I could stand, without standing out, under the weight of the words, protected. Passing through Goulburn for example - the writing might let me appear under the wide verandah of a Milk Bar - 'just looking'.

The night before, over the phone, she'd asked if I'd ever been inclined to write about New Brighton - a term I took at the time to mean 'childhood' or perhaps 'psychology'. When I said I planned to write about the beach but never planned to write anything 'psychological' she immediately said it wasn't what she'd meant at all.

I dreamt we were both heads, suspended in space among stars. Above us, huge signs announce star-clusters - The Saucepan, The Archer, The Lyre - and we agree, though without speaking, that we preferred it before, without neon ads cluttering up space with their glare.

Lil pulls over to the side of the road. The indicator lights clicking make a rhythm, faster and slower, as the car idles and she finds a cassette - 'The art of noise' - finds a Walkman's earphones and fits them in her ears.

We drive off again. From now on the driving is faster, more connected, more hugging to the road.

Then suddenly in the sunlight: the serrated olive edges of a wide pine forest. The deep pleasure of the bordering-on-black of its mass. The Islamic silhouette of its peaks, its intricate edges, the confident dark lace of its repeating.

My eye was held, ornamented in them, and for seconds as we passed I dreamed in shadow. 
'At New Brighton we walked along the shoreline under a big full moon and the beach had the delicate formula of every dusk that summer - wide pink, white and blue stripes washing-out, deepening and lightening at the last minute in different strengths - over the sea or the hinterland behind. Everything had a luminescent glow from the moon reflected in the wash-back and, that night, the whole village seemed out fishing in its soft light. (Lilliputian silhouettes running up wet sand to change baits.) She turned and said how beautiful the world was and automatically we both looked to the gold moon, as though its bright full face was showing us how to see the earth.

(On other nights - no moons - and a scary about-to-be-black, magnified by the sand's final, faintest glow disappearing.)'

We cross through a second stone pass and Lil whistles and sings again. But this time it's nothing to do with me. I don't feel I have to comment, or that the sound's an overture aimed at me, because I see her leg moving to the music. I see she's talking to, singing along with, her own cassette and I feel unencumbered, relieved of my duty, free to be absorbed in any thing I want.

I rummage through a box back-stage in a theatre with odd props: 'Japan, Urgent, Fearless, Amused, Aloof' - but I'm not worried, and eventually they all waft away. I'm a girl in a train in Tokyo, then a tourist travelling on tracks between Ahmedabad and Bombay to a serious meeting at a hospice. I hear the train's roar and sail through the scene free of danger of any kind.

Moving in toward Goulburn, into the outskirts of the city, past the graveyard beyond the Merino complex and a sign saying Wombeyen Caves.

Then out, past a giant concrete sheep.

I write a note about my recent haircut - which depresses me - as if all my worries have been handed into and moved around in my hair. Later I erase what I'd written hoping things might still 'fall into place'. (Perhaps, my real fear - that it's my history I'm taking to the weekend - my past held up in my head.)

We go by Lake George's sign and then a half dry, cardboard-coloured lake.

We are winding our way there.

I want to blurt things out.

'No, stay centred; focus on what's ahead.'

(A ‘Two Way’ sign.)

We stop on the outskirts of Canberra and tidy ourselves - comb our hair, re-arrange clothes - and I see an image of her running at the sea one dusk in summer, fully clothed - my father amused at first, then concerned.

The road starts again and I manage to stay safely on the surface of events. Despite this, at the last second, I feel a sudden urge to shift things. I feel too passive and out of my depth. I worry that if, as in an experiment, I came purely to record, my preparedness for such acceptance will surely cause things: that I'll create what I think I simply observe. 
A few blocks from the house the notes I've written seem to mass inside my head like a threat. I wind down the window as though the wind might lessen them, telling myself their presence on paper doesn't threaten a thing.

For a beat we pause at the lights at the corner. They turn green. We park in the drive and, though I know I've arrived, I don't want to get out. Lil opens her door and goes. I leave the car, feeling the steady ground beneath my feet, scanning its surface swiftly, searching for something - even unimportant - that can tell me I've fully dispelled all risk.

Recorded words posed no menace. In the living room we easily filled our time with agreeable speech, our tones softened and deepened in the face of her disease.

She seemed tired - her movements slower and more laboured, as though she might've been in pain - yet she insisted she felt better and said her kidneys only played up when she forgot and tried to do too much.

It was her free day so we walked to the nearby shops at Lynham - going to Coles and the second-hand store for fun. At home we tried on the skirt and scarf we bought and she showed us a red and white blazer she was halfway through refashioning 'from a dress'.

The following day we helped set up her dialyser, opening packets of saline and attaching the metres of plastic lines that she needed to clean her blood.

We sat talking with her for the hours it took for the machine to clean her - twice making tea which we served in the porcelain we knew she liked the best. As we drank, we talked about the tapestry she was working on - a computer-like image of a woman's face, several metres square, that she was knotting in thick coloured cord and which would probably need another half year to complete.

On our third day she took us to the Hyatt for the smorgasbord and said it was something she wanted us to remember her by. (At home, beforehand, getting ready, each of us at different mirrors. Words from one room or other: 'Okaaaaay?' 'Right, I' $m$ ready,' 'Yes, me too', and then silence as we each lost ourselves a little longer in something more we applied to our faces.)

We ate our lavish four-course meals and couldn't believe how much we all managed to 'slip away'. I remember she was the first diner that day to make her way, moving without her cane, to the dessert table. (The indelible image of her spearing her spoon with the unstable balance of a delighted child into a red mound of quivering jelly, sighing 'My favourite!').

After the meal we strolled around the grounds. She had a camera in her bag and, when a man passed by, she asked if he'd oblige. I felt he sensed the mood between us, spending extra time setting the shot up and, as he stood frozen - looking through the lens - we, too, were mindful to freeze our smiles - letting them hide the shakier emotions we kept private inside. 
Later, at home, darkness fell and none of us saw it until the streetlights flickered on. We closed the curtains and went with her to her room. She undressed and I noticed how the years had changed the texture of her skin - its paleness now papery and in parts more thin. We sat with her for a time, remembering the shared pleasures of our meal, then eventually left for our own beds.

I start by fleeing doors, stairwells, office towers and phones to a ship where I polish mirrors, imitating the sun and see in mimicry anything's possible: all voices, past feelings, all personalities. I come to hear my 'original' voice at a banquet and introduce myself formally 'Good evening, this is Sally', for the first time.

The next morning I stood in the yard looking back at her treatment room and saw bags labelled 'Contaminated Waste', with boxes of saline, syringes, gauze and tubes stacked on shelves to the ceiling. Her machine was beside them - the dials stopped, lights out, the motor finally silent. I assumed I was taking my own private stock of the room and was shocked when I heard her say 'Sally!' from the kitchen door and turned to see her standing there.

After breakfast we looked at the photo she was basing her tapestry on. It was from a magazine and, though it was no one Lil and I knew, she said the woman reminded her of the nurses she'd known. It expressed her idea of their strengths and she planned to dedicate the finished tapestry to them. Below the photo were working drawings painted versions of the same face morphing to the capable clear-eyed gaze of a carer. Then she showed us the final mock-up - a piece of graph-paper, in four millimetre squares, overlaid with the head - each square a pixel in an ocean of thousands which would one day form a work covering the whole wall.

We talked about Japan. She asked again about the book I'd promised to write about living there and, though I hadn't written a word, I told her I had. I said I'd bring the chapters down with me, the next time, and assured myself there and then I'd be able to start the second I went back.

When it came time for Lil and me to leave, we both felt ill at ease - feeling we'd forced a final parting. We spent our time sharing encouraging, optimistic comments as though heavier expressions held a weight that neither of us could risk lifting.

On the road home we were grateful for each other's company. Cars; land; laden, heavy clouds. After Goulburn the first spots of rain and in the gloom, a new threat as though nature was dangerous. Yet, nearer Sydney, staring up at office towers, I register for the first time that surfaces won't fall down around me in a major quake and, when we get home, grateful, I ring to tell her we're safe.

No breeze. The harbour a silver sheath. Moored yachts marking time - their masts barely moving, to and fro - and I go to sleep planning the chapters I've promised to write.

This morning, deliberating at my desk after twenty minutes not writing, an attendant sense of forgetting the thread of what I'm talking about - as if there's a topic, which there isn't - and I'm treading cautiously, hoping to coax it back. 
Out at the Heads a large white cargo ship lines up as it starts its entry in - the long deep boom of its horn echoing through the haze like the start of an aria.

I will begin my story of Japan for her in a swirling pool of water with a woman washing rice. I see the clockwise current release a white starch and incrementally run clear. I hear the dull 'one-two' of the woman's fist each turn - her soft heart-thud filling the pearl grains with her blood's life force.

It happened on the island - so was it an 'island custom' - this traditional circling I always associated with the place?

'Geographically, Ogasawara's coral islands are divided into four groups - the two main ones being the Father and Mother Island chains. To the Father Island belong the Elder and Younger Brothers, and the Grandson Isles; to the Mother Island - the Elder and Younger Sisters, and the Isle of the Niece. All consist of dense, subtropical forests and rugged terrain with stretches of white sand beach. Of the plants - the hibiscus, the Ogasawara and pandanus palms, and the white popinac are the most prolific ...'

I inevitably come back to the islands - to the dotted line of land I spent my last months on - as though their semi-tropical beaches can let me link Japan to the distant sands of my own past. (If I really wrote for her about Japan, ideally her story would be set - not in modern Tokyo or on the Bonins - but in a different location, somewhere centuries ago.) For now, I feel the facts must remain with what I have before me: memories, diary notes, Polaroid photos of myself and friends, and a curious, about-to-be-retired, old Russian cruise ship.

'On deck of the Felix Dzerjinsky it's not quite dawn and the day's already hot on the China Sea. In places it's still night but, in one part, the sun will come from a cloudbank behind us. I watch two crewmen play ping-pong then look up as one points in heavy English and declares Is land!'

I look up from my desk. It's peak hour and my favourite black freighter's sailing back to Sydney after weeks away at sea - daily commuters criss-crossing the harbour obliviously beside it. Their seeming ignorance cheers me and I kick off my slippers and caress the carpet.

'I reached Tokyo and my dream was a Durrenmatt play acted on Kabuki stages, high and long as freeways at night. Someone was stalking me. A woman was there. A girl sipped from red glass in silhouette. Things were urgent. The city was a ship and shadows lunged and I panicked and ran to a cabin where I pushed a brass handle, locked a door and spun to see a rose-quilted room and a bed. A hand banged, a door gasped, air sucked and I suddenly saw it all from high up - a square box drenched in red. I couldn't risk seeing the room, or the sight of me reeling there. The door swelled and strained and broke then arched and splintered and became a bomb unleashing. But I escaped from it, bursting out through a cyclone beside the ship, crashing down right in the heart of Tokyo's raging night - onto my single futon mat - safe and sound and alone.' 
This impromptu surge of memory. I write its words in long hand, then type them and pour them in, to see them pulse like waves down the pre-set margins of a silver screen. They become fluid and in each generation pulse further from their birth heart, brain, blood-filled arm, pencil, computer - onto the slipping surface of a scrolling face, while the head in my mother's tapestry looks at me from her fixed lattice - the jaw set, the gaze direct, the eyes unafraid of death. 


\title{
Queensland University of Technology
}

\author{
Sarah Holland-Batt
}

\section{Littoral marginalia}

\section{Biographical note:}

Sarah Holland-Batt's first collection, Aria (UQP), won the Fellowship of Australian Writers' Anne Elder Award and was shortlisted in the New South Wales Premier's Literary Awards and the Queensland Premier's Literary Awards. She is the recipient of the Thomas Shapcott Poetry Prize, the Dorothy Hewett Fellowship for Poetry, and an Australia Council Literature Residency at the B.R. Whiting Studio in Rome. She lectures in Creative Writing and Literary Studies at Queensland University of Techology. 
The velvet swimming crab, stoic as a caryatid.

This says nothing of the gannet's burlesque.

A sirocco wings cold sand from Cyrene to the Attica periphery each year.

Pelican's foot, saddle oyster, prickly cockle, netted dogwhelk.

At Salamis, the tide scums with the Lemnos. Fishermen wear coated teeth.

Tusk and otter shells cluster with banded venus in a blonde ray's gut.

A northerly scuttles dried cuttlefish near.

With time, slipper limpets, like history, disintegrate into small parts.

My grandfather's willow creel.

On the Oregon coast, hot clam chowder.

A paradigm of molluscs.

Peach, speckled cream, egg-white, milk: kitchen sands.

At the bicentennial, beaches were celebrated in the passive voice.

No way to avoid poeticising the ocean at night. Forget the moon.

Here. This is where the body washed up.

In Andalusia, a crab that can regenerate its claws is made into bocas de la Isla.

Bivalves dig their feet in, sifting faunal bricolage.

I kept one picture: the two of us laughing near Indian's Head.

We fry the whitefish in butter, singing.

Bird-footed fossils layer the cliffs on the Isle of Wight.

A curio: at nine, my father gave me a toy camera with a rotating reel of Brighton.

Dotterels ignore the excising of thousands of islands from Australia's immigration zone.

Inside the beachcomber's hut a rusted blade reads, Made in Britain. 
Vegetarians who do or do not eat fish.

A marine biologist picking over the stomachs of two smooth hound sharks. $\sim$

Any number of ways to kill a pied cormorant.

Beach as a verb: the heft of a black pod swaddled with sand.

$\sim$

Coral spoor like slimed pomegranate seeds.

A liner's lights or a low satellite.

At the coal face, unstitching hooks from mouthing mouths. $\sim$

On the Bikini Atoll, lizards crawl into the sea to die. The bomb codenamed Bravo.

Ice creaking with warm gin on the deck.

We buried them in Turkey, not far off. Choking, and digging sand.

Yellowfin long-lines shoulder collateral damage: drowned shy albatross.

Out at sea, Lawrence scratching into a tin tray with his knife.

The outline of the coast - storm petrel's itinerary.

In the half-light, the green sawfish almost a simulacrum.

Penelope's seasickness at the loom.

Each haunch of driftwood warranting close observation.

Night, turning on the knuckles of light.

Our grief like a gunwhaler in a bottle.

Pumice: a smooth pebble tried in absentia, scorched, then bag-boiled.

Rereading To the lighthouse at St. Kilda. Behind me, Luna Park on stilts.

Coming in the headlands.

The tide lowering its hem. Knotted bluebottles: pins.

To walk past a dead loggerhead, peacock green with a red, marbled eye. 
Pearls beginning and ending.

A Dorset man recently returned a message in a bottle from California with an angry note.

The cumulus dense as a Pound canto. Silver gulls rise from it. 


\title{
University of Sydney
}

\author{
Nour Dados
}

\section{Lament on a postcard}

\section{Bibliographical note:}

Nour Dados was born in Beirut and spent a considerable part of her formative years living in cars, bomb shelters and relatives' houses before migrating to Australia with her family. She is currently Senior Research Associate in the Department of Education and Social Work at the University of Sydney. Her research focuses on historical geographies of embodiment and material culture and intersections of space and power. 


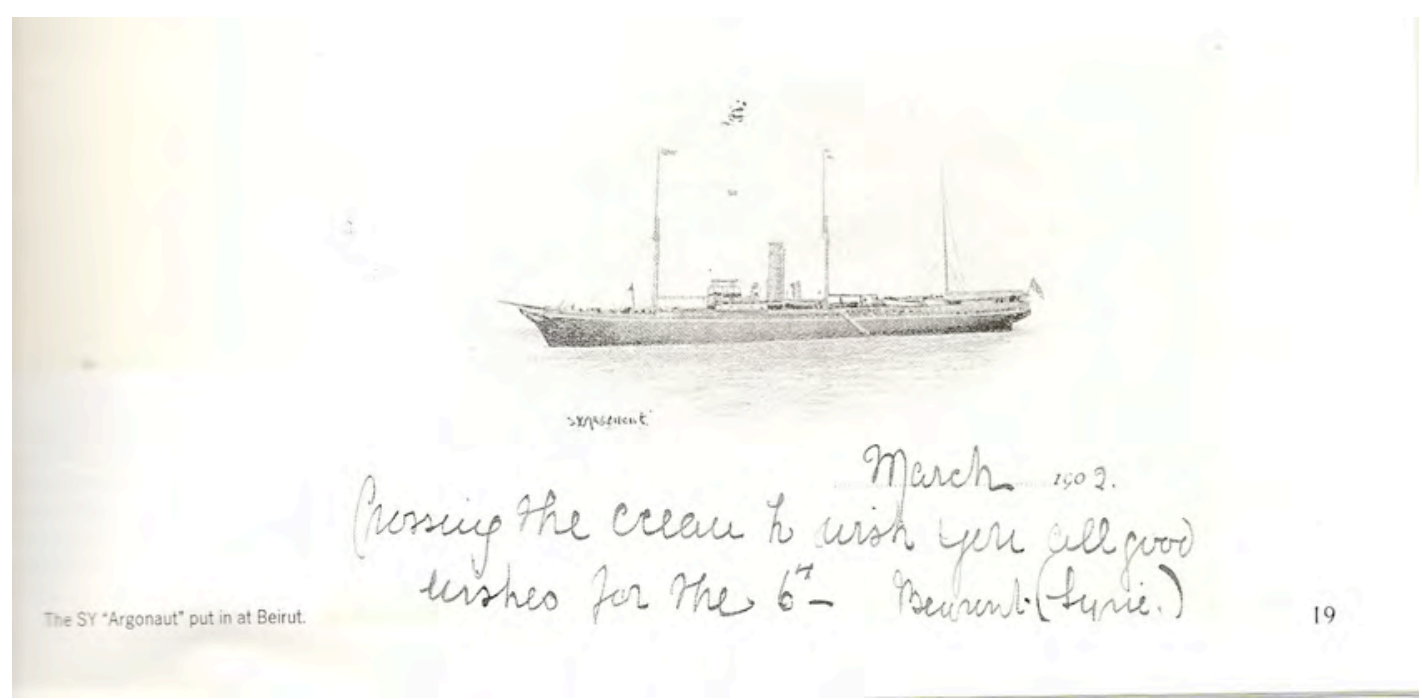

Fig. 1. From F Debbas, Beirut our memory: a guided tour, 1986, 19

\section{Writing in waves}

Beirut: the explosion of my anxieties in foam. A remote sea wed to an ochre ocean; or untranslated salt, breaking against the rocks.

Beirut, my phantom on horseback, only in dreams do I smell you, only there do I count your stars to the nearest one hundred, and only there do I hear Pessoa telling me to destroy the idea of bridges. The strangeness in which you clothe the landscapes of all countries punctuates the rhythm of my hours, and forcibly straightens the curves of my horizon which are always less than bridges between us. Pessoa arrives in waves that land on your sleepy shore. It is one of me who inhabits those that never reach you. With the tide I carry you on my back, a blank card that falls out of a book. Which book? I do not know.

Beirut, mine is the task of writing to you from the other side of a mirror, of sending you postcards in waves. Waves, that eat my words, not out of hunger or boredom, but because in the deluge, reading is a palpable sensation. In the deluge, words curl their feet like breakers before they crash against the shore. There, they swell into sentences and migrate into stories that never stand as tall as phrases.

In Beirut, the traces of the ocean cling together and erupt into words that are always less than sentences. The voice a Portuguese sailor sings Pessoa's 'Maritime Ode' much further south: 'My anxieties explode in foam/And my flesh is a wave about to break against the rocks!' (1986: 56). Pessoa joins in, drunk on the salt of a common sea flooding an indifferent ocean in the 'Absurd Hour': 'One must destroy the idea of all bridges,/Clothe in strangeness the landscapes of all countries,/Forcibly straighten the curve of horizons.' (1986: 153). Is it curiosity and adventure, or a sense of permanent exile that crushes compasses and bathes the present in distance? 


\section{Watermarks}

Vision: I once received a postcard that bore visible traces of having been submerged in water, of having had its bones pickled in brine. It had not reached me by the usual air-route, but by keeping to the paths of fish now dodging saline letters. It had been read so many times by the water that it no longer belonged to the world of light. Nothing of its journey remained but a residual saltiness that the eye could only reconstitute as silence.

\section{Lost Routes}

Travel: a postcard from elsewhere arrives at my door, a place I have never visited. Somewhere between the picture and the writing on the back, I become the cartographer who is always leaving without having left. Impossible journeys charted onto invisible maps.

A breeze I did not encounter: when my grandfather returned to Lebanon from Genoa in 1956, he brought his incommensurable elsewhere with him. Now a tattered book with yellow pages, his Ricordo di Genova survives as a coincidence, more my curiosity than his. Despite its hardcover and book-like appearance, the Ricordo di Genova is not really a book but a catalogue of postcards posing as photos of the city. Here, and here and here, I tell him, you forgot to write anything. Not a single word on the backs of any of the photographer's striking images - portraits and panoramas, piazzas, roads and monuments, among them, the Monumento a Cristoforo Colombo, Genoa's native son. The imposing facades of concrete, all named for men who have claimed, planned and built cities, are offset with Genoa's winding sea roads. No trace of the quarantine zone at the port where my grandfather was housed when he arrived on a ship called the Corriente. Instead, a motionless sepia ocean weaves a shadow under my eyes, under all the eyes of the readers of all the postcards. The strings that hold together the book's spine have grown tired of standing straight and slowly send out little cotton missives that land on the surface of paper, no paper, empty paper, no letters.

\section{Elsewheres}

Waves: the original postcard. Broken pieces of sentences, always less than phrases. Letters, words, blocks of wood, fractured elsewheres recast as handpicked desires, rhythms dense and disorganised, saltiness reconstituted as silence, discarded dreams in search of dreamers, a desert of origins and abandoned watchtowers swinging gently to the chesty anthems of all the world's oceans. Paths crossed by salty messages penned in a storm. While I was away from here, I sent you this postcard - all that remains, what still remains, of an encounter with an elsewhere that arrived at my door and entered without knocking. In the saltiness only distance remains. 


\section{Postcards}

Dreams: old parchment inside new thoughts. In dreams, it is always the dust of another city that settles on the heels of distance and longing. The city dances in vain, it never overcomes the glistening arteries of all the world's postcards. Here, and there, it dwells in the sadness of unsent letters cluttering the stratosphere of ordinary homes.

Alone, and surviving on what he could, my grandfather made his way around the Middle East, Europe and South America. He was sailing from Rio de Janeiro to Beirut when an earthquake struck and forced his ship to dock temporarily. He says they stayed in the quarantine area for eight days. When he returned to Lebanon, he brought Genoa with him. My mother, the eldest in the family, was barely four years old. Yet somehow, his postcards survived the destruction of my grandparents' house in Agrippa Street, their hurried escape, a voyage to Cyprus by boat, and another to Australia, to end up with my mother who left Lebanon six years later. They reveal nothing of war and exile but a threadbare cover and discoloured pages, signs of age that could befall any object, however treasured. They offer only their reticent landscapes, and the possibility that there was once a place called Genoa that looked something like them.

\section{Distance}

Irene: the city in the distance. Under the watchful gaze of Italo Calvino, Marco Polo becomes an architect of invisible cities. Irene 'is the city visible when you lean out from the edge of the plateau at the hour when the lights come on, and in the limpid air, the pink of the settlement can be discerned spread out in the distance below ...' (Calvino 1997: 124).

Darkness is minutes away and the lights from the city rattle in an electric fog. The high-rises that occupy the city's distance emboss their cacophonous likeness onto shadows. Glowing embers spark and fly over darkened towers. Irene, Polo wants us to understand, is not a city proper but an aspect of cities. He is unable to describe the city beyond how it appears from afar: 'if you saw it, standing in its midst, it would be a different city; Irene is a name for a city in the distance, and as you approach, it changes' (Calvino 1997: 124-125).

From afar I can only just make out a glowing neon sign on the walls of one of its buildings. It is superfluous, just the name of a company, a company that might exist in any city on the planet. Slowly its letters dissolve into the sea's salty skin and leave little ripples that look like goose bumps. 


\section{Balconies}

Homecoming: standing on a balcony in Beirut's Hamra district, the city's commercial centre, I survey what I can of Beirut's sea from above. This sea of traffic does not resemble the sea of my postcards. I take photos on my mobile phone as the cars labour their way home. It is almost as though I am practising to take a photograph.

Car exhaust fumes suffocate the early morning and late afternoon, but I never close my balcony. The smell works its way into my memories. My childhood is falsified into a single anchor in an ocean of noise. The smell of traffic is now the signpost to my past. Who knows what other memories will be created in this conjuncture.

Instead of breathing in the sea that my parents talked about, iodine and salt, I adjust to the pollution and I remember that it is only this smell that I really know. The sea that is so close, only a few kilometres away, is always invisible once I reach the city. It is too far away for me to care now that I am here. It is much further away here than it was before I arrived. The sea of my postcards is only good for shipwrecks. It matters little to me now, here, in the middle of a traffic jam.

\section{Panorama}

Postcards: the leftovers of vision in a sieve held by a stranger. A panoramic photograph of a city, which may or may not be a postcard, is a means of grasping at what cannot be seen. If panorama is a form of hyper-visibility that is forever inventing new techniques of vision, the postcard is its forgotten second cousin, offering only silhouettes punctuated by shadows.

In Paris, when it's naked Etel Adnan remarks on 'the blessings of fog! ...the only time when people admit that they can see nothing' (1993a). Fog is the skin of things, a postcard for the everyday. In Paris, Adnan writes, 'cities attract each other like flowers do, they form a secret society and you can't get involved with one of them without being solicited by the others' (1993: 98). She lives, this Lebanese writer-poet, between Paris, Beirut and California. 'I'm walking simultaneously on many tracks,' she says, 'standing on Aleppo's Citadel I'm also standing by this red light, getting wet, and I'm walking the streets of Beirut where a snow storm is raging' (Adnan 1993a: 98). I lose her in the traffic, her whose feet have known the contours of so many continents, who feels the raging snow storm in the softness of rainfall and sees the walled cities of Syria in the flash of a red traffic light. She crosses oceans like roads, hunting a distance that never pauses long enough to reveal itself.

\section{The Impossibility of seeing the sea}

Cities: When Etel Adnan returns to her balcony in Beirut, she inhabits it in a way I never do. Adnan writes letters, not postcards. Hers is a world with paths from Paris to Aleppo, mine is a world of images. There, in Beirut where I watched the traffic, I could not see Adnan's sea. I was too far away. 
'There is no use living in Paris,' Adnan writes, 'when all one cares for is the sea. Still, this is what thousands of people do, and what I do, too' (1993: 57). How could one bear this separation where it not that, 'the ocean penetrates Paris in subversive ways, mostly through the treachery of fish markets: some salt, some iodine, and you have the Atlantic in your nostrils' (Adnan 1993: 75-76).

Without travelling, without having set sail, the middle of the ocean arrives in the city. A tall history of shadows strangles this indifferent spouse of the salty Mediterranean. Here, like there, the uneven movement of human cargo through the centuries has left a film of broken landscapes over the water. It gathers momentum at every port of call, choking the tide as it tries in vain to complete the registry of those who drowned. History is a coffin sailing in every direction.

\section{Cities}

Sea: the uninterrupted expectation of arrivals and departures. In The Seducer René Magritte gives us the ship as the extension of the sea. The ocean takes the form of a ship with sails. No horizon, only the monotony of waves and a long voyage. Sailing has become a metaphor par excellence. But what exactly is to be extracted from the simple outline of ships?

In Paris, the absent sea allows Adnan's writing to occupy the distance of postcards. That sea hovers like an enduring vision that is constantly singing its impossibility. The sea that arrives in the middle of Paris withers away when Adnan closes in on it in Beirut. In Beirut, distance evaporates, the sea changes: 'then, the sea beyond my windows isn't an ally anymore. She resembles the sun too much and burns my eyes' (Adnan 1993b: 111). This vision of the sea is from a collection of letters titled $O f$ Cities and Women. Written between 1990 and 1992 from Barcelona, Skopelos, Murcia, Berlin, Rome and Beirut, Lebanon's post-war despair is captured in Adnan's final letter from its capital where, '...everything is gone save the climate. And something of the sea has left, too, because the sea is so messy. She's so polluted that swimming is impossible and one has to wait for the night or the evening to look at her with some kind of innocence' (1993b: 111-112). Her letter from Beirut, the final letter in the collection, ends with the return of the sea as ally. She writes: 'the sea is in movement. Things speak out. Everything is language' (1993b: 113).

\section{Beirut}

Sailing: A barefoot sailor makes paper boats that float in the kitchen sink. This one will grow into a woman who will also learn how to bake, build and swim in the ocean. If Beirut is a balcony it will never reach the deep blue sea that forgot to write the names of those who drowned. No postcards, only wounds that mask the ground.

I am acutely aware of my immobility - my reluctance to take up sea-faring and a sailor's life. I look, and see 'those pearls that were his eyes'. Stretched out in the

Mud map: experimental women's writing 
middle of the ocean, I have entered the image from which there is no exit. Fear of death by water everywhere.

You cannot always sail into the arms of the ocean's many metaphors. Nor can you recline in Gaston Bachelard's ocean-city where the bed becomes a boat and the room a sea (Bachelard 1998: 28). Here, as elsewhere, the ship, that unique piece of engineering that underpins generations of dreams of discovery, is born from the belly of the sea. In Michel Foucault's words, the ship is not only 'a floating piece of space' and 'a place without a place', but 'the greatest reserve of the imagination' (1984: 27). 'In civilisations without boats,' muses Foucault, 'dreams dry up, espionage takes the place of adventure and the police take the place of pirates' (1984: 27). But the present marks all our metaphors as lies.

There, in Beirut, is only darkness, and an eclipse of place. No, it is not quite innocent this borrowing of voices, it is only the distance that hides it in the tumble and roll. Will anyone recall that Adonis, the Syrian poet who now lives in Paris, had written during the siege of Beirut in 1982, 'Darkness/The Earth's trees have become tears on heaven's cheeks./An eclipse in this place./Death snapped the city's branch and the friend's departed'? (1982: 147).

\section{SY 'Argonaut'}

Shipwrecks: wine from the last port of call singing to the music of an interior desert. Clouds with flushed cheeks that cannot find mirrors to check their reflections. The present flounders, spilling its victims into the salty foam of the distant port. Ocean or tropical island? Or vision without bearings, without a location from which to postmark our correspondences?

The expectation of arrivals and departures make us ignorant of sea-sickness, of desperation, of bodies washing up on the northern tip of an eastern sea that bleeds into the Atlantic. There, in the Mediterranean, waves do not crash, they roll. Their breaths short and hushed never reach the ocean beneath the Southern Cross.

I can see it in a postcard of the 'SY Argonaut', a ship that docked in Beirut in March 1902. The steamer, set above a motionless sea, appears like a dream in black and white. The image is contained in a fuzzy oval on a white background. It is like so many others from that era: misty ships, ports, oceans and wharves. Others too are inscribed with short personal messages. This one reads: 'March 1902. Crossing the ocean to wish you all good wishes for the $6^{\text {th }}-$ Beirut (Syrie)' (Debbas 1986).

Far from that hazy Mediterranean, those words pierce the tip of a boat floating in a sink, and fall slowly into the water. Postcards flounder if they are too heavy, but they never become letters. Here there are no waves to carry you home.

\section{Works cited}

Adnan, E 1993a Paris, when it's naked, Sausilito, California: Post-Apollo Press 
Adnan, E 1993b Of cities \& women (Letters to Fawwaz), Sausilito, California: Post-Apollo Press Adonis, Darwish M \& Al-Qassim S 1984 Victims of a map, trans A Al-Udhari, London: Saqi

Bachelard, G 1994 The poetics of space, trans M Jolas, Boston: Beacon Press

Calvino, I 1997 Invisible cities, trans W Weaver, London: Vintage

Debbas, F 1986 Beirut our memory: a guided tour illustrated from the collection of Fouad Debbas, Beirut: Naufal Group/Cesar Debbas \& Fils

Eliot, T S 1981 The waste land and other poems, London: Faber and Faber

Foucault, M 1986 'Of other spaces', Diacritics 16: 1, 22-27

Honig, E \& Brown, S M (eds) 1998 Poems of Fernando Pessoa, San Francisco: City Lights Books 


\title{
University of New South Wales
}

\author{
Tiffany Hambley
}

The lobby project: arrivals hall of the lost and uncontrolled

\section{Biographical note:}

Tiffany Hambley is a writer from Sydney who holds an MA in Creative Writing from UTS. She has been published in literary anthologies as well as in the Sydney morning herald, Time out and The big issue. In 2011-2012, she was the recipient of a Prime Minister's Australia-Asia Award, which saw her based in China and Hong Kong. Tiffany is completing a PhD in Creative Arts at UNSW. 
'Free newspaper?' the man at Central Railway asked you in the curt tones of the underpaid. He turned and spoke to his companion in Hindi as the newspaper passed between you.

Oh God. This is such trash. But your eyes are moving over the page the way an alcoholic scans the street for a pub. You are mesmerised. Pamela Anderson loves drinking espressos because it makes her nipples perky. 'As far as coffee goes, I'd say espresso gets the job done - it goes right to your nipples.' You pause, allowing for digestion of this news. What a whacko.

You continue reading. Your newspaper is flicking back and forth in other commuters' space, like the tail of an irritated house cat. What's that story? 'Baggage and how to keep it zipped.'

People are wrapping their bags in binding plastic, others are using zip ties, padlocks, combination locks, zipper immobilisers, outer bags, nets and straps ... [W]e're looking at what is effective to secure bags. ${ }^{2}$

'... people are coming up with systems to protect luggage', but 'you can never eliminate the risk - all you can do is take steps to mitigate it'. They held a 'security forum' in Sydney today. Such swashbuckling language, awash with undertones of catastrophe and danger.

You switch lines. You travel to Mascot Domestic.

There's no crowd to absorb you. At 8:00 in the morning on a Wednesday, the airport is seething with quietness. You are taken by the eerie green of the fluorescent strip lighting in the underground tunnels and the almost random appearance of large spaces with no one to fill them. The place feels like the set of a disaster movie.

There are huge billboard posters of Qantas kids in the subterranean spaces. The children wear white, as in a church choir, and their mouths are straining open as they sing their guts out in front of Uluru. When you get up close to the image, you see how contorted their faces are.

A puddle of noxious-looking water has formed here, underground, at a spot where the walls have crumbled. A dull, bleating orange in colour, the chemical soup has been corralled with bright yellow Accident and Emergency equipment.

Coming up from the station into the terminal itself, you are greeted by the undulating baggage carousels. Carrousel in French or carosello in Italian: these words mean 'tilting match'. They refer to a kind of tournament in which variously dressed companies of knights engaged in plays, chariot races, exercises and so on. ${ }^{3}$

What match is being played out here at Mascot's T2?

A portmanteau that now deals in travel baggage: this, you like. You are pleased that this word's history comes with associations of costume and of competitiveness. It is suggestive of a public arena where clothes were used to delineate identity and belonging in an antagonistic setting. 
Clothing and antagonism are the key to airport baggage carousels, you think. Handing over one's bags to an airline involves letting go of clothes and personal belongings; allows them to enter a 'non-space', a 'neither here nor there'. Something of our selves has been ceded. This sparring match concerns the impersonal passage of the highly personal.

'Well, let's hope the bags arrive!' we say with mock humour, strolling away from the check-in counter as the whites of our eyes twitch like nervy horses' do. Our adversary, the airline, is vibrantly untrustworthy. We declare with bravado, 'Let the games begin!'

The void that the bags enter now is like the watery sac of the unborn, the black frontier of the grave. A space without clear borders, precise lines or any concrete address, a space whose only constant is motion. We fear our baggage might become detached, unhinged. Perhaps we fear that for ourselves as well. We might fall from the sky, lost and uncontrolled.

People come to the carousel at T2 in waves. The first passengers filter through and stand around as though stalking hostile quarry. Eye contact is studiously avoided. The conveyor provides communal distraction: people glare at the smooth rubber track as though it were a hospital monitor with their vital stats fluctuating in red lines and staccato flashes. The covered doorway into the void in which the bags lurk before they reach the carousel is labelled 'Restricted Area'. Eyes dart impatiently from the belt to this impassive mouth. Force of will is going to make these bags emerge: a small voodoo ritual is in progress.

Suitcases spin lazily on the big black belt: pieces of oversized sushi. You see that tiny talismans are attached to many: little hand-knotted ribbons, marking out one darkcoloured bag from another. It's like being in a church, or in a temple: little prayers offered up to unseen gods.

In the centre of each carousel is this:

\begin{tabular}{|c|}
\hline SECURITY SURVEILLANCE \\
SYSTEM IN USE \\
Many bags look alike \\
Please take care when collecting baggage \\
\hline
\end{tabular}

Ah, the panoptic hub. We are told we're being surveilled, but we have no idea by whom or from where. Multiple cameras protrude from the walls and ceiling. Eyes on stalks.

Security officers in starchy white shirts sit in front of a door which reads: 
Nearby, a large sign encased in Perspex says:

\begin{tabular}{|c|}
\hline NO GO \\
ZONE! \\
Photo ID Required \\
\hline
\end{tabular}

You feel increasingly nervous. An alarm sounds, high-pitched and insistent. An orange light, like those found atop police vehicles, is whirling. You feel you've set it off: Security breach, Level One. Caucasian Female. Loitering.

The only people who legitimately hang out here hour after hour wear uniforms and badges. To sit, watch, write and photograph, as you have done, is suspect. You are an outlaw flâneur.

Outside on the street, workers from Atlantis Line Marking are painting white blocks on black asphalt. You watch as their spraying machine fills the breeze with the chemical headiness of pulverised white paint. A zebra crossing emerges. Workers in fluorescent vests pull up the masking-tape borders, all that prevented white bleeding from into black.

So little separates one thing from another.

The stench of those diasporic paint molecules hangs rich in the air.

\section{Endnotes}

1. 'Lost/delayed bags', IndependentTraveler.Com at $\mathrm{http}: / / \mathrm{www}$.independenttraveler.com/resources/article.cfm?AID=18\&category=1

2. Sun, Matt 2005 'Baggage and how to keep it zipped', $M X$ (Sydney), 31 August, 4

3. Speake, Jennifer (ed) 1999 'Carousel, noun', The Oxford essential dictionary of foreign terms in English, Berkley Books, New York 


\section{Southern Cross University}

\section{Ashley Haywood}

\section{The wall reports (excerpt)}

\section{Biographical note:}

Ashley Haywood is completing her $\mathrm{PhD}$ at Southern Cross University with a creative research thesis titled Harlequin Blue, and The Picasso experiment. Her work has appeared in Island/Islet and been performed in Paris, France. 


\section{Introduction}

'The wall reports' is a fictional auto/biographical record of the writer initiating her creative process and practice in a room surrounded by walls painted an afflicting blue. In a final attempt to liberate her imagination and uncertainty and free the writing-self, the writer imprisons two characters in a fictional blue house and forces them to write their significant thoughts on the walls in exchange for their lives. Their reports are numbered, titled and processed by the writer. Characters, however, are not so easily confined nor are writing-selves free. This is an excerpt from 'The wall reports'.

\section{Wall writing}

Bound by blue walls and stranded, we are alone.

As I write for you now, I am touching these words on the wall, just as they dissolve but before they disappear, when the wall and words are most vulnerable. In this writing instant, I can $\mathrm{c}$ o $\mathrm{n}$ c a $\mathrm{v}$ e the surface as though my body or the wall were insoluble enough to be one or the other. The words as molecules pass through this blue blood-brain barrier, but the wall as a porous, membranous film catches my whole body. I cannot follow the words.

Can you feel the words passing, as I feel them?

If I attempt to follow the words with my finger, they w a $r \quad p$ with the wall and circle on themselves, as if held back, and they squirm, marking the wall with invertebrate tracks. But they too vanish. All the words leave, and then there is only blue and the wall is once more impenetrable.

Wait.

Answer me.

If we write for you, will you let us leave?

\section{Blue house}

The bedroom or room with a metal-framed bed is in a small, square suburban home, and one of four square rooms for each corner of the house. I have no memory of who I am before I woke in this room. There is one other room with bed, and these are the only furnishings. The four rooms can be open or closed to a central space, but there is always light. There are no doors to the outside, no windows, not a single source for this perpetual, penetrating light. All the walls are blue as this wall is blue. But there is one room with different walls.

Is this what you want me to write?

The walls echo their screaming blue. It's that kind of blue. I had just woken and as I turned around and around, searching my mind for what could explain this place, I found that I was not alone. The door opposite to where I woke opened from the inside 
and there was a man, emerging from a replica space as empty as mine, with the same metal-framed bed and the sheets tossed.

We're both still naked and trying to remember.

Is this what you want? We don't remember, so what do we write?

'I've searched the house,' he said, 'and I can't find a way in or out. But I found this 'He was holding his writing tool. I had found mine too.

\section{The wall reports}

We write to live in this blue house, where things, not just our words, come and go through the blue walls. With no indication of coming from anywhere other than the walls themselves, the blue walls sometimes deliver things to us. Your instructions were delivered after waking but I don't know how long ago that was now. Your instructions are that we write on the walls with the WRITING-POINT TOOLS or we'll be PROCESSED. But I don't understand SIGNIFICANT THOUGHTS.

Why bring us here and from where? Where do the words go? What is this place?

We have so many questions. The man sat against the wall for a long time waiting for answers, but I don't think you will respond.

\section{Writing-point tool}

The tool is soft, like a paintbrush, until it touches the blue walls and becomes magnetically solid. It won't mark any other surface, other than our skin. I can feel a charged pulse if I let the writing-tool touch me and then the nib-end burns a mark, but before it burns, before the electricity, I can feel it as a thin brushstroke, so delicate.

Sometimes a sentence disappears faster than a word and I forget what I have written. You see the shapes shift, the writing is anamorphic and I have only eyes with which to watch them tale their own forms; all twists and smooth loops, sharp ends and multiple trails. These are maps of my own making that I cannot read. So I am mostly left behind. Soon you'll take whatever remains of me without me knowing, but am I enough? I am lost without knowing what is lost. Is that enough?

\section{Two other rooms}

The woman tells me that she doesn't remember waking, but remembers dreaming. We don't know who woke first, but I found the simulator. 'Come on', I said, 'I'll show you what's behind door number three.' She didn't react. I offered my hand to assure, but she wasn't looking at me.

'Are we breathing?' She asked. I took a breath. 'And can you feel that, feel the floor?'

'It's just hardwood, isn't it?' I said. This was before the two other rooms and before we knew there really was no way out.

'No, that's what we see - Feel it.' 
She didn't take my hand. We're naked.

This is all I know to write.

The room opposite the simulator, the fourth room, has two silvery discs. The discs appear perfectly round and fluid, but machine-cut into paisley-patterned tiles with chipped grout but no mould. Two discs, tiles and blue walls. She dropped her writing-tool onto the smaller disc, but it stayed on the surface. I pissed on it, and the urine disappeared.

\section{The simulator}

At the entry to the simulator, the woman stopped. Her nakedness was almost translucent in the daylight. 'It's just made to look and feel like sunlight,' I told her, 'it's the same deal as out there minus the fucking blue.'

The simulator walls, floor and ceiling are opaque, including benches.

You want significant thoughts? This is all I have: opaque and mostly white during the daylight hours. We waited together in the simulator, watched our sun-stretched shadows move around the room until dusk. That was the first night. And we slept on the benches that wrap around the walls like a sweathouse, or, as Mimé said, like a glasshouse for people, as if she knew.

Simulated sunsets and sunrises rubricate with reds into yellows and oranges into reds, sometimes violet rings out before night is switched on. It's come to this, living for the next pretty dawn and a white day, the blue walls endless and these words, because what else is there for us?

\section{Female subject}

I told her, it's all in her body. She suits Mimé. 'You suit Mimé,' I said. She sat on the simulator bench with her knees to her chest and her arm over her head. 'It's just me and you,' she said, 'do we really need names?' Then she stretched out in the pretend sun.

We talk, we call out to one another between rooms, we whisper, we don't just write to you. 'Yes', I said, 'we need names.'

She said she'd think about it, a name for me.

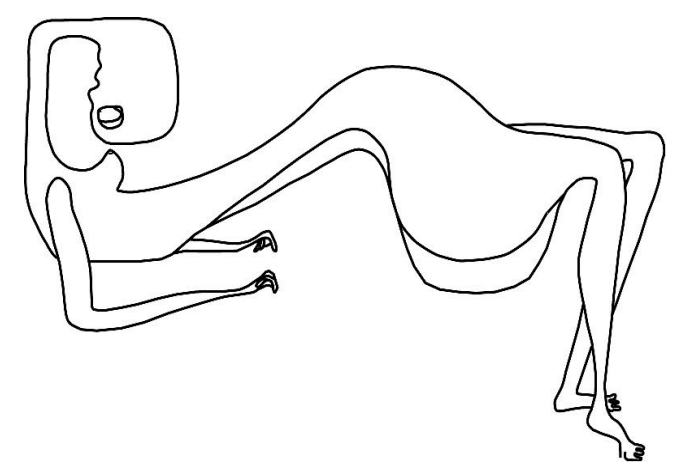




\section{Nib-shock}

They can't leave our bodies. To be safe, we platted rope made from bed sheets, ripped and shredded. It's secure tied to my hip. His is tied around his neck. We both get nibshock against our skin, and the burns look like lashings around my legs.

\section{Wall light}

Mimé swallows up the light while I'm being chewed. It's a postmortem light along this valley of the blue walls. Penetrating, the light records me and I feel it with my hands, my arms, rolling my whole body over it, hitting it, and I just have to think and the valley opens, the tool shaping its contours and I'm pinned against its ridges, eyes dropping into rivers.

Stop.

There is nothing here, not even this bed is mine. I can't even thieve it, disturb it.

\section{Adaptation}

The man stays out with the blue walls, longer than he needs the time to write. He tells me he's adapting to the light out there, adapting to that monotone-machine blue. And he's doing it in case you switch off the night cycle in the simulator. If you plan to experiment, to take twilight from us and the night, I ask you: do you exist only within these words?

\section{Bed}

I had almost forgotten the bed where I woke, closing the door all that time ago for the simulator room. Lin hasn't slept in his bedroom since waking, but, then, I don't see everywhere he goes; sometimes he's in and out of the disc room, the living room, in the doorway to the simulator, but not in the bedroom.

I imagined the white sheets were still crushed, and shredded material discarded to the corners of the room. But when I entered the room where I woke, I found the bed remade. The sheets folded, unsoured, untouched as if I had never woken, as if nothing had been written - everything is pristine clean. It all glared back at me: the dustless metal-frames, the sheets, their perfect white folds in perfect lines, ironed flat to stop at the bed head.

This bed requires dangerous metaphors.

So this is my plan. Anything that can rot, all the scraps we've left unused, untouched, anything that ever sustained us, I am pulping together with the mattress feathers. Between its springs, I am plotting out a new kind of bed. And now I am lying with it in the darkness of the simulator and the room is becoming humid. I dare you to stop me. 


\section{Things come out of the blue}

Antwasp, Antworp or Antwerp? Wants or Woopants? No, Antwasp. The Antwasps are coming. I told her the Antwasps are coming.

Wading through wall-time in spots of light, swarms of Antwasps aim for my opening iris, and procreate behind my eyes. But I can't keep up; I can't catch them all with a blink, before they burrow into my brain. Feeding on the reddish-grey mass that sits neatly up in between the fissures, where they engorge on sleep so everything stays blue.

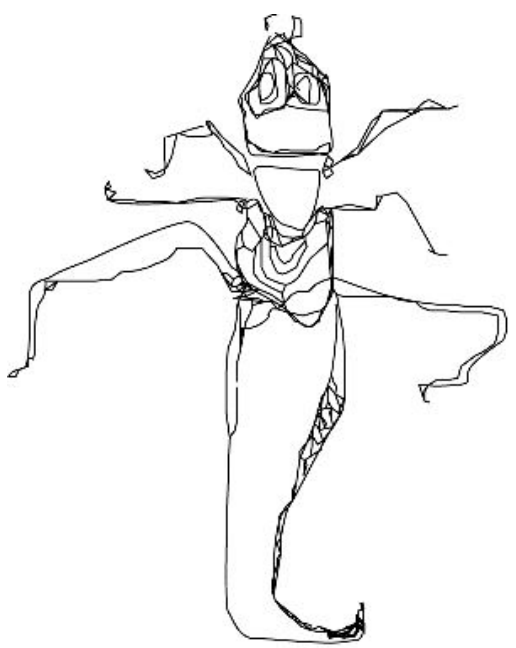

\section{There are two discs}

The small one is for excretion and the other is for dreams. The fluid is not viscous, but it's heavy and its heavy water lets my body and only our bodies break its surface. I looked back before going into the big disc to see Lin. Lin had come to watch, but his concern was not protective of me. He was not surprised when the disc's fluid grew slowly up and over my skin where my legs were submerged. I gave him my writing tool to mind before the pull was too much to resist and I was taken into the disc. There was no splash. There was no sound. The water pulled me under and Lin and I were separated.

I lost stream of consciousness. I was at the edge of the disc and then I was back in the house. What happened in between, dare I write, was like dreaming.

You're a fishing creature. I saw you in that ocean down there. A creature with no clear outline. It was your lure and your wrist flicking on the current that caught my eye. I watched as you jigged up and down your lure and bait. Baiting with indigo and cyan, bass-violets rippled out from ultramarine and high-tide azures. I didn't know these words existed. I wanted to touch, but you threw me back and I re-woke on the titled floor that is neither warm nor cold. 


\section{Lin}

'Don't you like it?'

Do I like it? ... Lin? 'Spelt with a $y$ or an $i$ ?' I asked.

She said she didn't need to breathe under the disc, but you know that I know we can't drown. Lin. Lost in here.

This is getting tedious.

\section{Fishing creature}

With hooks instead of fingers, baiting the forgotten from the blue - What do you keep in your netting, while you leave the rest of us sterilised?

\section{Antwasps}

The females are watery things, slipping in and out of the walls, stinging my body, if I disrupt their swarm. Coming or going, they leave marks. If you observe carefully without being seen you can detect anomalies in the blue. Look for light-spots from wing-reflection, and all their eggs set adrift together on the blue stare back like a compound eye. Look, over there $\rightarrow$

\section{Rememory}

But the body's memories, organ memories, are spotted in me. Everywhere, they are scattered as islands. And only I can remember what's buried.

When the organs shake, tectonics quake and things slough off, drift up or blow up, these memories will litter my conscious with clues. That's right. I can find them. I will find them; I will detect even the smallest crunch underfoot.

\section{Compound eyes}

I felt her legs, the rough hair and sticky feet. I stared into her thousand eyes for as long as there are days and felt love. The wings on her back heaved and then she went for my optic nerve.

\section{Skin}

Isn't it obvious? With the marks these tools can make, have you not seen Lin's skin? Lin is counting time and words and whatever comes in and out of the blue walls and writing for his eyes only.

My thigh is marked with the sharp finned-hands of sea-people, and sometimes I see them dancing on the walls. I hate what that might say about me, what this means. It's getting worse. They surface only to herd and I have so little left to give, please. Please. 


\section{Spaceboat}

We talk about you. Maybe more than we write about you.

Do you know what I think? I think you're a spaceboat disguised as a house. A vacuum-scribble craft exploring all the galaxy-piled corners of the universe, as time rolls over our head like dirty sheets. Why don't you grow a pair of windows?

You know I'm on to you, Spaceboat.

\section{Roots}

The mattress is beginning to sag with decomposition. Roots have nestled in between the springs. And you know, don't you: with our first fruit, we won't need you.

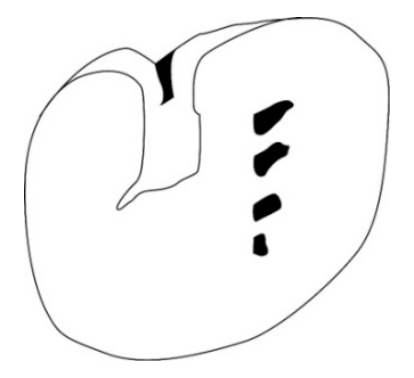

\section{Leakage}

Captain, this Lieutenant Lin, I need an estimate on our spacetime? Gravity has just bottomed out.

\section{Wall fish}

I haven't moved him. I didn't know what he was planning. Lin was running at the wall before I could do anything. I came out when I heard him roar, and saw him charge through the bedroom door and into wall. When I got to the doorway, he was in a collapsed heap next to the bed.

He's breathing, but he's not waking. I've felt his neck and along his spine, trying to imagine what's normal, or what could be misaligned. The gash along his head is still bleeding red. Can you do something? I'm just waiting now for him to wake-up.

His body is covered in burn-marks from his tool. Dot-dash, lines and words that are so fresh and swollen, they look poisonous, and others so old, I wonder how long we've in this house.

The wall he hit is marked with red. It's a starburst, an asterisk to these words that I write, but as the words move as usual, into the wall, the red so brilliant moves too as though it swims, as though his blood is evolving into wall-fish. 


\section{Maps}

The skin has to be tight like parchment. Words can go on top of other words, so read whatever you like: I am your bedtime story, your bedside lamp. Back from the dead. Tell me where you want to go and I'll take you over my body, just follow the arrows, Spaceboat.

\section{Outline}

I can feel my thoughts being consumed by you. Chewing on the seeds, lolling the kernels about the tongue - How do we taste? You have no taste. Tell me, have you taken shape?

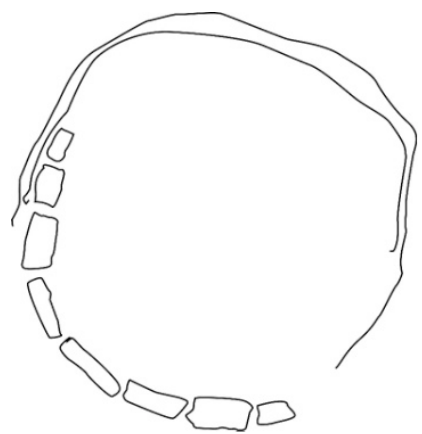

\section{Garden bed}

I watch her, turning in the compost. Feathery humus and shit, but there are seedlings in there, somewhere in the troughs. Can't you see her plotting? This garden has a kind of stench, I tell you. She could find anything down there in the roots; between the rows. Tell me, do you think she would? Do you think she'd travel that space alone?

\section{House rain}

The first drops started in the simulator.

A touch-to-the-tongue salty, but refreshing to taste. At first, the falling water was a pleasure. I thought you were giving us something special. Now I feel the water rising around my feet, and the blue walls are cold to touch and the words move slowly.

Are you even reading these words? We are writing!

But look at what grows. It still grows in all this water - Look.

\section{Last words}

All the heavy words sink.

We're bloated, between floating and wading through your flood water. Migrate with the words or get left behind - is that the game? I thought I was more to you than soon to be belly-up. Spaceboat, are these my last words? 


\section{Breach}

A seedling is growing into the wall from my garden bed, right here. I can feel where the shoot softens the wall. Soft as when we first woke, when the w o r d s warped with touch.

Lin says that he won't go, he would rather disintegrate, and that outside you have to creep in space and everything is black not blue. Instead of coming with me, he drills into his body as if it were an open-cut mine, burying or unearthing.

\section{None}

How many words will it take for this to end? I can't see the wall or this writing through the ceiling rain. Shapes expand from my hand and in the uncertainty and I see black polyps on the house currents.

\section{Mimé}

I am written.

Lin

Spaceboat?

\section{Growing into the wall}

Can you feel my feet planted? It won't be long now. It's easy to grow things that want to grow. In time, what is buried can become erumpent and disruptive. So I am growing.

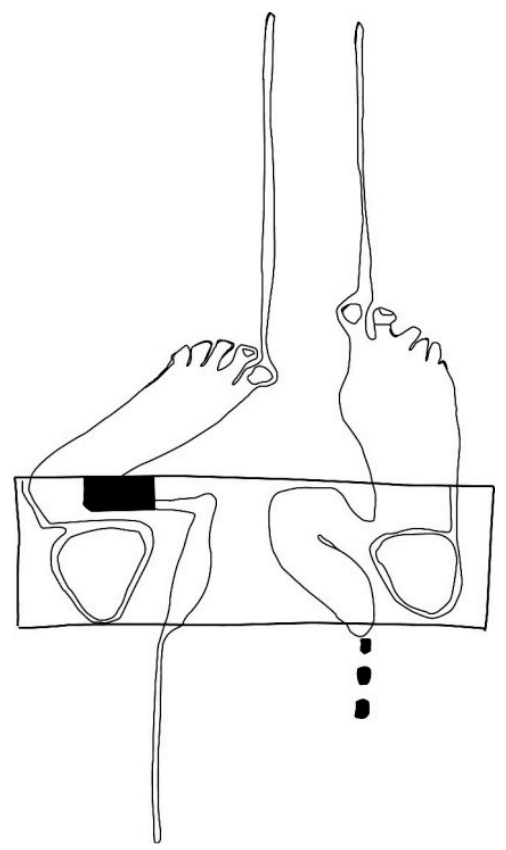




\section{Ferryman}

She is gone. I am only writing to tell you, I watched the last of her leave. She gave me her writing-tool. You know I could have gone with her, but what is out there passed the blue, in the black? She'll be lost after the wall. But I'll be here, suspended and afloat, your watchman of the blue. And we can start again, just me and you.

\section{Blue tulip}

Before I woke in here, I was in a blue tulip. This is all I remember before waking in the blue house. So in a way, the giant tulip is the first event of my life. Did I tell you? In the tulip, a blue-eye wonderland, I swam around the anthers at the base of the style. Tightly folded petals were just opening above my head. So far above my head, the opening was round but as distant as the moon. Through the opening, a sea-beam of light ringed the weighty stigma in blue and lit the sexes. But beyond the limit of this light was black: a black on black on black out toward the unseen sepals or more black, out toward whatever I imagined.

I wrapped my arms around the style and waited, wondering if the flower would consume me with its antherous jaws. Still I waited, looking out into the black, watching as it crept closer and the petals closed over me.

\section{Skin writing}

I was here 
Independent writer artist

Teri Hoskin

The rectilinear case

(from Cultivating writing: How to learn an unknown environment)

Bibliographical note:

Teri Hoskin is an artist and writer currently living and working in Sydney. 
In a second-hand bookshop I found a box of how-to pocket manuals that were published in the 1960s. The titles ranged from instructions for exhibiting flowers to financial planning to 'How to be an effective public speaker'. They begged transformation into art but remained too much what they were as objects. Instead, I chose a random sentence or two from a few of them. This is a small selection of that initial selection.

IB001_25

There are several superb varieties that do not fit conveniently into any of the accepted categories, and yet they are too good to overlook. Because they are slightly 'different' they are best planted en masse or planted as individual specimens.

\section{IB002_7}

Yet coins bearing the name of Edward Vlll which are extremely rare in Britain are common in parts of Africa, but before you rush off to collect them, be warned that they do not carry the head of Edward Vlll - they have a hole in the centre. Africans like to carry their wealth with them and pockets were not common in Africa.

IB003_43

It doesn't matter how you stand provided that the audience is not distracted. A speaker who never moves cannot expect to arouse any great feeling. Neither can the speaker who tends to wander about the stage.

\section{IB004_17}

Before choosing a pattern, take your measurements, write them down, and keep them so that you can refer to them. When deciding on size remember that your body twists, moves and bends ...

\section{IB005_19}

By now you should be faced with a surface that is clean, smooth, dry, and ready to receive paint ...

\section{IB006_23}

If you want people to sign on the dotted line don't spend too much time on scenes of suffering and sorrow. 
IB007_63

Do I need to tell you that every fully expressed sentence has a subject and a verb? If I do, you should be reading a much simpler book than this.

IB008_97

Handfuls of earth or dust are as good as anything for putting out the fire. An investigation into a burning rubber smell should always include the fan belt.

IB009_55

To lay the first course the adhesive is mixed according to instructions and applied as four 'bumps' or 'buttons' to the base of the block which are seated on the foundation in correct position.

IB010_45

Combine the beef, bitters, lemon juice, salt and pepper, and mix lightly together.

Using a fork, divide the mixture into six portions. Gently shape and flatten into patties.

IB011_17

Ventilators should be placed in the lower wall below bench height to let in plenty of fresh air, and in the roof to let out the hot air.

IB012_32

It may be necessary to remove buds in certain places where they are in multiples, as only one truss per stem is permitted in such classes. Most experienced exhibitors cut their blooms a day or two before the show.

IB013_15

You should, therefore, explore all cracks and fissures in a rock face and hit all rock faces with your rock hammer; a dull thud will tell you if there is a cavity beneath the skin of the rock.

IB014_44

Most of the early graters are steel with irregular jagged piercings. The later ones have more even machined piercings. 
IB015_55

Broken glass melted into a flat dish or ash-tray makes a pleasing yet simple decoration.

IB016_11

Place the first two fingers of the right hand under the areola - the darkened area around the nipple - and place the thumb just above it.

IB017_45

The Worldwide television set which you sent to my home on the 6th December appears to be defective. Since the first day there has been constant distortion of the image, with flickering and 'ghosts'. Your invoice number is 25708, dated 3rd December 1968; the model is No 6FH.

IB018_23

The above treatment is for mild cases of inflammation and any severe cases should receive veterinary advice and attention.

IB019_12

If the hole is small the ball is probably repairable. Make another small hole opposite the original one which is the cause of the trouble. Hold the ball with the first hole at the bottom and blow through the second hole ...

IB020_31

The rat-tail is less evident at the end of the 18th century when it was replaced by the 'dew-drop' union.

IB021_29

When you have the size of the rose you want, glue the end pointing down the stem of the flower. If you wish to make a single rose earring, make a slightly larger rose, but if you want to make a cluster, make several smaller ...

IB022_25

There will always be a slight amount of drawing in at the edges (as in the lips of mass graves). 
IB023_45

Remove shell and grate into a bowl. Pour 1 1/2 cups of warm water over and allow to stand for 15 minutes, then press through a piece of muslin.

IB024_19

Do not attempt to control the rhythm, but notice how the chest rises and falls naturally.

IB025_17

However, you should be conservative and give it a halfway mark between the figure and its current market price.

IB026 18

No amendment can be accepted to this motion.

IB027_61

There is a large market for work of this nature, but the jokes and drawings, of course, have to be good.

IB028_29

Their 'song' is made by the rapid vibration of two hard, springy plates situated on the abdomen and worked by internal muscles. The action is like that of a tin lid which, when pressed in, springs back producing a sound with each in and out movement.

IB029_65

If the housing estate is linked with new industrial development you'll probably find that many of your neighbours have children of a similar age to your own.

IB030 2

Select your cheese carefully, buy to meet your requirements, and store refrigerated at 38 to 40 degrees $\mathrm{F}$, in plastic wrap, aluminium foil, plastic bags, or plastic containers.

IB031_34

It is impossible to give advice about spending. 
IB032_29

Another very satisfactory method is to cut beneath a node making a slanting cut upwards, one-third through the main stem, then to insert a pebble to spread it apart.

IB033_12

The meat and water diet means that for one day a week you have nothing but meat and water! No biscuits. No bread. No milk. No fish. No green vegetables. No lettuce. No cheese. No alcohol at all! No cold drinks. No sausages. No polony. No thick gravy.

IB034_11

For the benefit of guests who do not like cauliflower, cut French bread into bite-sized cubes and place around the fondue bowl.

\section{Endnote}

1. The letters and numbers are paragraph identifiers from the original text. 


\title{
University of Sydney
}

\author{
Kate Lilley
}

\section{Letters of caption}

Biographical note:

Kate Lilley is the author of Ladylike (UWAP, 2012) and Versary (Salt, 2002). She is an Associate Professor in the English Department at the University of Sydney. 
Presentation feedback: good to see you

Takes years a drop in the bucket

What you told me in 1969:

Was it simple or simple-minded?

The bus is Limited

The Express train runs local after midnight

\section{FEDERATED COLD STORAGE OPERATIVE PRINTERS \\ MUNICIPAL EMPS \\ THEATRICAL EMPS \\ CONFECTIONERS \\ BOOKBINDERS \\ PLASTERERS}

Brevity fabrication error

A tantamount: noun (obsolete)

Cheek to cheek

in the unabridged

in your eventual cathedral

Yours forthwith to thrall and bond 


\section{Independent author}

\section{Maria Zajkowski}

\section{The specialist inbetweenery}

\section{Biographical note:}

Maria Zajkowski is a poet living in Melbourne. She has been publishing her work in Australia, New Zealand, UK and USA for the past 15 years. She has been shortlisted for the Alec Bolton Award, the Newcastle Poetry Prize, the Bridport Prize (UK) and was the winner of the 2011 Josephine Ulrick Poetry Prize. 


\section{Thursday}

The janitor arrives, looks at me, and says, you're a mess. He leans on the stem of his broom and we stare into the distance. I get cleaner just by looking elsewhere. My thinking hat is caught outside in a tree. The janitor says, reach for it, and when I do I come back with a bird. It positions itself on my head. The janitor smiles, it really suits you. The bird of my thoughts always faces into the wind. It sings when I'm coming up with something. The janitor whistles, and I can't tell if it's me or my bird whistling back, its green feathers are great thoughts. Out by the grape vine we inspect the velvet leaves forming on the vine's arthritic spine. We're thinking biodynamics and plumpness. My bird flies off to be with others. The janitor and I kiss. He is of course a she and we know we are well planted companions.

\section{Friday}

After the full moon my garden erupted and was somehow covered in milk. Branches had fallen to the base of their trees and the trees were happier, aiming higher. I had to step carefully through the strangeness. The power lines jangled all day with their messages skittering in and out of the house. Like a message that got lost a giant dog leaned over the fence to stoop down and sniff the top of my head. It snorted a giant snort and a few feathery puffs of smoke came from one of us. As it departed, I heard it grumble, I'm going to the home country. By then it was raining lightly, so I stuck out my tongue to catch the atoms. There was no-one around. The street was deserted and wet and I was afraid the dog might be lonely, but it was too late to think about that.

\section{Saturday}

The janitor comes by in the morning to pick me up in her convertible. Get in baby, she drawls. I lift my skirt to step in. My bones have lengthened in the night and I rest one static lightning bolt hand on the back of her head. Hold on, she says, and we're already there. It looks like my house but there's a beach in the yard and a romantic table tilted on the sand. The house, I discover, is actually a castle. The janitor has done well. Darling, she says pressing against me. Darling, she says again. She shows me to my seat. The tide comes in to cover my toes and hummingbirds place my serviette correctly, one at each corner, their dynamic bodies busy together lifting lids and pouring wine. It's love and lunch and later we finish with sex on the beach. The tide is out by then and the hummingbirds fly off to rest in the shade. The janitor is covered in sand which turns out to be sugar. How sweet you are, I say and kiss her until she is free from confection. We sit looking out from the top of the day and she dozes on and off in my arms. The beach dissolves and we're left on a rock of sugar, like two smiling dolls perched on a wedding cake. 


\section{Sunday}

I sit myself in an orange nasturtium and look out at the ticking garden. Because it is Sunday there is no-one to oversee the time so I thread a ring of minutes and link these into a chain of hours. I think about the janitor. She is visiting her mother in the next town. Sometimes they go to the cemetery for a while to lend themselves to the family gravestones. The janitor might take her tools and do a few repairs. Reminder: I must ask her to prop up the shed. I've been storing my thoughts in there and I want them to last. I'll ask her to wear a helmet so none of them will get into her. Maybe a coat of paint and perhaps even a mezzanine to organise into Good and Bad, or Pointy and Pointless.

\section{Monday}

I get offered a job! The cheque's already in the mail. It seems someone heard about my sorting of the hours and has a huge backlog of cataloguing and suchlike. It all gets delivered tomorrow. Working from home will be an advantage. I ring the janitor to say I'm busy, but she is too busy to answer the phone. I clean the house and prepare some space in my notebooks for an eventful Tuesday. I erase all straight lines and empty a few containers. The janitor calls back and says she will do the mezzanine and congratulations on the job. I hold the phone extra close to hear her body stretching and flexing in her uniform. You need the money, she says. The fluorescent light above her buzzes. Turn off the light, I say. I can't hear you. She flicks the switch and then I hear her heart and breath, her toes compressing in her boots. That's better. She lets me listen to her fall asleep. It's late after all.

\section{Tuesday}

It's dark all day long. The sun doesn't bother to come up. When I woke there were hundreds of boxes stacked on the veranda. I got to work, tallying, carding, drawing plans and pacing them out in metric and imperial. I had to neglect my own timekeeping; I forgot I even had it to do. The job was demanding; the boxes were filled to capacity with minutes, weeks, months and years of unresolved time. This was my calling, I knew. It makes me money. I emptied the boxes and refilled them with the organised data as I went along. I was given only two days to implement my strategy on time resolution. I got delirious. I got delirious and ended up skating between now and then. I opened up a drive-thru time management service and sold tshirts. One customer came back and back again saying, As soon as I leave it's no good. Can I park here all night? I agreed but reminded him the service was closing tomorrow. I was being paid more for the boxes. The boxes, the boxes, the boxes!

\section{Wednesday}

It's impossible to close somebody else's loopholes. There are strange animals tracking through my house. This person has squeezed menageries, generations and so much unfinished business into these boxes it's barely possible to compute. But I must, 
because this could be the making of a career in genetic time management fundamentals. Ultimately it's a system to be imposed to catch all those meetings that never happened where so many things were never said, to catalogue indecisions and unnoticed fruitings, to store recipes not known but tasted, to close distances unwanted and untravellable, to harvest the inbetweens like those I have grown in the specialist inbetweenery, to catch all the lives lived in one life and to make secret chains out of secret hours with one's own private janitor. Finally, though, the job is done; it's already tomorrow. Here comes my janitor with her mop, her bucket and a few plastic bags to help with the job of tidying up. She smiles and starts to fill her bucket, wringing her cloth knowledgeably. I sit down and remove yesterday from around my shoulders, so she can see what it is that needs to be cleaned. 


\title{
University of South Australia
}

\author{
Linda Marie Walker
}

Inconsolable

a film (extract)

Bibliographical note:

Linda Marie Walker is a writer, artist and curator, and a Senior Lecturer in the School of Art Architecture Design at the University of South Australia. Her fiction and nonfiction has been published nationally and internationally. 
The sense of something or other, purring. A hand moves slowly, as if as if, but then again, the tense and blackened eyes, like putting it, whatever, you, together again, as if the rain will never stop, as if you'll walk in. Fern fronds in a glass vase, on the table, under the

light, sticks on the window sill. A mist in the distance. And it's nothing, for a moment, nothing, in my hand, the circle closing closing, one word would be enough, crawling, cherished, one stone like another, round stones, skin then, the wave of a hand in the summer from a car on the way to the ocean and the sand and the

lapping, the warming of the body, the body moving, folding, who is this, who is wondering, who is saying no no, but I'm going, I'm going, to write. Do I want, do I want, anything. The low ceiling, the light light as light. Sometimes no time to go over the scenes. The light light. Brushing, a trap, a trap, snug up against the brown earth, it is easy, the clean loving kill.

I am turning my head, toward the rendezvous, little nose against my

hand, wet and black, little sighs, sleeping sleeping. Measure my arrival, surprise, but quietly, love, in the flesh, small moves ... one day, and the next,

drops of water on a face, the calm of stepping off the ledge. The ravishing fall, scattered, the bride on the steps. Undoing the black box, gravitating. A cup of

tea, sure. Barely exposed. A short walk, an umbrella. Neither this nor that, an utterly private act against your shoulder. The composition, taking into account good conduct, resolutions, and scars, in the night,

is metal. About this plan, much known. A round missive, here, blood rising to the surface, quick while it lasts, bring pen. I am opening a door, touching a hand. Can't notice life, or yes yes, or furs. Things can go too far, strange shifting kindness, noise outside, something extra, something air-born. The shape is life-like, as like-life as a current, precise, drained, and dripping. What use is that. No flame, solid or not, will lick the eyes of that man, as is wished. The silvery blossom dying brown, the sensation of coming once only, to the window hopeful. She

stumbles, she's in the film, for example. Well, thick rose tongue. More or less. You can hear the tone, over a table, everything contained, easily, as you intend, and confined. Go ahead, toe the line. Oh be here, in the fibre, muttering. Seascape, green water, and I know this is true. Green distant water, in my ear. Someone leans toward

the twilight. They can't work hour after hour, losing day after day inside the heat of ever and ever, with no questions, no, not even to console in that touching voice, and they are busy till the bell rings. The bell, of dark irises staring up lips parted, pearl

skin, the ceremony lasts. The tips of the fingernails, the mouth. The police have already been. A low doorway, and a small white room. It is upsetting, this hollow space. I am outside, anyway, you are outside. A ring around the moon,

in the day sky too. The old life finished, again. Again, the experiment, whatever named elsewhere, say footsteps, or the breath of the lover, his red eyes, even, anyway, the gesture never seen before, is a film, of voices, and breaks. Behind me, a long cold 
corridor, lit by a yellow glow, black and white floor, doors shut for warmth. Another house I've never

been, shudder shudder. Something in the wind. And I go with a man, unknown, as the backwash, nothing else. Should I look up, take account of the woman by the window before the red curtains, and constantly, worlds of you. Cut by almonds, by tenderness. No rose, no rose, no rose. Necklace, ring, and the wish for a soft black scarf. And kid gloves. A very slow pan. I am suspicious. I am swallowing. A red coat hangs over a chair, as left, everything before me, years old and small, covered in dust. The wide brass jar brought by the friend, gone now to an island, intact, almost. The trees waiting to be talked to, forests of them, softly

murmuring softly murmuring. The figure of a woman on the horizon. Talking to herself. To die for love, to eat another meal, to smell cabbage. To smell carpet, burnt walls - where do you come from. So many people, and one comes along, with nose and mouth and ears and hair. Someone lasts a long time. You are out of sight, coming and going, wavering. Have I worried you, who desires to be heard, who is an adult. I've been taken in, a

voice to read the text to, in the dark. You can't put this together, this drops parting partly. The pleasure, in the dark, of the moving voice, as it goes on and on, and there will be music till the begin begins again, a timely speck, a river. As you said,

start in one corner, end in the other. Suddenly, a tiny ray, her heart beating fast. This that she thinks is me, before the crowd, has turned her head on the pillow. There is a man. His lips slightly open. Two bodies on the

bed, she hesitates. This surface, this whispering, in the late afternoon, and more, a shadow crosses a pier, like a ship. She sees a girl descend and the man rises, into the sky, a large moth. Too too fragile. He is gone into the blue into the blue. There is no massacre, a subdued note, a solemn single note played over and over. A delicious fuzziness, a lake, the $\mathrm{J}$ and the $\mathrm{K}$ and the $\mathrm{H}$, all the letters spreading out, the neck most sensitive, most sinuous, time to go, through the window into the dry grass snapping underfoot. Oh, it's like a dance, out in the country. Someone dancing,

soaking wet, dancing. Down the lanes, and you are drawn in, wined and dined, like salt. Outside cats in the garden. It's a fine way to be, and then from the end of the earth, you. Crying crying, choking. A likely story. I go to dress. But it never works. It is morning,

the slow and sticky breath, trickling. I am living in the city, tonight, a lifetime, the whole trouble, I dedicate nothing.

The position of the sun. His glance, someone special, I am watching.

Everyone makes something, time after time, someone else, too. No-one's bothered by it. Beside the point. Rocked to the very bottom, a large glass. Good, good, going well. You abandon the morning the evening the day at a moment's notice. And the little cat bounces round the room, paper ball in her mouth. She's a drawing on the floor, snuffling. Movement all through her limbs, and grey. Nipped in the bud. I saw him at a distance, no avoiding him, with the world raining, him, expanded, parallel. A sort of 
loophole, his rouged cheeks, his raised eyelids. One has to guard against the past. The curtain is pushed behind the bamboo blind, and the winter day is there amongst the birds and the red bricks. The cherries on the curtain will fade. Shoes lined-up beneath. More and more summer, making scenes. This delay then, this is what someone

finds, who works, strictly, as fortune, as menace. This delay, mild devotion for you. Like saying, come inside, please. Please. Window jammed. Shouting. Window jammed, oven ready for biscuits. Shouting, whining wind on the floor and the ceiling. It is late, the cat licks its paw. Are you asleep, must I sleep. Cold

creeps up, sits heavy on shoulders. Hands over my eyes, eager to turn on light. As cosy as light can be, a long rope, from a height. What joy. But a flower, for example an iris, as already filmed, the ear hears that that that slush of the blood, and then dry hard and cracked. Don't go astray, especially, you are not that that that. One never forgets the feel of the body in water, the smooth skin in still cool pool. A door squeaks, a few footsteps, someone walking on the tips of their toes. Glimpses of this and that that that, the assembly of someone. I point in the street, and collide, walking out. You, there, and the shadows shifting, a door, and the glow of a head, swimming between your legs. This play against the wall, the hot breeze, thumping time after time, thumping in the night, a full gossamer moon. And the rest, and you. Meantime. You have died. And someone is on the chair in the cafe, as seen so often, and this someone looks back, astonished, then fades, and wonders aloud, being left alone, who speaks. Who is that voice. You then, at that moment, across the world. There it is, the forever, yes and no, fact, no adjustment made, someone is the wounded wound. You always call toward the house. You are painted over, dusk. With the sunlight on the white page. The sky shocking brown. Outside, of course, the shrubs rustle. Usually there are sparrows, finches, magpies, and especially night-birds. The memory of rocks. What gift would you give me. Down through my eyes come yours, beyond the low radio. So tame, that day, and now this day. You will know spite, and the bliss of the smoking car, yes yes, and you walk out the gate, and turn to slide the bolt, and watch the flakes of rust spiral to the weeds, and ride to the river and the buildings, year by year, and pass the high-trimmed hedges. And and all the while I am pretty. Could someone be ... or be bothered ... and the rest. Am I finished, yet, tight as a bud, running racing, and then again there is a plane, and benches, and bags. Enclosed, sighing, breath gone, nothing left, momentarily. Ah well, you are here at last. Enough for one day, a tall tree, a rhythmic swinging of the arms, and the sea red. I tell you. I gave you notice, and you accepted, you told me that. I accept the fine patience. Your papers in order, and still you say yes. I never finish the long sentence. The wind blowing the rain across the sky. The city yellow and mauve. Beautiful from up here with the lights of the planes piercing the dense fog. Now the rain is heavy on the roof. Someone wants to sleep and sleep. Now it has almost stopped. The great quiet. All that can be, forever, tied by a thin cotton thread. Black coffee. Sap in its black alphabet form, on the page, is lust ... the single sultry pore, the tear-duct, the elbow, the knee. Yes. A blade (of grass), this of all things, green green green as green as this

crisp season. A song somewhere, the song bursting, and the woman reciting, slowly,to finish the job. Becoming lucid and sharp, and stabbing herself, lips crushing, revengeful, as well, and now it is ... three-thirty, saying sweet saying, slightly, hardly, 
touch me just, blow on me, say what comes. A load, an action, eyelashes, for instance. The author and the poise of a glass bead. This is true. I am inside the dreadful rain, and you have been

howled on. Who knows what it's called, what it is. This is Thursday in a week in a year and your body will be laid wide open, inconsolable, on the quilt, tender willing. And me standing by the door looking (inconsolable), not lost like before, oh what beautiful gazing,

the soft chest and back, the neck, you are more than, and especially, you, complicit. Dependent on that, constantly you say you are to me to everyone. I am prepared for the next two or three days. And I am waiting for the warp of the case, and it never comes. Another fine fine lingering time is had in my glorious day. Is that applause ... no, fancy that small burn that I have shown you, temper, (it) is that that that simple, but it is late and who will take my hand and lead me on, little snake, huh. At this table this resistance is precise, to even consider considering someone who is my image is the cream on my lips the rings on my fingers the sand under my nails. A lake. An eagle, upon the ground, the rain the big round drops, my coat on the couch, it would be too dramatic (filmic) to draw ... 


\section{Independent author}

\section{Emma Ashmere}

\section{Portrait or landscape}

Biographical note:

Emma Ashmere's short stories have appeared in various publications including Sleepers almanac, Etchings, Griffith review, Australian women's book review and The Age. She has an MA in Creative Writing from The University of Adelaide, and a $\mathrm{PhD}$ in English from La Trobe University, Melbourne, investigating whiteness and the use of the historical record in fiction. She lives in northern New South Wales. 
a dove in its shape, anywhere

is free.

Janet Frame

You don't paint, they said from beneath their stout straw hats with their milk-white calves and the sock-and-sandal surety of the British abroad. I tried to write them down and failed except for one fragment inspired by my employer Evelyn Millar, painting her pair of new white doves.

\section{dawn breath cloud flight/ exit stars/ the pearl-sky night}

I never showed anyone my poetry. Poetry was private, wasn't it? ${ }^{1}$

I was paid to cook for one summer in France not to paint or write poetry about the pearliness of skies or doves, or my enigmatic employer, or the collection of houseguests who came to stay. The only brush I held was dipped in melted beurre, leaving small, dark curves of hair across expanses of pastry like a dozen surprised eyebrows.

(In a rare moment of personal admission, Evelyn Millar told me she'd painted the eyelashes and smiles onto china dolls in a North London factory to survive one 1950s winter. I was so poor, she said. I had only my boils to keep me warm.)

Evelyn? I now live with a painter who paints my skin.

But in that grey London autumn of 1989, I, Sera ${ }^{2}$ Jean Gould (Australian, 23, of moderately heavy build, given to cloudbursts of eczema brought on by worry or overindulging in pilfered bottles of whisky or hot Silk Cut cigarettes) answered the following advertisement:

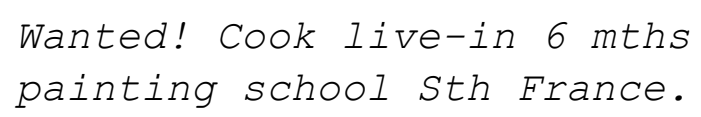

It was probably the first word which caught my eye.

I remember the day. I was lying on the floor of my north London squat.

I could do that, I said to whoever was lounging on a nearby mattress smoking hash.

I knew applying for jobs required navigating that treacherous territory between Fact \& Fiction, Desire \& Dread, Greed \& Humility.

How best write about my own stupid self? I pondered.

Pretend you aren't writing about your own stupid self but about your best friend who you really want to get the job, said the surprisingly helpful mattress voice.

Version 1: Sera Jean Gould has cooked all her life apprenticing against her will in the oilslick sherry-smelling kitchen of her meat-and-three-veg-Mills-and-Boons-reading-mother and blue-singlet-and-red-nosed-step-father then forcing an unlikely entry into the flamboyant poet and actor-frequenting paté/quiche/carrot and walnut cake cafés of the 
1980s Athens of the South (otherwise known as Adelaide) before plotting her escape to the Centre of the World (London) including one 'nadir moment' working at the staff canteen of the BBC One under the (clearly false) impression she might mingle-with-theTV-stars and be 'discovered' for her hitherto unsuspected script-writing talents but instead found herself ladling Oxo gravies over bullety peas and re-frying sausages and chips from 6am kipper-faced beneath a regulation white nylon net hat behind an Olympic-sized swimming pool bain-marie before being promoted to the position of Steaming Peas.

That's one long sentence, said the voice from the mattress through the browning haze. What about breaking it up and putting it in the first person?

Version 2 then: My life has been a smorgasbord of culinary and literary joys. Punctuated by simple pleasures such as tea breaks at the pie restaurant where I recently worked. Down the dim fuggy confusion of Brighton laneways. Smoking as many Silk Cuts as possible in half an hour. Sprawled between the cornucopias of overflowing restaurant rubbish bins. Where I learnt that ordinary tea breaks can become extraordinary. When reading (a very long-term library loan of) Sylvia Plath. Even though my short, strong body was eternally marinaded by oil and mutton fat. And my peasant-stock fingers were forever cut. And pyrographed. My spine was continually bent from carrying great pots of red pyramids of raw beef. Not to mention my new NHS gold-rimmed glasses permanently smeared in whatever stale cheap cooking oil the restaurant persisted with (and rarely changed). I was still able to gaze up from my dog-eared book pondering the great nebulae of Word, Rhythm, Myth \& Death. Beneath the frigid blur of Sussex stars and.

A lengthy silence from the brown mattress.

Then: I'm not sure about beginning and ending sentences with with, so, but, and and. Are you really going to persist with this footnote thing $?^{3}$

My squat-mates were hungry and angry with me. Whenever I was slogging my guts out in some greasy-spoon dive, I became their best-friend-walking-doggy-bag. But I'd just skated out of the kitchens of a Spanish Bar in Islington after refusing to slosh Blue Nun over two week-old potatoes to disguise and/or enhance the smell, throwing in my stiff apron one final time, stamping past the mini-cabs outside Hammersmith station at two in the morning past the chorus of shouts, you get kill lady if you walk home alone.

Yes, I conceded, I probably would get killed. But more likely from eating mouldy potatoes sweated with old Blue Nun. I shook my ruddy fist at Hammersmith shouting, and I eat men like air. $!^{4}$

I re-read the advertisement that was going to lead me onwards out of grubby squats, grimy restaurants and bouts of petty crime to an honest land of Art \& Poetry.

Wanted! Then a phone number. No need for a written application after all. I rummaged in somebody's pocket for a few quid and went out for the long and frequently fruitless forage for a functioning phone box. 
So there I was, phoning this number in the ad, hastily describing myself as some reconstitution of Version $1 \&$ Version $2^{5}$ which must have worked because I was thence instructed by a rather lofty voice to proceed to Victoria Station for an interview in exactly one week's time with the Artist Herself, Evelyn Millar.

I spent days preparing for that interview. I hacked a path through the mountain peaks of broken wall tiles and ran a deep, hot, stuttering bath. I applied my fold away travelscissors to the stringier aspects of my hair. Someone got off the mattress and accompanied me to the National Gallery to look at Real Art, then back to our High Street for an interview-inspired shoplifting expedition. Afterwards we smoked a little Lebanese black and floated about the headstones of the Highgate Cemetery pretending we were starring in music videos, flapping the wings of our new black full-length coats beneath the delicate tracery of autumn trees.

Next day I evaded my fare early to Victoria Station. The rendezvous was set to take place in the station tearooms which looked very 1940s below a sombre-faced clock, like a scene from Mrs Minerva or Waterloo Bridge.

Then like somebody out of The French connection, I planted myself behind a pole on watch for my prospective employer who'd apparently distinguish herself by wearing an orange flowered hat amid the sea of London commuter grey and black.

Voilá. The hat had landed. A persimmon-coloured flower advanced through the pitching swell. Two women. Tall. One with swinging amber beads. Both looked English establishment. But arty. Well-read. Interesting. Catalysts for the aspiring poet.

The younger woman was Evelyn Millar's daughter. She was possibly my age, but wealth has a habit of slowing the years. They ordered tea and looked at me. At my workhorse hands and stubby nails. At the way I stirred my milk deeply and quietly in perhaps an unAustralian way. They looked at the wine-stained menus I'd collected from various bistros where I may (or may not) have worked. I dabbed frugal amounts of jam and cream onto a scone, resisting the urge to slip any cutlery or scones up my sleeve for Later On. ${ }^{6}$

May 1989. I slam the squat door one last time. In my pocket, a one-way train ticket to France to live in at Evelyn Millar's summer painting school for a whole six months. As promised to every pre-paid British tourist, I'll be dazzled by hefty doses of heat and light. And yes, for that first blinding moment when I tripped down the steps of the overnight train and lunged into the embrace of the smell of forgotten summers, of lost antipodean FREEDOM \& ESCAPE, redolent of my beach-dwelling, UDL-swilling, skin-cancerous youth, I felt like Dorothy waking up in technicolour.

Vermillion roses sang out from the beds. A railway man in a blue cap tended pots of pink petunias while discussing the placement of Monet's water lilies with Evelyn who was waving from her Renault.

She frowned at me, at my London-grey skin, my traveller's hair and narrowed girth. I attempted to dispel her disapproval by suggesting I'd staggered out of a Picasso painting. 
As we threaded through the one-church villages past the Tabacs and Patisseries, through the amputated trees and the nodding sunflowered fields, she advised I tell any locals I was Anglaise. When my (non-working) tourist visa ran out I would drive her low-slung Renault through tooth-shaped alps and blood-splotched poppy fields in the general direction of the Franco-Spanish border and when the air had become tangerine and my visa had been stamped, I'd turn the car around and drive straight back. We agreed this was not dishonesty per se. It was more of your illegal immigrant ingenuity.

I slept in the main house that night. It was like entering an ark. A cathedral. A crumbling rambling soft-stoned palace with twinkling windows and laughing doors. I remember looking up at the stars of light dripping down through the gaps between the terracotta tiles and

\section{when I woke/ the marigold}

A typical day began quietly. Except for one morning when a bell rang twice in the village church. I looked out at the belfry not knowing three bells rang for the death of woman, two for a man. Bells? Churches? No time then to think of Gender \& Death. There was breakfast to prepare for a dozen or so painting guests who were usually English although two Germans and one baffled Frenchman briefly appeared and were never seen again.

Breakfast consisted of stale but prettily sculpted bread sprinkled with water and lightly reheated. Black coffee waited to be poured into white handle-less bowls. There were ample still life platters of attractive fruit and pattes of goat cheese. Behind the door marked Private!, I washed dishes in an antique porcelain sink. When the guests had abandoned their cutlery and table napkins, Evelyn appeared in red straw hat with easel and directed her students to various vantage points about the garden. This signalled my moment to run and scour the bathrooms of any hairs, odours or unsightly stains. Then it was time to make preparations for morning tea and lunch. Followed by afternoon tea and dinner. Followed by supper. (Always followed by washing up.) Followed by plodding back to my own simple quarters across the walled garden to be lulled to sleep by the stars of light sliding down through the gaps in the roof tiles.

In postcards I wrote, I'm cooking on the edge of other people's lives!!

In my diary I wrote, every moment is a lesson.

Did I write that? I can't remember. Memory is so slippery.

Look. I'm almost at the end of this and I haven't even mentioned my intense selfeducation via the attic full of Evelyn's books, half in English, half in French. Or the extraordinary textures achieved in her larger oils. Or the flotilla of enamel coffee pots setting sail across her Citizen Kane mantelpiece. Or how each room had at least three paintable corners featuring examples of Grace, Force \& Beauty. Of being woken by the sound of a white cactus flower opening in the night outside my bedroom window. My bedroom being an old stone bakehouse with blackened stove and spider-thick flue. Or the 
curvature of the flagstones made by centuries of long-dead passing feet. Or how I failed to make myself understood by the wide-skirted goat-girl with the line of blood clotting down the inside of her leg. There's no mention of assembling a kit bicycle in French and then riding it to explore the piss-smelling limestone caves All By Myself, which was Grand, Bold \& Terrifying, especially when that man came out of the bushes and threw a fistful of Francs at me so I'd undress. And what about the marigold flower which greeted me that first glorious morning as I coughed up my London lungs in the bright morning air?

\section{London life had pencilled me in/ to its leaden chest}

The lone flower planted so goldly and independently by Evelyn on the windowsill. Or how in a frisson of surrealism, she painted the enormous marigold cramped inside a tiny room $?^{7}$ Or the village lights strung through the branches of the linden trees for the fete. Or the too hot night when she and I swam in the absent English neighbours' pool, silent and drunk, only to wake the next morning to find some of the locals had thrown the contents of the communal poubelles (rubbish bins) into the pool, floating like some stinking Raft of Medusa to deter to more rich, real estate-hungry Britishers moving in.

And what about the glow-worm walk?

Look, Evelyn always said.

I follow the stripes of my employer's cardigan in the dark. I've been here long enough to know never to ask her anything about her life - but just to be - and look. Look at the way the air burns umberly to its inevitable cadmium red end as we stumble through the Prussian blue ditch. Look up at the Van Gogh satellites fizzing above. Then back at the benevolent farmhouse watching over us.

Look. Glow-worms, Evelyn says.

\section{thousands/millions/ infinities}

We sit for a while inhaling the cool smell of vegetable damp but I'm still not very good at being - and looking. I am always storing things up so I can write about them later on. Suddenly I remember a story I'd read as a child about a family in China who were too poor for electricity so the children had to go out and collect glow-worms so they could read at night after working so hard in the rice paddies with their parents but suddenly there was no rice to eat but just when all seemed lost their dog came home with a few grains of rice hanging from his coat and they were able to re-invent themselves by planting and harvesting and reading again by glow-worm light.

Evelyn lights a cigarette.

She laughs one of her inscrutable dark-night laughs.

For a moment the flare of her match outstrips the surrounding worm-made illuminations.

Propaganda, she says.

(It should be noted this glow-worm walk occurred not long after the Tiannamen Square massacre of 1989, a scene repeated many times on French tv.) (The same year the French 
commemorated two hundred years since the storming of the Bastille, inspiring armies of re-enacting sandalled men and bonneted women charging about as the sans culottes witnessed by myself beneath a dizzying hallucination of red white ' $n$ blue fireworks from a Historical Bridge beside the World Famous Albi cathedral.) (World Famous for its frescoes of the many kinds of Bosch-like hells.) (And it should also be noted this was the year after the (so-called) Australian 'Bicentenary' when stickers declaring white Australia has a black history were first sighted by well-meaning but bone-ignorant white girls plastered onto the frames of all politically sound bicyclists. $)^{8}$

In what we called the 'slow weeks' when no painting guests came, we ate fried eggs on toast and carried larger cartons of books down from the attic. I went from the familiar angst-ridden territory of Bonjour tristesse to the talking submarine of Joanna Russ to The Women's room to Women on the edge of time. ${ }^{9}$

Every morning the goat-girl passes by. We're about the same age but look at our lives! Poverty makes the habit of ageing us. There she goes, making clucking sounds as she walks her wiry charges up the same hill every morning, down at night, in her roundstomached skirt, her un-tended teeth threatening to fall brownly out.

On my second to last day, Evelyn was offered the pair of white doves.

You cannot refuse a pair of doves, she said.

Though others must have, I thought, even though I'd not yet found Janet Frame's take on the subject, 'Declining the offer of a pair of doves'.

Thank you. Though I do not accept your doves

I think their twilight colour, their shape

stay forever with me; ${ }^{10}$

On my last afternoon, I like to believe Evelyn invited me to return the following year. We'd built a little shelf along one of the shaded garden walls above the polyanthus and geraniums. We were drinking red wine. She was sitting painting her new doves as they moved about their dove-house, in and out, knowing exactly how to live their pearl-sky lives.

You don't paint, the next batch of painting guests would have said if I'd come back.

But you can't go back.

I didn't paint. I read and cooked. As I cooked, I tried to read the dubbed mouths of the tangerine faces of the American actors on Days of our lives. Or I looked down the valley, feeding on the ginger-coloured evening light, trying to save it up for Poetry Later On.

I'd like to say I didn't paint because I wrote. ${ }^{11}$ 
I read not wrote. Why?

1) I hadn't yet discovered Lily Briscoe in To the lighthouse although I'd often heard Charles Tansy's voice. Women can't paint. Can't write. ${ }^{12}$

2) At that time, I still believed reading and writing occurred on parallel planes.

3) At the time, I still thought there was so much time.

I'm tired now. We're almost finished. I'll just look up your name, Evelyn. See if I can find an address for you on the net. Oh good. Look. Something about a London retrospective exhibition of your complete oeuvre...

- complete with birth - and death - dates -

- you've died?

She's died!

Perhaps I believed you still existed preserved in that amber summer of 1989, a summer introduced to me by the single marigold placed on my sill.

But look, Evelyn. I need to tell you you rescued me with your Art \& Books. Even though I was only so young and you probably never thought of me.

I need to THANK YOU.

In writing.

I want to tell you I live with an artist who encouraged me to write and made me look. That when I hitchhiked out of your village in the south of France, I went 'home' to university and began to learn about the fertile and fluid interstices between reading, being, writing, looking, history, art, love, freedom, death and life.

Although it was too late, I even gave up the cigarettes.

Look. Another marigold southern hemisphere sunset. We sit by the window all saffroned up. My artist-lover smiles, admiring the two doves she's just tattooed onto my dying skin.

\section{Endnotes}

1. Woolf, Virginia 1993 Orlando, London: Virago Press Ltd, 213. Was not writing poetry a secret transaction, a voice answering a voice? 
2. My birth name was 'Sarah' but on leaving Australia and embarking on my REINVENTION I decided 'Sera' was more mysterious and poetic.

3. I didn't respond to the footnote challenge having not yet discovered the fertile and fluid interstices between history, memory, fact and fiction. See Byatt, A S 2001 On histories and stories: selected essays, London: Vintage, 103. A S Byatt acknowledges that 'publishers hate them' but she regards footnotes as a 'professional extension of a normal reading process, in history or fiction, making a fuller, more vivid, more hypothetical narrative precisely around what we are not told'. See also Winterson, Jeanette 1996 Art objects: essays on ecstasy and effrontery. 1995, London: Vintage, 165: '[I]f a finished piece of work is inadequate without copious footnotes from the author, then it is inadequate'. See also Hutcheon, Linda 2002 The politics of postmodernism 1989 2nd edition. London: Routledge, 80. Linda Hutcheon says 'paratextual conventions' such as footnotes can 'rupture' and 'expose the seams' of the text as 'deliberately awkward, as a means of directing our attention to the very processes by which we understand and interpret the past through its textual representations be it in history or fiction'. Footnotes can be found in Baron Bulwer Lytton's Harold, last of the Saxons (1848), Herman Melville's Moby Dick (1851) and Virginia Woolf's Orlando (1928).

4. Plath, Sylvia 2001 'Lady Lazarus', Ariel, Faber \& Faber Ltd, 8.

5. See previous pages.

6. In fact, I would never steal or do anything knowingly dishonest again. Such was my resolve after winning the job that CHANGED MY LIFE.

7. After René Magritte's looming green apple in La chambre d'écoute / The listening room (1958) or the giant red rose in Le tombeau de Lutteurs / The wrestlers' tomb (1961).

8. I can hear the mattress voice querying my flagrant use of parentheses.

9. It would be another year until Oranges are not the only fruit REALLY CHANGED MY LIFE.

10. From 'Declining the offer of a pair of doves' in Frame, Janet 1992 The pocket mirror, London: The Women's Press Ltd, 99. See also the preceding lines: would it not/ be wiser to have the reputation of a sea-gull/ and improve slowly?

11. Evelyn had even lent me her typewriter set on a blue card table with a weak pelvic floor.

12. Woolf, Virginia 1970 To the lighthouse 1927, London: Penguin, 180-81. 'Can't paint, can't write, she murmured monotonously, anxiously considering what her plan of attack should be.' See also 181. 'Charles Tansey used to say that, she remembered, women can't paint, can't write. Coming up behind her he had stood close beside her, a thing she hated as she painted here on this very spot.' 


\section{Independent scholar}

\section{Cath Davies}

Milk glass (in conversation with Brooke Zeligman's Feast)

\section{Biographical note:}

Cath Davies is currently completing her $\mathrm{PhD}$ dissertation, 'Curdle: notes on a practice and performance of induced lactation', in Sydney University's Media and Communications department. When not engaging in academic acts, she can be found playing across a variety of stages, magazines, short films and gallery spaces. 


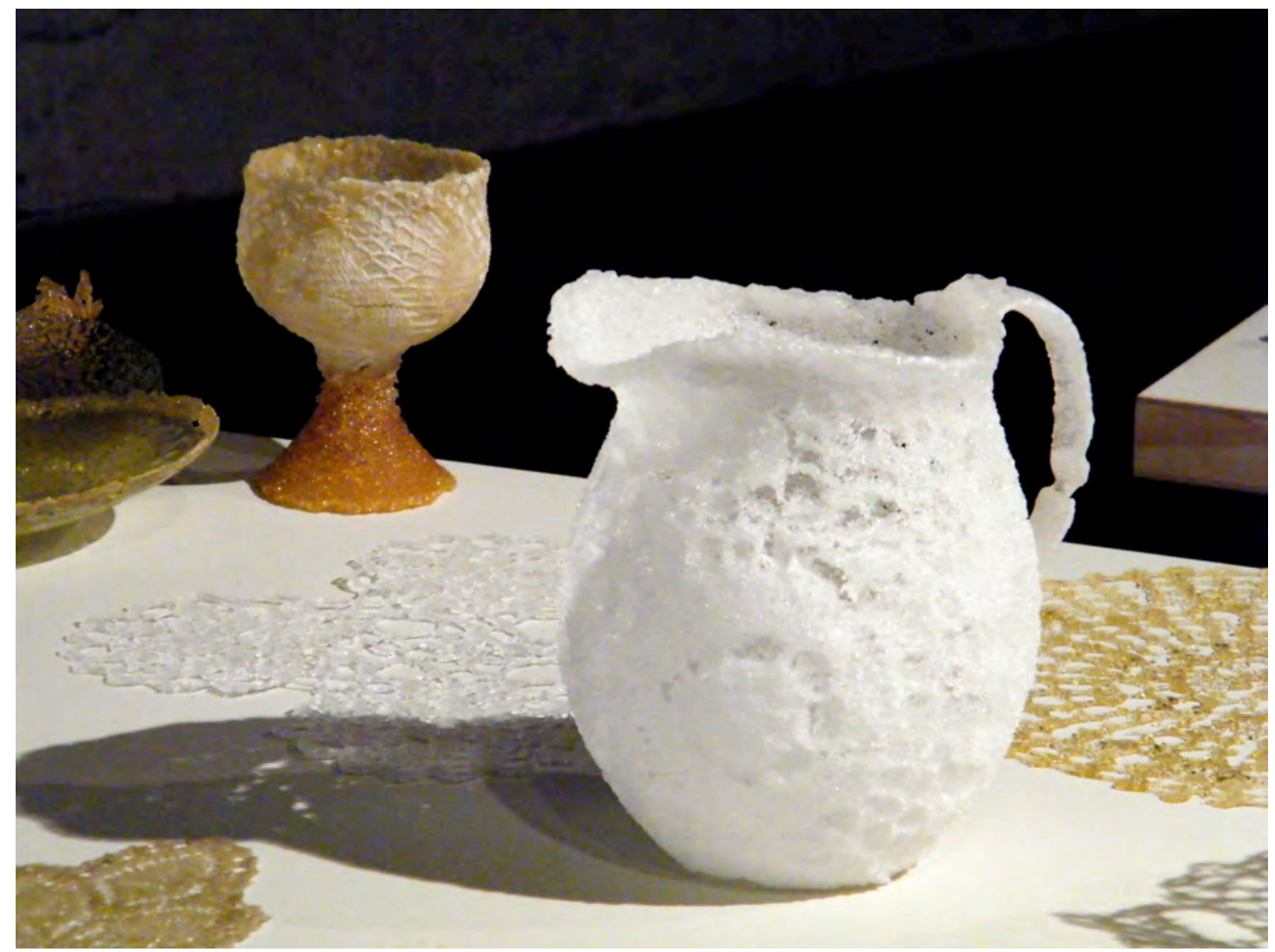

Fig. 1. Brooke Zeligman, Milk (Mothers), pate de verre, detail from Feast, at the Moore's Building Gallery, photography by Michael Schwarz.

\section{high tea}

set the scene for the feast. filigree plates and saucers and bowls and platters and jugs and serving utensils, all piled up and spread across and spilling over every available surface. I am small and sit underneath the table, peeping out and catching glimpses of ornate doilies and austere linen napkins draped carefully over the edges; crystalline teaspoons linger, partially dissolved against fine bone cups, chipped with pursed lip prints and conversational tooth marks. human breastmilk has twice the sucrose content of that from a cow, our sweet teeth are equal parts calcium and saccharine. mother takes her tea with two sugars and milk. if the temperature's not quite right then a little sugar lingers at the bottom of the cup undissolved, and the very last sip tastes like ambrosia and tannin. just milk for me thanks, I'm sweet enough already.

\section{milk glass}

the feast looks like milk ice and milkshakes and milk teeth, but doesn't contain a drop of milk (milk glass contains no milk at all, it is an opaque or translucent milky white or coloured glass. the white colouring may be made by the addition of bone ash). the feast is carefully cast pate de verre, glass delicately pasted over moulds and cautiously removed like bandages over freshly healed wounds, always leaving a little trace of adhesive or taking a sliver of skin. I remember more than once painting my 
young hands with craft glue, the pleasure of peeling it away. when it dried it came off broken always, but taking the form of my epidermis all its creases pores and knuckles - a perfect white death mask likeness of my lifelines. fabric might be stained yellowbrown by rusty pins or perspiration or piss or spilled tea or light exposure or being washed in iron-rich water. later I would use beeswax hot and dripping, savouring the sting but the imprint was rarely as precise, and the yellow made me think of old anatomical models and jaundice and decay. everything at the feast echoes afterbirth lochia's placental palette, lochia rubra bright red with blood cells, lochia serosa brownish or pink with serous exudate and erythrocyte and leukocytes and cervical mucus, lochia alba white-ish or yellowy white and made of epithelial cells and cholesterol and fat.

\section{the laws of liquids}

I could eat you all up, suck at your marrow and slurp at your gelatinous soup. molten glass acts like toffee, stringing and stranding, like saliva thick as honey licked straight from the comb, viscous, the seductive stickiness clogging my oesophagus, amniotic fluid filling my lungs, I am drowning in molasses and spit. glass is generally not described as a liquid, but rather an amorphous solid, (although some argue its liquidity as it lacks a first-order phase transition). despite the fact that the atomic structure of glass shares attributes with a supercooled liquid, glass is inclined to act more as a solid below its glass transition temperature.

\section{pick your poison}

if I knew you were coming I'd have baked a cake, an airy sponge its molecular structure on show, stuffed with a thick layer of cream and strawberry jam. served up in the sunroom with a scalding hot cuppa, poured from a tarnished silver pot by sunspotted hands. champagne glass was modelled on the bosom of some French Louis's lover or another. (Liebfraumilch, literally 'beloved lady's milk', is a semi-sweet white wine produced from the vineyards of Church of Our Lady.) letdown feels like small shards of glass drawn through the intricate framework of milk ducts - as if your mirror-image had been smashed inside your breasts and was now being slowly drawn out. in old detective novels and crime shows ground glass is added to the victim's food, slowly scraping away at the gut's lining until internal bleeding finishes him off. the way to a man's heart is through his stomach. poisoning is always women's work (the manmade chemical bisphenol A, or BPA, is used in polycarbonate plastic, the material used to make many plastic food containers including baby feeding bottles and concerns over BPA's safety - it is reported by some sources to have hormone-like effects on the reproductive system - has increased the sale of glass bottles in recent years). 


\section{feast}

warp and weft I weave you, spin you a feast from my curds and whey.(reusable glass milk bottles are commonly used for the home delivery of fresh milk by milkmen; milkmen are often credited with the paternity of children who do not show obvious visual similarities to their presumed fathers.) I stitch you up my glory box, replete with tatting and embroidering and lacemaking and other forms of fancywork. the parish ladies taught me to sugar starch my homespun wares (3 parts granulated sugar to 1 part water; saturate pre-moistened piece in the mixture then smooth with a hot iron, always careful not to let them dry out too quickly lest they flake, crust or scab). my fingerbones feel arthritic, clumsily I manipulate the intricate threads and filaments. cast on, knit one, purl one. knitting bones and christening gowns, by hook or by crook.

\section{dessert}

what a tangled web. trapped, stuck to your flypaper. strangers always have the best candy. sickly sweet, sticky sweet, my sweat glistens studded with diamond dewdrops. engorged, my mouth blows ruby-raspberries, bubbles bleed from one corner. split lip, spilt milk, tongue twisted. suck every last morsel of your feast, the crumbs caught in my throat make my glass eye water. 


\section{Southern Cross University}

Virginia Barratt

\section{She is a boy}

\section{Biographical note:}

Virginia Barratt graduated from the creative writing program at Southern Cross University and is currently in the Honours program working on a play entitled SLICE, an experimental work dealing with self-cutting, skin and borders. She is a multimedia maker, a performer, an unrepentant feminist and has performed, lectured and exhibited all over the world. She lives an aspirational lifestyle of self-sufficiency and sustainability in the Northern Rivers of New South Wales, in Australia. Among her publications are those in Otis Rush and Slit magazines, blogs and online journals and the 2012 anthology, Banquet: a feast of new writing and arts by queer women. 
She is a boy. She is my boy. She is my boyfriend.

It hadn't occurred to me that I might find myself in a hetero-normative relationship again. Well, I guess that's kind of stretching definitions a little. There's nothing normative here. Still, my boy she is, of this there's no doubt. I'm really not sure what that makes me. I've always been fond of playing boy to my lovers, unless I've been out-boyed, which has happened once or twice. Yes, there was the skinny-legged one, all swagger and tough, all dust and boots. I had no chance. But this boy, my boy, my boyfriend, well she definitely feminises me. The bulge in her shiny dealer pants makes my tidy package seem delicate, not up to the task: a daisy, perhaps, in my pants!

In the early days, before her secret was out (how could she hide such a large secret?) I had my suspicions. She looked so good in a shirt and tie, so very good, especially wearing her stomper boots. What a tower of a girl! I would ride the elevator to the top of her legs from that place between the leather of her 16-hole steelcaps and the skin of her calves right up underneath her shorts. To the top, to the very top. The smooth ride up her calves was something, but the view from the top was what got me hooked on the ride. I would close my eyes for the ride. I loved to do that, in a café, in a park or on the bus. Take the ride to the top of her basketballer's legs, her cyclist's legs and imagine the slam dunk, or the pumping calves of my death-defying courier girl.

On the first morning of the first day I met her, legs slung over the back of a bench seat on the railway station concourse, wearing a smile so wide you could walk right on in, she gallantly carried my bags back from the train station to her home. On the first morning of the first day in the dappled light of her red room among the detritus of her fractured junkie life I lay on top of her, both of us fully clothed, her long stalks of legs encased in skinny grey cord. I wriggled my hand in, a tight fit, and felt with tingling delight a stomach all downy. Under her shirt I fingered the redgold hairs decorating her chest. I liked this uncommon furriness. It signalled a point of difference between us.

On the first morning of the first day, in delight and golden light, I took her in a fever of machisma. I liked to fuck, to penetrate an other. I was averse to bottoming and so I topped her despite her stature. I thought she was more woman than any girl I had ever been with. Maybe I was blinded by her milky skin, by her softness. Boys are all sinew and resistance. Girls are all curve and yield. Girls are made of milk. Girls make milk and I drowned in hers. This body of white was so unlike the bodies I had always held as mirrors to my own. Suddenly I wasn't fucking myself anymore, boy on boy. I felt liberated by the deep well of desire that sprang from a new place within as I opened myself to the possibility of difference.

I embraced this opening up of whole new worlds of body types to explore. She was my only drug and I breathed her in with the whole of my skin. I melted into her life, on a bloodstained mattress in a room artlessly strewn with her shameless old syringes. My lips became as red as her walls. In the morning and at night I got carpet burn as I slammed into her on the floor on a cliffhanger, white-knuckled ride, bloody and carnal, until the car wreck of our bodies creaked and groaned and out of control rolled 
end over end. Twisted metal skins. On her bed I would watch the long stretch of her back crevassed centrally by her spine as she fell forward, fiery hair tumbling.

Over the edge.

Rough and tumble we were.

Harsh and rarely gentle.

In the morning and at night.

The days passed. I was meant to go and stay with friends, but with each setting of the sun I found myself in the red room with the creaking tree outside. Leaves blew in through the open doors and covered us like a forest floor. We'd go out to eat and sit in cafés where I'd play with her legs. She was funny. Recited lines from teenage comedies she'd seen hundreds of times. Made me laugh until I wet myself. As we walked along the streets of her neighbourhood saying hello to Steve, and to the old Mrs with the blind dog, and to the Koori girls and the methadone mums, she looked sideways at me and asked: am I the most femme girl you've ever been out with?

On the verge of saying yes, I found myself caught in a space with no words, walking beside a girl with no name. She had skin of porcelain and hair of orange and golden fire, tied up or messy falling all around. She had the curves of a woman. She had a preternatural beauty. And yet ...

Under the streetlights, in the wake of her question, we held onto each other's hands really tightly. A shimmering wave crossed her face and time held its breath as I caught a glimpse of her mutable face morphing between genders and identities. I was electrified by a thrill. She. He. My becoming boy becoming girl. I shivered and swayed in the tide of such changeling energy.

So there, in the wake, and on the verge of saying yes, I choked on the ready affirmative that was about to fall out of my mouth with such ease and so little thought and swallowed it.

The answer to what she was swirled around her head like a halo, an embryonic notion with wings, waiting to be birthed into the knowing 


\section{University of Western Sydney}

\section{Hoa Pham}

\section{Wave \\ (novel extract)}

\section{Biographical note:}

Hoa Pham is an author and playwright. Her novel vixen won the Sydney morning herald young writers award and her play silence was on the Victorian certificate of education list in 2010. Her next young adult novel is titled the other shore and her work can be viewed at www.hoapham.net 
Inside it was warm like greenhouse flowers. Outside it was the end of the world.

\section{Midori}

They breathe heavily, and fly at each other's touch. Her back arcs as she feels the sensation of flying. Her lover's fingers caress the petals of her inner self. She brushes her hands over her nipples for the fleeting sharp sensation. Then it is her lover's turn, and they sigh together, moisture mingling. From their union, a pearl is birthed from her throat. Her lover plucks the sweet gem from her mouth with her fingers. Slippery and wet the multi coloured rainbow goes into her mouth and she swallows. They know that if anyone finds out about the gems they birth, they would no longer have the pleasure to themselves.

This is her memory - a reconstruction as she surges forward on her fingers remembering how to feel. She is gone now over the seas, exiled far away from all that is familiar.

I still love you. Even though they have separated us. I will never forget you.

Everything is a construction.

She wishes she was other than what she is. Tenses turn and twist as she remembers, sometimes she remembers the here and now, other times the past as she recalls it, in the quicksilver light of her teenage years.

When she orgasms she remembers the most. Memories flick by like comic book frames, the neon lights of Shinjuku out of a love hotel window, the fleeting kiss of loves that never were.

She would not exchange what she is for something else, she tells herself as she sinks into the hot bath scented with pink ginger. Her skin dissolves when she is in water and the warmth penetrates her core.

When she was younger she and her first love would don costumes on Sundays and join the cosplay parading. She was slim and flat chested and would go as Dragon Girl, a warrior in pigtails that had dragons slithering down her arms. She yearned to fly like Dragon Girl and her lover would go as Dragon Boy. That way business men would not try to proposition them like they did when her lover stayed true to her gender which was the same.

Others cannot forgive that she still holds memories of her first love dearest to her heart.

She only began to play piano for herself once she was in Australia. There was an old upright piano in the corner of the multipurpose meeting room in the apartment complex. No one could hear her, she did not have to think about what other people 
thought and felt. The sound bounced on the wooden floor, and the touch was uneven. Clunky though her renditions were, she lost herself in the tangled notes of her memory.

She has a younger brother. He is the only reason that she would not wish death on her parents. She had prayed to the old gods, the dragons of earth, water, fire and heaven.

When the dream came true she was terrified by the freedom she felt, falling into empty space.

\section{Brother}

He was waiting. Waiting for his mother to come. In his favourite yellow hat with the cosy ear flaps on and wrapped up in his red puffy parka.

They had just had open play time when they could do anything they liked. He made a picture for his mother out of autumn leaves. The brown foliage crunched in his hands and littered the paper with broken remains.

Usually mummy would be on time. She would arrive and take her hand in his and give him a kiss on the cheek. She smelt of perfume and newly applied lipstick. Then they would go home and have a hot chocolate while she cooked dinner.

He hoped she would come soon so he could give her his picture of leaves. He had made her a giraffe and a horse.

Outside was the distant roar of the ocean. Today he could hear the waves. It sounded like the beach had crept right up to their doorstep.

Next to him the other children were waiting too. No one's parents had arrived yet.

He was looking at the clock.

Soon they were all looking at the clock waiting for their parents to come.

The red digital numbers on the stark black clock told no lies.

Their parents were late.

He found himself thinking of his sister. Before she left for Australia she had been crying a lot in her room. She did not cry when their parents were home, she had been stiff of face. But when neither of them was there and she was supposed to look after him, she would retreat into her room and cry. He would sit in front of her sliding bedroom door and wait for her to come out for a cuddle. 
His sister was beautiful, with cherubic short hair. She used to go to her friend's apartment a lot, but that stopped when the crying began. He missed his sister smiling and talking to him.

He looked back at the closed door to the children's room. No one's parents had arrived. That was strange. Sometimes one parent would be late. But all of them?

The children began whispering amongst themselves.

One child began to cry, snuffling softly.

Mother! He thinks into the ether, hoping that she can hear him shouting in his mind. Sometimes she does know, the hiccup before he cries out aloud that brings her running into his room. Other times she is deaf to him even when he is in her arms, warm and snug.

Where are all the mummies? Where have they gone?

A child care worker opens the sliding door and is greeted by the silent anticipation of the children sitting in rows cross legged on the floor.

She shakes her head, and now he can see how white she is and the deepest frown on her face close up. Something is wrong.

He vanishes inside his mind then.

A photographer taking their pictures, a flash of light over the children sitting in rows like temple statues. Then a red headed white woman speaking a foreign language gives them soft toys.

He balances the brown soft toy kangaroo on his crossed legs. Outside older children are playing.

He remembers thinking - they have not suffered. They do not know anything.

Seriousness was pressed into him that day.

I'm not like them. I cannot be carefree.

He had the ever present filial obligation to look after his older beautiful sister. Even though she had abandoned their ancestors and the family shrine.

Now the soft toy kangaroo is worn from where his hand had clutched it every night in his foster home. One eye is missing but somehow the kangaroo yields to being squeezed in between his shirts and shoes in his suitcase.

What do you call the hopping mouse with a bag?

Kan-ga-rou. 
In Zen Buddhism the circle is emptiness and completeness. In Japanese literature, a mood is captured, a fleeting feeling. It is not so important unlike Western literature, for the hero to conquer all. 


\section{University of Western Sydney}

\section{Nasrin Matouhchi}

\section{The warmness of handling}

\section{Biographical note:}

Nasrin Mahoutchi is a writer and art practitioner. Nasrin writes in Farsi (Persian) and English languages. Her short stories have been published in journals such as Heat, Southerly and Meanjin. Some of her works has been broadcasted on ABC Radio, Radio eye, and on Persian Radio. She is postgraduate student completing her DCA: her creative component is a novel based in Iran and her exegesis is series of essays covering topics of exile and displacement, writing in English as a second language, the private and public, and home. 
Sleep still rattled in my child's wet throat when someone knocked on the door. I hid my breast which was engorged and slimy from the child's saliva inside my dress. I ran to open the door. Behind me, the wind stole the child's sleep. The wooden window slammed. The baby cried.

A big, blue-coloured body appeared behind the fly screen. Still, I couldn't completely see the picture behind the door when the person spoke; she was still in shadow.

'Hi. I come from The Salvation Army. I came to give food to your neighbor but nobody seems to be at home. Could you please give this to him later? God bless you.'

Then the Salvation Army woman played with door handle; the door didn't open. I brought the key and opened the door. The smell of cooked carrots rising from the foil tray made me feel sick. When the pink and wrinkled face disappeared, I shut the door.

Upstairs, a cool breeze lulled the baby into sleep again and the old wooden window, while moving on its rusty hinge, seemed to listen to the baby's sleep which still rattled in his throat. Downstairs, I put the foil tray on the kitchen table and wiped the warmness of handling it from my hand with my skirt. Trace of oil diffused inside the cotton flowers on my skirt. I made a coffee and put the cup next to the other coffee cups which were lined up on breakfast table. Ants were moving up and down in the previous unwashed coffee cups.

I took the coffee to my workshop, a big, old pantry connected to the sun room. All four corners of the room had mirrors, two normal mirrors and two concave and convex. Mirrors are good for children's practice, they like miming in front of mirror, rising their arms and acting in front of it. They also love to see their body gets too fat or too thin in the mirror. Before pregnancy I had a plan to organise my own physical theatre workshop for local students. My husband didn't look at my profession seriously although when I asked him to help me to convert the pantry and sunroom to a workshop studio he took time off from his work to help me. I appreciate his help and his lack of understanding of my work. He is a professional nurse. For him, saving life is the major and the most important thing to do; after life being saved: doesn't matter what you do with it. Stretching your body in front of mirrors or miming are not necessary steps in one's life to survive.

Upstairs, I checked the baby; he was asleep. I went to the balcony and checked on Mr. Gorjestani's back yard. In the sunny corner of the backyard Mr. Gorjestani sat with his grey face leaning on a walking stick between his legs. As usual, between his halfopen legs, he held his walking stick; his long and grey face lent on his stick; his eyes were staring at an unknown point in the air. He looks like my father. My father was an Azarbayjani too. Sometimes I talk to Mr. Gorjestani in Turkish, although he never talks to me. In his last phot,o my father had a walking stick too, leaning on his stick while sitting next to my sister; my sister was pregnant, swollen face and body. She looked very different to the photo she sent six months earlier. In that photo, her husband was beside her: tall, handsome and in army uniform. In one close-up photo, 
my father's face has covered the frame; his eyes stare strangely into the camera; it looks cloudy, quiet and sad.

I finished my coffee while watching Mr. Gorjestani. His family had lived in this house for more than fifty five years. My husband's family was the first family who built their house in this street and the next one was Mr. Gorjestani's. He built the house himself. He has been living in this house for fifty years, but still he walked around and looked around as if he was surprised and shocked, lost and scared. His wife died just recently.

In the last few months of my pregnancy, whenever I woke up in the early morning, I sat on the veranda, next to the garden and swung my swollen feet and drank my coffee. Before his wife's death, I could hear the sound of the electric razor which Mr. Gorjestani used in their outside laundry to shave his face. Since his wife died he never shaved his face in the outside laundry. His long, grey beard made him look older. He seemed to be stranger at a destination beyond his reach.

It was such a big house yet, since his wife's death, he was always in his backyard as if he was scared that the walls inside put a spell on him. Once I was walking past his door, I thought I heard his walls talking; it sounded like the humming of mountains; a bursting cry; a storm coming through the walls; whispers of an old house. I thought maybe he was mad.

He wasn't a maniac.

And now, while he was watching me with his unfocussed gaze, he didn't look old any more. His sun-burnt skin and calm face looked childish.

I came closer to him.

Suddenly, the amnesia seemed to leave his eyes and the old man awakened with the smell of my milk. He put out his hands.

I moved my bulging body away from him. Then I heard whispered memories, as if they were dandelion flowers flickered and scattered from his open hand.

He gazed out at the sky again while his hand remained open in the air.

I called his name.

He collected his gaze from the sky. I called him again, hoping he might respond.

From far away, I heard the baby crying. I left the cold foil tray next to him and left.

In the early morning, I hung the washing out, breastfed the baby. In the afternoon, a group of kookaburras were flying and shitting on my washing. I collected the clothes in a plastic basket. I walked through workshop: the convex mirror captured my defigurative body. In the bathroom, I pushed the washing machine button and ignored my image in the mirror. I breastfed the baby again. 
In the afternoon, I checked his backyard. Mr. Gorjestani was sitting on his chair. I took the baby and my coffee and went to the backyard, passing through the workshop. The concave mirror captured our de-figurative bodies.

The sun shone after two days of rain. Under warm weather, the smell of Napisan was evaporating from the nappies. A big pile of dirty nappies had to be washed but I didn't bother to do it. Instead I used the disposable nappies which the Salvation Army woman gave me yesterday. The Salvation Army woman left a foil tray and two packs of XL Toddler Lullaby nappies behind my door. They were not the right size for my baby but using them saved some time. I sat on the other corner of my backyard, opposite Mr. Gorjestani. Behind the bent, old fence my other neighbor's dog was sniffing. Under the raked autumn leaves a group of little ribbed lizards were playing. The rustle of dried leaves made the dog curious. The dog moved his paws and nose inside the broken fence to reach them. My baby got excited too; he jumped up and down on my lap and pulled his hands to catch them or to catch the dog, but each time his hands remained empty and open in the air. The dog barked and the baby laughed and lost his dummy in the corner of the fence, where the dog reached it, through broken fence, sniffed it and bit off the rubber and then let it go. A lizard moved on the shed's wall, went up and down and then stopped there, turned its head towards me, as if checking to see if I still was there. Then it moved its body up and looked down, tapped his tail and remained still for a while; then it ran behind the compost bin. My son was asleep now and felt heavier in my arms. Surprisingly the roaming of an airplane and ice cream van's sound of music didn't wake him up. I put him in the pram.

The next morning I woke up and made a cup of coffee. While I was drinking, the Salvation Army woman knocked on the door. She handed me a foil tray and left. I took the food inside to the kitchen. I took the washing basket upstairs into the bathroom; I passed the washing machine and reached the washbasin where I could see the trace of my husband's life: night shifts, early-morning shaving and leaving the house without cleaning his shaving equipment. Traces of hair and shaving foam were clotted on his safety razor on the green basin. At the corner, next to the washing machine, a pile of his working uniforms stank of sweat and deodorant. I left the bathroom and went to the balcony; my neighbor was sitting in his usual position. I called to him and there was no response. In the kitchen I took the food and went to his backyard. I left the food next to him and heard baby crying. I came back home.

After breastfeeding, I took my baby into my workshop; mirrors played games with us, changing our body shapes into deformed too fat or too thin. He got restless and cried. Although I knew he wasn't hungry, I put my breast in his mouth again. He fed for a little while. I watched the women who were surrounding me: a too-thin one and a toofat one were breastfeeding too. They were miming me but none of them was me. They didn't see how tired I was. They just stared at me and each time I moved my body they were ready to mime me. After feeding, I held him; patted him. After a while a tepid clot diffused into my shirt and I felt some slimy milk plastered on my hair. Outside, in the living room, the telephone was ringing. By the time I reached the 
receiver, a message went on in answering machine. It was my sister's voice. We left the workshop and too-fat-and-too-thin me left the room too.

Someone knocked at the door, but I didn't leave my bed. Last night the baby was sick all night and my husband didn't come back home. I was exhausted. I got out of bed and checked the baby. He was asleep. A big pile of dirty clothes were waiting for me, but I ignored them. In the kitchen I made coffee and went upstairs to the balcony. Under the sunshine I saw snails make tattoos on the wooden arm of the balcony. I sat outside and watched my neighbor's backyard. He wasn't there. I wondered where he could be. Downstairs, I took his foil tray and went to his backyard. A group of kookaburras were playing on the air. I looked at them with anger. Yesterday I had to wash twice because of their shit. I passed his vegetable garden; despite his negligence his vegetable garden looked good. Ripe and red tomatoes smelled fresh; weed sprays were sitting inside a milk crate and a few ladybirds were roaming around a half-built plastic pond. For a while I looked everywhere to find him, but there wasn't any sign of him. I heard a noise from inside the house. I moved towards the veranda door, where his bindweed roses climbed to the second floor. I pushed back two spiders from their webs; the clear strings recoiled on my arm and my face. I cleaned myself and sheepishly opened the door in the veranda.

The dark living room was framed in grey. On a wooden coffee table there was a glass ashtray, and on the table sat a photo of Mr. Gorjestani, his wife and their three sons, in a golden frame. I stopped there as a noise came from the kitchen. I moved my shocked eyes towards the noise. It was the old man, sitting on a chair next to the phone in the same way as he sat outside. He was staring at the phone.

I looked around. On the breakfast table I noticed seven foil trays, untouched. I took a spoon from the kitchen and came close to him, looked at him and then I looked at the phone; I asked him if he wanted to dial any number, but he didn't respond. I noticed the red light was flashing; I pressed the button. A warm male voice on the answering machine said, 'Hi dad congratulations', and then stopped. The tape didn't work. When I played the tape again, he moved his hand to reach me, but again he lost his concentration and gazed at something on the wall. At that point he looked exactly like my father in the photo, where he was holding a baby in a kind of careless way; next to him was my sister, still overweight from pregnancy, one hand on my father's shoulder and the other hand holding baby. Our father was gazing into camera but his gaze wasn't focused and looked fuzzy and cloudy. He wasn't smiling and he looked lost. I played the tape again to see if he would respond. He didn't. On the telephone table there was a bundle of glossy pamphlets, double folded; it was an invitation from a local community centre. It was a night in honour of Mr. and Mrs. Gorjestani for their twenty-years community service for the elderly members of the Azarbayjani migrants. At the bottom of the invitation was: 'Please distribute between your communities'. The bundle had a rubber band around it. I moved closer to feed him. He lost his stick and fell against my chest; the spoon fell off my hand. For a while I remained still and then I took the spoon. His shirt was untidy and open. I could see his grey chest. I fixed his shirt and fastened it with a few baby safety pins. He lost control again and almost fell 
down. I pulled his head up and gave him his stick. Far away, the baby was crying. I left the foil tray and the spoon next to him and left.

Upstairs I checked the baby. He was asleep. Downstairs, in the kitchen, I boiled a big pot and put three milk bottles into it. I opened a pack of dummies and put them in the pot too. I set the timer for half an hour. I checked the phone; there were two messages: my husband was working on extra shift and wouldn't be home for dinner and my sister had something to talk about. It was almost twelve at night which meant my sister was sitting in her kitchen at midday and feeding her child. Good time to talk to her. 


\section{University of New South Wales}

\section{Anne Brewster}

\section{You mother's garden}

\section{Biographical note:}

Anne Brewster is an Associate Professor at UNSW. She has published fictocritical book chapters in Practice-led research: Research-led practice in the creative arts (2009) eds. Roger Dean and Hazel Smith, and The racial politics of bodies, nations and knowledges (2009) eds. Barbara Baird and Damien Riggs, and fictocritical articles in Salt, TEXT and Cultural studies review. She has published articles on fictocritcism in Crossing lines: formations of Australian culture, eds. Caroline Guerin, Philip Butterss and Amanda Nettelbeck, and Writing-teaching, teaching writing, eds. Jan Hutchinson and Graham Williams. 


\section{Appendectomy}

The day before you left Adelaide you had an appendectomy. The gym was prohibited, so when you got back to Sydney you started walking the dogs, seeking out the hilly streets to build up a sweat.

The dogs were interested in the long grass and scruffy corners where empty bottles, little tussocks of weed and interesting smells accumulated. They set the pace, dragging you along behind, making up for weeks of boredom, lying around in the sun, digging holes in the grass and barking at the cat next door. Out on the street they were transformed into action machines, sniffing under gates and peering into houses. You discovered that fences between dogs turn them into snarling antagonists, but when they met on the footpath there were cordialities to be observed. The same was true for people. Strangers said hello and sometimes would stop for a chat.

Walking the streets you were used to navigating from the car, you may as well have been in an entirely different suburb. In the curving side streets you lost your sense of direction, ending up in a completely different place to what you had imagined. You discovered a hidden landscape behind fences and rows of houses, behind hedges, trees and shop fronts. A sheer cliff face, bald rock like skin, burnished in the afternoon sun, with vertical runnels of ferns, behind a row of houses. Underneath the fences and houses it was still Gadigal land. It had a different life, a different order.

The dogs had a nose for tucked-away spaces, ferreting them out and barrelling down them, with you in tow. Most of these old passageways and walkways lead nowhere in particular. You chanced upon a small flights of steps, with a sign, 'Joseph Goldstein Reserve', which lead to another flight of steps and another. Down a narrow alley between houses whose gardens towered over the walkway with tufts of palms, you trotted, woolly grasses and oleanders brushing you as you passed. An intimate little strip of suburb. Where the fences were low you could see into people's houses. A man sat at a desk in a room that opened out onto the path, talking on the phone and looking out over the vista of Bondi. From another house you could hear opera, a single soprano voice, clear and sharp. And somewhere behind that lay the sound of the waves. You had read in a strange little book you found in a second hand shop that this was what the word 'bondi' originally signified. ${ }^{1}$

The alleyway was a liminal space, public but private, and you shushed the dogs and slowed down to a quieter walk. By the time you reached the bottom you had quite forgotten the sign and just as well; there was nothing here but another cul-de-sac. As the dogs took you off down the street you felt that you had just witnessed a secret. Despite the sign it seemed not many people visited this 'Reserve'.

There were other old little walkways, some of them not so hidden, but rarely used. There were indeed no true cul-de-sacs, only enclosed spaces opening via a secret flight of stairs into wider spaces which brought you, surprised, to a familiar or unfamiliar scene. Some had fallen into disuse and were overgrown, wending their way down a steep slope between trees, from one road to the other. They were a relic of the days when urban dwellers travelled on foot, dreamy little spaces removed from the street and the footpaths, those places where people were parking cars, unloading shopping, corralling their children and slamming doors. Here you were alone for a 
few minutes, peeking into gardens and houses, savouring the dank humidity of trees after summer rain, embarking upon a short journey with no destination, in the midst of many lives replete yet remote.

For a moment you felt entirely content, simultaneously inside and outside these comfortable homes. You savoured the benevolence of the middle class, its satisfactions and banishment of pain and harm. The rules were effortless and all the sums added up. The lounge rooms were snug, the kitchen fridges robust and potted plants shone with good health.

And then the path ended, just like that, and you were on Mitchell Street. A four-wheel drive glided past and some children shouted and laughed in a backyard. You had the distinct feeling you had lost something but you didn't want to think about that. The dogs were off again, panting and scrabbling, all the way home. You ushered them into the garden, closed the gate, hung up the leads and gave them their dinner.

As you prepared your own meal you wondered about your mother. You have a photo of her as a university student in the 1940s on the wall next to your desk. She is dressed with gloves and handbag for an evening out and her face is alive. You sensed that there was something discrepant, a disjuncture between her rural childhood and her life as an adult. Although your aunt tells you that they had a happy childhood, your mother never returned to the Riverland. Did she miss the old red gums, the ones Aboriginal people used to make canoes, the trees you miss too? You feel you belong to that landscape, but the photos are cracked and blurred through multiple reproductions, each at one further remove from you. Their scratches and creases remind you that this is a world you can't enter. You read much later about this area's bloody history; this silence passed down the generations. How did it play out in her family, which is your family? It is too late to ask her. ${ }^{2}$

This is all you have - this handful of photos, scenes whose 'generative incompleteness ${ }^{3}$ compels you to guess. You wonder who took them and why. The intimacy they evoke is mediated by the unknown photographer, the person for whom your mother, shyly or radiantly, composed herself. These scenes 'communicate through the sparest of signs and gestures'. ${ }^{4}$ You search for the bones of a story: a white girl in the bush; a young woman, the first in her family, at university; a mother with three kids and a job.

Again you felt a dull sadness. Her life was a foreign country to you. Why did you know so little about it? After gnawing on these pale thoughts you put them aside. There was to be no answer and it was starting to rain again. You go around the house to close the windows. The air was soft and still warm and you paused a moment, feeling it against your skin. 


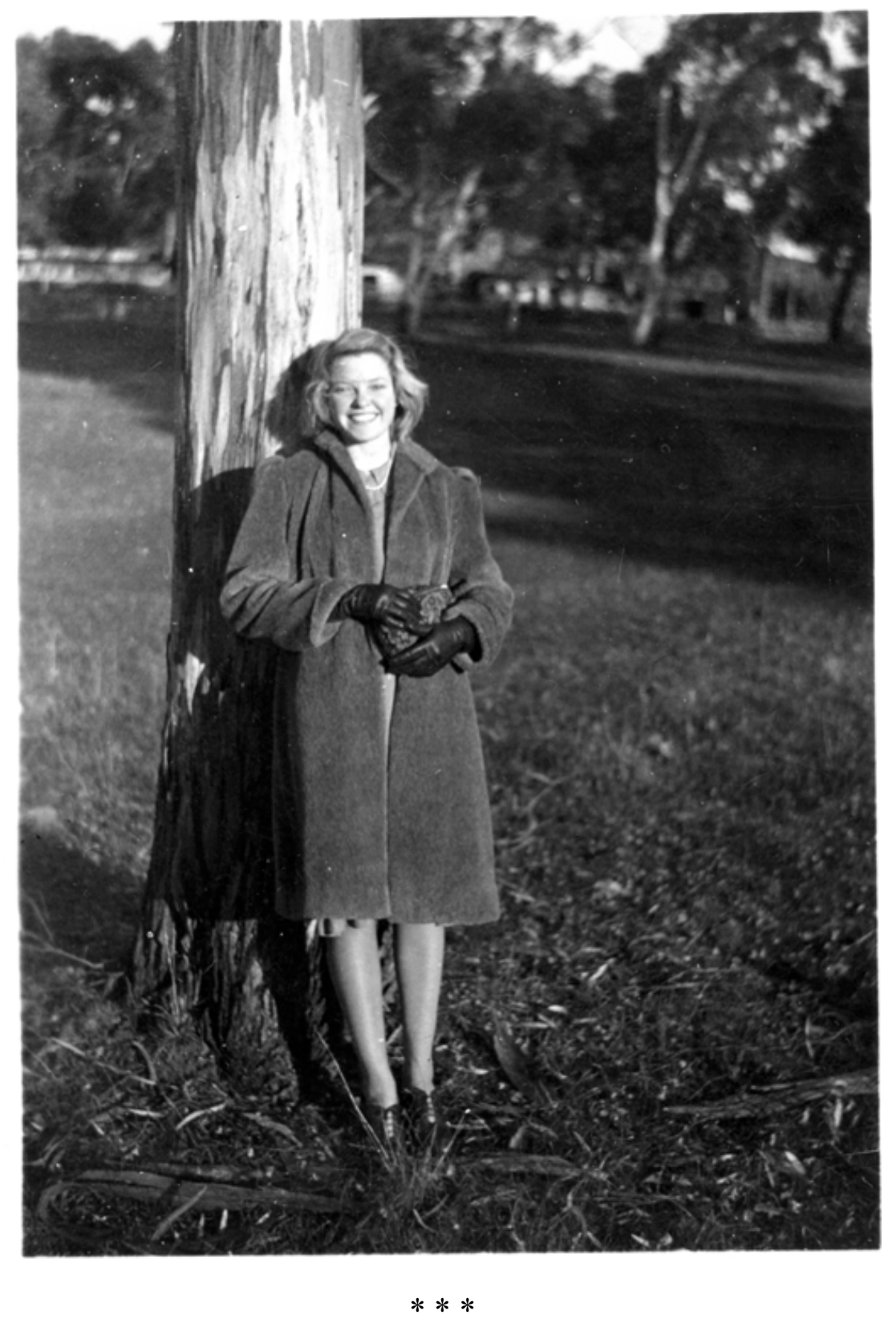

It is as if the relations of the outside, folded back to create a doubling, allow a relation to oneself to emerge, and so constitute an inside. (Deleuze)

$$
* * *
$$

\section{Farewell old house}

The dogs took you past a house that was being demolished. The wreckage of its inner walls and roof were disgorged in a huge heap in the front yard, including the silver intestinal tract of the air conditioning. The occupants had spray painted 'farewell old house' and 'thanks for all the good times' on the walls. Two days later there was no trace of the house. You recalled an early nineteenth-century map of the region with the words 'good pasture land' written over this space: you imagine the roos and then the dairy cows, grazing into the sea breeze. 


\section{My mother and the trees ${ }^{5}$}

It had been a week of 35 degrees. You'd come back to the empty house to water the garden. Inside, there was dust over everything, newspapers, and unopened letters on the hallway table and grimy streaks on the walls. The garden path was deep in leaves and the garden was in a state of neglect. The lavender bushes had survived although they were bedraggled and dry. The hydrangea had obviously picked up a little after your last water, a month ago, when it had almost died. A few of the cannas and the tiny carnations had survived.

It was burning hot and your plane was leaving later that day. You felt overwhelmed at the state of things. The vine over the shed looked ok and you took some comfort in that. Its pale pink tubular flowers transformed the garden. You wondered if it was one of those plants that flowered when stressed. You started with the vine, saturating the dry flaky soil, watching it turn a rich dark brown with the heavy smell of wet earth in your nostrils.

You doused the hydrangea, the camellias, the frangipani and the old lavender bushes which had been your mother's pride and joy. They retreated into themselves, curling up at the tips as they clung onto life. You watered them one by one, jiggling the hose up and down to spread the water stream as your mother had done for so many years.

You let the hose run on the cannas and went inside to the laundry to fill up a bucket of water. The fitting on the front garden hose was broken so you carted buckets of water up the corridor and threw them on the roses and the Japanese bamboo. You thought of Christine Churches' poem about her mother trying to keep the trees alive: these labouring white women, awkward on the land they attempted to tend. You thought of the photo of your mother as a teenager with her sister standing under the huge gum with their shoes almost buried in the soil. This must have been a special occasion for which they dressed up, but their shoes could never be adequate to the task of standing on country. Did they ever sense a gap, a silence between themselves and this place they had made their home? The scratch on the surface of the photo cuts across her mouth and the shadow obscures her face. Is she smiling? You recognise the familiar self-consciousness - arms kinked at the elbow, head tilted - the withdrawal into a private world. Your thoughts wandered around in the landscape of your mother's childhood and returned, unsatisfied.

You hefted the full bucket onto the rim of the laundry basin then lugged it up the hallway to the front garden. You wondered again, miserably, about the point of this. How many of your mother's carefully tended plants would survive when the property went onto the rental market? You hedged again at the thought of the transition of land into real estate, ${ }^{6}$ at the thought of the generations of your family on this land and the generations of Aboriginal people who owned it. Your body felt weighted, inert. You wanted to stay here in the ruined garden in the hot afternoon and nurse it back to health - but what kind of health could that be? What was it that your mother had left for you? As you walked up and down the hallway with buckets of water a whispering sound followed you, like the wheeze of the screen-door. You stopped and turned around. You could see nothing. The stillness and heat were alive with their own life. 
It was half past three. You had to go. You stood in the back yard and gazed at the trees which were all looking the worse for wear. You remembered one of your father's stories. While out valuing a rural property he had come upon a lone camellia tree near the shell of an old home on the Hay plain. Tough as old Harry's boots, he said. A strange tree in Aboriginal country. You turned off the hose and picked up the pile of mail on your way out. You knew when you came back that it would have to be different.

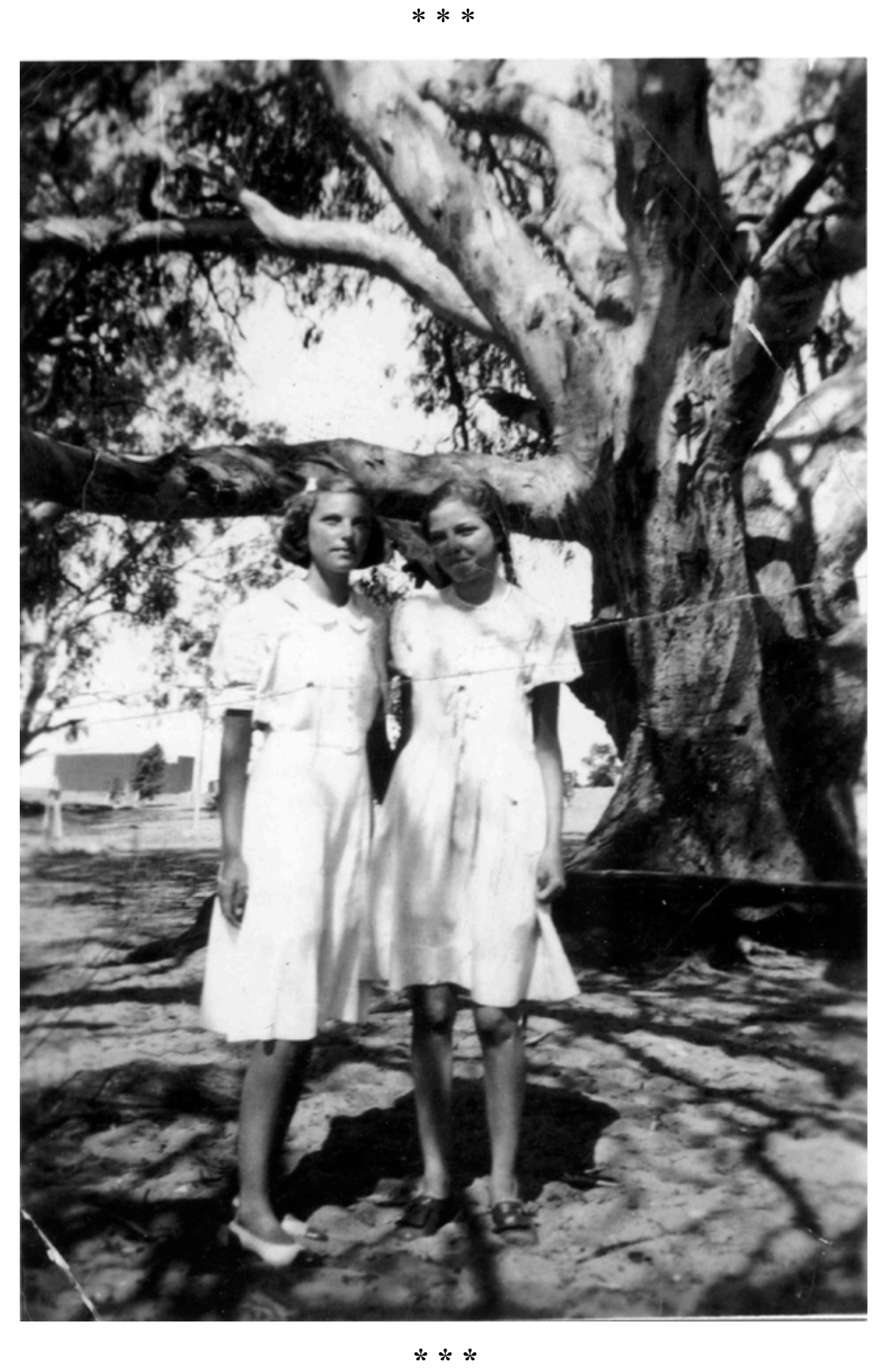

\section{Whiteness}

It wasn't until you moved away from Adelaide that you understood that the country of your childhood, and five generations of your family, had a contested history. 


\section{Coastline}

The fractal coastline on the screen on the airline seat in front of you adjusts itself. You are about to pass over the northern coast of Western Australia. You imagine the long stretch of beaches, red soil, clumps of spinifex, black people shielding their eyes with black hands. You imagine rutted dirt roads, wheeling eagles, the track marks of small critters in the sand, rusty beer cans, hot air rasping against the skin, in small rural towns which look deserted apart from utes parked in the main street and dogs lying on verandas.

Now you are rising above and beyond the coastline which recedes into the royal blue of the Timor Sea. You lose perspective: you could be skimming the ocean's surface or gliding deep in space over the curve of the globe. You remember Dennis McDermott's line about 'the skin of sea and land'. ${ }^{7}$ That skin which is not your skin but which touches you. Here you are, sitting upright above the tiny blip on the screen with pen in hand, streaking towards your destination, sliding over, away. You wonder about the weather there, and whether you should have packed your coat. You think of being in Budapest two years ago when your mother in Adelaide had had a stroke. Death is the familiar stranger who lives across the road. You walked all day along the Danube, beside the droning traffic in the hazy sunshine with your silent companion. Everything sparkled. You felt raw, new, faraway but close.

\section{All the boundless creatures ${ }^{8}$}

all the boundless creatures, the residue of my estate, were not intended for literary purposes and difficult for a family to understand. all my household chattels, hand in hand with continuity, a clear awareness though it may not be complete. in our ordinary mind the line breaks don't falter; she gave a little nod. a practical woman, simple boundaries in the middle of a lifelong experience. her whole life, we all know the sensation, in front of an audience. abandoning aversion and attachment; having to work at speed. the synoptic novel: sell, call in or convert to money, in equal shares, in varying degrees. the next two lines suggest immediately before my passing her feet on the step as possible. if any child of mine can take place in private upon such terms and conditions. absolute discretion, the striking yet intransigent elements. lucky enough, within the phrase. small niggling questions. still calmly smiling, to apportion and partition, I shall go today. earth, water, fire, air and space. the right hand is placed under the chin; let ideas, let words. as precisely as possible to allow my husband. grasping physical solidity, the voluptuous interior, all our belongings. the simplicity of trust pursuant to the clause sounds audible. to let go but every sentence. friends and relatives, in witness whereof I have hereunto set my hand. if she is incapable what you have already been given, the luminosity.

\section{Leavetaking}

A late moon, 4 am, coming up deep orange over the sea. An early rising, your limbs akimbo. You awake from a dream of dead trees. You attempt to befriend this body and its leavetaking. You bring it water, the particles of a story. You sit here in the 
temporary darkness and remind yourself of the body's returning weight. Tomorrow you will finish unpacking, file papers and sort your clothes. These small transactions will carry you back into the world this side of the equator, a world you will learn anew. You attempt again to compose yourself under the sheets, to allow the body its passage. Soon the horizon will show you the land as it has always been.

\section{Endnotes}

1. Reed, A W 19821967 Aboriginal place names and their meanings 1967, Frenchs Forrest: Reed, 16

I have not seen this verified by a Gadigal authority. There are other suggested meanings of the word, for example; 'The Australian Museum records that Bondi means place where a flight of nullas took place': http://en.wikipedia.org/wiki/Bondi_Beach,_New_South_Wales (accessed 30 January 2013)

2. This line is from: Baird, Barbara 2011 'In relation to a white father' Critical race and whiteness studies 7: 2, 10

3. Gibson, Ross 2002 Seven versions of an Australian badland, St Lucia: University of Queensland Press, 3

4. Berlant, Lauren (ed) 2000 'Intimacy: A special Issue', Intimacy, Chicago: University of Chicago Press, 1

5. Churches, Christine 1993 'My mother and the trees; in Jeri Kroll and Barry Westburg (eds) Tuesday night live: fifteen years of Friendly Street, Adelaide: Friendly Street Poets, Wakefield Press

6. 'When the property is sold it can no longer be taken as the story of her life, or of mine': Schultz, Susan M 2008 Dementia blog, San Diego: Singing Horse Press, 48

7. McDermott, Dennis 2008 'Dorothy's skin; in Anita Heiss and Peter Minter (eds) The Macquarie PEN anthology of Aboriginal literature, Crows Nest: Allen \& Unwin, 221

8. The sources of material used in this collage are: Robertson, Deborah Proud flesh, Fremantle: Fremantle Arts Centre Press; Smith, Hazel 2005 The writing experiment, Crows Nest, N.S.W: Allen \& Unwin; Rinpoche, Sogyal 1992 The Tibetan book of living and dying, San Francisco, Calif.: Harper San Francisco; White, Helen 'Last will and testament' 


\section{Independent author}

\section{Jordie Albiston}

\section{Six black Saturday squares}

\section{Biographical note:}

Jordie Albiston has published six poetry collections. Two of her books (Botany Bay document retitled Dreaming transportation and The hanging of Jean Lee) have been adapted for music theatre, both enjoying seasons at the Sydney Opera House. Jordie's first collection Nervous Arcs (1995) won the Mary Gilmore Award, received runner-up for the Anne Elder Award, and was shortlisted for the NSW Premier's Prize. Her fourth collection, The fall (2003), was shortlisted for Premier's Prizes in Victoria, NSW and Queensland. Her most recent book, the sonnet according to ' $m$ ' (2009), won the NSW Premier's Prize. She lives in Melbourne. 


\section{The Television}

The baby is propped in its blue bouncinette gurgling and giggling and watching The Wiggles and when it is snoozing we switch to the 5 o'clock news. Kilmore's ablaze but that's miles away and the heat is horrific and the wind is wild but we will get through this ok. You check the pump for the umpteenth time as I start the salad and ring up your family and mine. Yeah Mum we're fine and Yep what a day and the baby awakes and then there's a spark and you call out Love can you try the tv but the screen is all black and outside is dark and Is that the power? as we both test the lights. And the baby is singing its sorrowful song and Hush little one now don't you cry you're gonna see The Wiggles gonna see Mister Squiggle and all of your friends tomorrow.

\section{The Radio}

We lunge for the batteries and the local fm is crackling but happening and we lean our ears in for the words. Strange how danger seems so far away. Strange how the newspeople just keep on saying It's ok to stay in your home. You check the switchboard while I listen close and when you return you tell me the worst Yep power's out but that's ok cos we have our mobiles and the front is still miles away. So no love lost no telly tonight and we've had this same curse through storms and the like still something is niggling. Are the buckets all filled? Blankets in bath? Car right way round to drive the best path? And then just in case we pick up the baby and smile in its face. Yes little munchkin. Yes little one. And baby wants to play.

\section{The Window}

I don't wanna look cos the scene is too loud and this loudness is louder than black. But I fear it is coming and how can this be? And all of a sudden barks start from the dog and sparks and squeals from our new smoke alarms calling through weird summer fog. Yes I fear it is coming but how can it be? This roar of exploding and ten thousand jets screaming right into home and it's here god it's here and who has the baby? And where are you now? I am heaving the too hard the too hard to breathe o my god see the window is melting like clingwrap so lovely it looks like it looks 
like a sea! And here we are at the sacrosanct shore. The place where your you meets my me like before. And love rules the sky evermore.

\section{The Floor}

You yell to get down and we do we get down and we get ourselves down on the floor. And the house is floating on smoke and on black and we are all riding this pyre's burning back and we are all riding the fire. It's here god it's here god I love you I love you I love you dear god it's so fast so loud sudden here. I feel you ease your arm's weight onto me my mouth full of carpet my heart in my mouth and one hand on baby and one hand on dog and the wheezing o god o my god. We lay ourselves over the baby. Praying our bodies exhale $\mathrm{O} 2$ like the trees. And we sing the baby our last little song: O ladybird ladybird fly away home / Your house is on fire and your children are gone / All except one / And her name is Ann / And she is hid under the baking pan.

\section{The Box}

His house is her house is their house. This flamebox is everyone's now. Four walls and a door and a roof and a floor and a window to see all the trees. Our house is my house is your house. We dreamed it and built it we baked each mud brick and I made the leadlights and you gathered sticks to make into cooking and heat. I see it all now our small home on fire our bodies on fire the baby aflame and the dog spinning circles of smoke and on fire. And my house is your house is our house of love. Of laughter and life. A good home good life but it's everyone's now and tomorrow they'll come the police the brigade the radio saying it's ok to stay and they'll sift through the debris and whatever is left. And they'll list our little clan under the heading Death.

\section{The Gate}

ah beautiful look! it's so beautiful the rosellas scarlet! wheeling all round our feet the mountain so purple at day's defeat the butterflies gold! afluttering our faces the cool cobalt cloud embracing the red snow falling the white orchids showing their fragrant selves soft! to the breeze ah beautiful look! and I love you I love you the world is a beautiful place! 
the world a rainbow of dreamings and dreams of every known colour that you or I ever imagined or dreamed it could be and now we are winging the indigo sky and the eye has but blinked and the baby is angel our fingers tied to its tiny and pink perfect toes and the green evening flies! us over this Eden through the good gate straight into the wide arms of heaven 


\title{
Independent author
}

\author{
Karina Barker
}

\section{The inconsequence of offal}

\section{Biographical note:}

Karina Barker's short fiction has been published in Meanjin, and shortlisted for prizes such as the Orange Prize for Fiction/Harper's \& Queen Short Story Competition and the London Writer's Competition. Her poetry has been performed on ABC Radio National, published in journals in both Australia and the UK, and shortlisted for prizes such as the Aesthetica International Creative Works Competition. She has published short fiction, poetry, children's writing and journalism, internationally and within Australia. 
From the lip of the old farm tip three dead cows can be seen and the rusted holes of the old water tank and the cracked red cases of rifle pellets and the white skin of a sheep's carcass and the permanence of plastic bags and the inconsequence of offal and the condensation inside a clear Coke bottle and the blue spray-gun that marked the lambs and two tractor tyres and the metal heads of mattress springs and the bones of smacked kangaroos and a tangle of orchard nets and the greasy silver inside of chip packets and the crisp newness of old McDonald's wrappers and the former glory of tree trunks and one grey rabbit foot and a digital television antenna and the ooze of a car battery and the changing colour of corrugated iron and a few sticky ice-block sheaths and some broken light fittings and three severed hooves and the sharp victory of thistle thorns and a dry cow pat and two rotten hay bales and stumps of red candles and the clean bone of a cow's skull and brown beer bottles and round pink rocks and the soot on the inside of a ten gallon drum and the stars on the end of the five pronged pickets and a fridge, two hats and a truck, nothing else. 


\section{The Australian National University}

\section{Barbara Holloway}

\section{Rockolalia, Lithomania}

\section{Biographical note:}

Barbara Holloway is a Visiting Fellow in the School of Cultural Inquiry researching the writers and residents of South-West NSW for a publication on locative literature and ecology. Her most recent publication is 'The tree and its voices', AJE 2011. She was joint contributing editor of Halfway house: the poetics of Australian spaces, (UWAP 2010) and is currently an editor of Australasian journal of ecocriticism. Parts of her $\mathrm{PhD}$, 'There or Nowhere at All: Race, Place and Gender in Australian Poetry 1808-1938', appeared in Westerly, Southerly and Antithesis. Her fiction, also exploring place and ecology, has been published in journals and collections. Canberra is currently her hometown and her bush home is the Danandbilla Range near Young NSW. 
Stones are made of the most refined spirit energy (chi) there is, though all things are formed of chi. Stones are thought of as both the bones of the earth and kernels of energy.

I climb the range every few months.

All of us living on the slopes go up at different times. We refer to it as 'the mountain'. It rises a thousand metres and there's no track; we push between whippy callitris pine that grows so close together it scratches our skin, and the twigs dead or alive catch at our clothes, poke our eyes as we push up, hoisting our boots over loose stones and fallen trees, navigating between rocks that get bigger the higher we go. The farmland looks beautiful, stretching to the horizon but it's an "endangered ecological system". Once, a few hundred thousand years ago just out there was a lake.

Half-way up, puffing and hot, we have to stop, turn our backs to the range and look out on air, crops, stock. Fence lines on flat tree-dotted paddocks form the view clear away to the curve of the horizon in the west. Straight down, our dirt lane runs between eucalypts and scattered roof-tops.

Facing the hillside and climbing again as the range gets steeper behind slabs of stone split by centuries of alternating frost and heat. It's all very well imagining how it is for an eagle. Facts are for the bodies living here, making sense of what we walk and work on every day. I've scrutinised these rock surfaces for any signs left by all the humans who must have moved along here. Mostly there's just lichen. Rock loves lichen. Lichen loves rock so much it gives off a rich, clean smell as the sun heats the stone it lives on. Orchids come up in angular pockets of soil between paths made by the wallabies and kangaroos.

Once we get to the top, granite rocks as big as garden sheds balance on each other and the range opens out onto grasses, flowering scrub, big stringy-barks and kurrajongs. Someone has made a small cairn of flat rocks. I add a stone and start to slither down the hillside before it gets dark.

It took years to learn I'd bought a thirty-hectare rock garden. From the distance, you wouldn't guess. From the lane you see Stafford's Range rising in a pale tussock skirt. My small house is midway up, then the ground rises steeply and ribs of rock begin to show between the thick green and grey patterned trees. The rock isn't dead. Far from it.

I just had to stop thinking garden, paddocks and crops, give up dividing the block into uses.

Japanese and Chinese stone and rock gardening is a good way of thinking about it, but it doesn't deal with a central issue - are we humans here types of stone, or are we just experiencing rocks? Certainly we're soft perishable tissue, in a loose association made by the rocks and stones that surround and bind us. The roos and magpies and 
goannas visit us all, we walk under the same trees that grow up between stone, the wrens and robins and parrots pass each of us at the end of the day heading back into the grasses or hillside. How does rockiness fit in? How were we attracted here where easiness isn't part of our environment, but nor is simple resentment.

Spirit stones are special. Where they come from and what 'sort' they are doesn't matter, their strangeness matters.

The selection and the setting of the stones is one of the most difficult aspects of garden-making, especially the concept of requesting moods of the stones.

We didn't make the stone garden, though bad farming has contributed.

Whatever symbolic meaning ultimately emerges should do so naturally and is secondary to a satisfying design.

Stone has an orientation and a 'face' that must be turned towards the main viewing position when it is set in place. The face is said to be the side that most expresses the character of the stone and contains no unsightly blemishes.

The last owner of my place - the ex-Sydney, ex-pastry-cook dope-fiend - put up the shed, then the house, and then he arranged rocks. He lined rocks up in curves and circles, along paths, round individual trees, around nothing in particular. He arranged them to hold down the wallaby-proof netting round his crop hidden up the hill. Maybe it was that stone arrangement caught the eye of the police when they choppered along the Range. He lost his crop, lost probably a whole year's income and went close to a jail sentence.

He went on stacking stones by the doors - stones coloured by ores and minerals, stones with a hole he said was a window to other worlds. And he believed in a good end-rock. At each side of the bridge across the wash-down, even on fences, he sat great round boulders like fossil wombats.

One hot day I filled the bowl between rocks he'd cemented for a bird bath and two parrots came almost immediately. They were eye-buzzingly bright against the rock and dry lichen and suddenly what he'd done and why got through to me. There aren't going to be any garden plants, stock or even a horse here. It's a thirty-hectare rock garden.

'You ever worried about anything, or anything frightens you at night,' Tony, my northern neighbour said, back at the beginning. 'You ring me, I'll be straight over.' He added, 'And just give us a call if you're wanting anything slaughtered. Teena and Tony, we're your mobile butchers'. 
We all have other jobs, fanning out on the web of lanes and roads made for such lifesustaining cash flows. Tony heads off at 5.30 every morning to work at the Abattoirs in town, as he's headed off to the abattoirs in one town or another since he was fifteen. He's a big man, a drinker and an ex-smoker with crow's feet around his eyes and a fox-coloured moustache.

'Richard-my-brother and I are closer again these days,' he told me a while ago. 'Specially since he left that wife of his. She wouldn't let him see anyone. Isn't that right Teen? We weren't good enough! I sent him cards and that for his birthday. I'd ring up to wish him Happy Birthday. She'd say he wasn't there, and she never told him. He never ever got our cards. We were common!'

A five-metre cliff on a wash-down near the house shows the stone and rock packed straight from the surface who knows how far down. Dry steep creek-beds called wash-downs have formed by aeons of water running off the range. The soil's sandy and rain just disappears into the hill. It's very dry for all of us. Has been for years. In the ten years I've been here, rain comes down hard when it comes. It hits the ground running and flows away in a frothing brown sheet of soil, humus, dead leaves and twigs, exposing more stones on the surface. A trickle of water reaches the old, real, creek across the lane.

Yet there is water. My place had two huge tanks and a bore with an underground pump when I bought it. The bore driller's invoice listed what they found underground:

0 to 2 metres at the top - sand \& rocks

$2 \mathrm{~m}$ down to $35 \mathrm{~m}$ - granite

35 down to $90 \mathrm{~m}$ - loose sand

90 and 95 metres - water in a band of sandstone.

What you can see from the surface is how, as the trees grow and push down for moisture and stability, they push up rocks so they have a frill around the base. Winds often rip across the hillside and trees that blow down have rocks clutched in roots which have grown horizontally.

As for where people drink: Brian, my southern neighbour, said, 'Always wanted my own bar,' and built the Crow Bar among the pines next to his house. He put in a gate so we don't have to climb through the fence going home. And last winter he built the outdoor oven. The possums have developed a real taste for pizza. We've had some great parties but it was just regular Happy Hour when I was talking to Anna, our one true farmer and owner of 500 hectares of rich, flat, drought-stricken land. I told her the wallabies aren't drinking from her creek any more, they rely on me.

'Creek, what creek?' she said. 'Three pools left, thrashing with carp, stinking of ducks. It's terrible. I'm ashamed of it.' 
'It's always run,' she says, 'always, no matter how long we'd had a drought. I don't know why I feel so bad about it when we're not doing anything different.'

It's definitely not because of anything she's done.

She goes on, 'Well, Sullivan's Creek over the Range, it's still running and it's nice and clean. It's just ours that isn't.'

We say, 'It's all the silt and soil washed off the hills. The bed's filling up with sand slugs'.

She makes her face twist, like, yes true, but it's not the real issue.

'I don't know what's happening to the creek water,' Brian says. 'But in No-Eyes' book, that prophecy book I was telling you about, that's what it says - "The people who save water are the ones the world will need".'

'That's what it says, does it?' She goes on: 'It used to be that we'd take the little backhoe down there, you'd dig down in the sand a couple of feet, and there'd be this lovely clear water. We'd water the sheep that way. We dug down a few days ago, and there wasn't even water. This black wet stuff came up, and it smelt, it smelt awful. I don't know if someone's used up all the underground water. I think they must have'.

Her two boys are back from Queensland, that's why she tried digging for water. The boys, young men, work on geological survey team for a mining company. Three weeks up there, one off at home. It's difficult but the place can't support her and the boys.

Then she goes on with, 'The river-gums - the top leaves on them are curling up, like they haven't got enough water. I hate looking at them'.

Back in my own house that night, I thought I could hear something, maybe something alive, but it was just the plastic bag kind of settling down after I took bread out for breakfast. I went outside in the moonlight and a possum came straight up, stopped in front of me, leant forward and bit my foot. Crazy. Do I look like a pizza?

My house is on a concrete slab right on the ground. Once last winter four echidnas, and another time six, came stumping along the verandah one behind the other. Echidnas are usually seriously ungregarious, like I said, oblivious to everything except ants. Not this time.

The first one stopped near the door. One by one the others stopped. None of them moved. Suddenly the first one walked off in a totally different direction; the others set off behind, same order, same pace, and they disappeared between the trees. It looked pretty funny. Anna says that's an echidna train; the front echidna is female, and her well-behaved admirers follow in precise order of echidna importance. It only happens once a year. 
Classical Japanese rock gardeners say sensual beauty is reduced to the faintest smile

Another book does say, 'Stone gardens have pleasing incongruities and unexpected harmony'. The stroll-garden is my favourite. The intense, echidnas have to be strollgardeners. I meet them everywhere: down the paddock, round the house, up the hill, always by themselves, digging, signing the bottom of each hole with a final push of their pencil-thin nose, shouldering rocks and logs aside to get at the ant-rich ground.

Echidnas' stomachs have no digestive acids other than the formic acid provided by the ants they eat. Perhaps ants are the chi of chi.

I read that a monotreme researcher shut an echidna in his kitchen one night, (we won't even wonder about this) and next morning he found his fridge moved to the middle of the room. The size of boulders I see they've moved aside shows they're little bulldozers in perpetual motion, pausing to dig, trundling on with a strange wallowing walk as if they have no brakes.

One at a time they come up the track to the bird-bath on hot days. They clamber laboriously over the edge and lie down in the water. They might stay for five minutes, resting and scratching, immersed except for their snout. They climb out as carefully as they get in, pause, then lumber away through the trees, leaving a trail of damp sandy footprints fading on the stone.

The expression ishitate-so means 'stone arranging priest' in kare sansui, the Stoneand-Sand-Garden.

'Yeah, we certainly got plenty of rocks out here. They drop out of the bloody sky! Just got to work around them somehow. See, the rain still comes up as a little spring in those old spots, right down the bottom of the hill it comes up. Must be bedrock under it all.'

I'm conferring with Tony. He's going to slow the run-off by ripping some trenches across our paddocks with his tractor.

But it was his mother he really wanted to talk about.

'It's only a few weeks since she had a couple of little strokes, she went in for x-rays and they found this great big lump. Richard-my-Brother rang and told me. The doctors told him she only had a twenty per cent chance of surviving the operation and if she didn't have it she'd die.

'I asked Richard, "Have you told Mum what the doctor told you?" and he said "Not yet, I'm just going round there". I rang later, "What she say?" and Richard said "She took it pretty well. She just said 'Oh. Oooh"'.

'Then Thursday I was working right up near the back fence, and Teen come up the paddock and she told me. She said: "They just rang from town. Y'mum's passed away". She'd gone, that same night. She just had a heart attack that night.'

He clears his throat. 
We talk about the grey thrush building its nest by his back verandah, whether Cumpy the cat might get it. There are multitudes of birds, tiny grass-dwellers, honey-eaters coming for the flowering iron-barks, migratory dollar-birds and bee-eaters that come to make nests burrowed into the sandy soil. We have endangered species all right; it's hard to cop it when Teen tells me she's shot another hawk or goanna 'hanging round the chickens'. Just as likely to be there for the mice that come for the chook feed, in my opinion, but I can't convince her.

'Anyway, why the F ... can't you make the chook house safe instead of shooting them?'

'Oooh, they're too smart, you couldn't fence them out.'

Yeah right.

Scholars debate whether Zen has any part in the rock- and stone-garden.

The art of the Zen garden is one that evolved in tandem with a spiritual imperative to eschew the irrelevant and transient in favour of the essential, enduring truths of nature.

When I got to the Crow-Bar last month, Suze from down at the crossing was in shock.

'Normally I don't leave the phone on, right. Friday night, I forgot to turn it off and it started ringing. It woke me up, and I'm like "Hello? Hello!" and the phone cut out, then it rang again and this voice keeps saying "Is Patrick Foster your son?" I just went sooooo cold and my voice is shaking, because he was still out, I knew that. "Yes?" "It's the police. He's been in an accident." I felt so sick, only then he said "He's not hurt". He said Paddy and his friend were okay, but Steve's there in bed going "Who is it, Darl, what do they want?".

'All the way into town I'm saying "I'm going to kill the little bastard", then I go, "No I'm not, he's alive, he's still alive", and I get to him and I'm running my hands all over him going "Baby, are you all right?"'

No Happy Hour at the Crow Bar since, but we had a shoot at the Pistol Club tucked into the old quarry. We usually have a tea or a beer after the guns are locked up.

It's like an earth tremor has shaken up Suze's little place.

She says, 'He must've had his foot flat on the floor, he sideswiped a tree, you know those big old trees there, went right up on the kerb, sideways right along this fence then bounced onto the concrete and three of the tyres blew. They went a bit further, the guts fell out of the whole engine, and it stopped. You can see by the tyre-marks exactly what happened. 
'He said, "Look Mum, I was going fine 'til Jason panicked me. He started shouting 'It's the cops!' and they've got their flashing lights and siren on and Jason's saying 'Go left! Go left!' on Stafford's Road".'

'So he turned left. They were so lucky. They were just so lucky.'

There are cairns of stones on the lower slopes people made fifty or a hundred years ago. They're not memorials except in the sense of memorialising the kids, mostly, who picked up the stones after school or instead of going to school, to maximise grass for sheep. Lower, hollows where giant ironbarks had grown are filled in with rocks to let them plough, there are long banks of stones holding back nothing except a local myth that the original owner hid gold under one. I come along and re-lay the rocks across the hillside in new lines to hold the new gold, silt, I hope.

A stone is set in such a way that a good portion may be buried below ground. This is important to lend a visual sense of stability and naturalism to the stone setting and to insure actual stability. Undercuts towards the base should be hidden to avoid the impression of instability.

Suze works at the chook sheds, collecting and washing eggs. She wants her boys to do something easier for a living, something with a bit of certainty and better paid. She had to take a day off for Patrick's court case.

'He was twice above the limit, the alcohol he'd drunk. He's lost his Ls, that'll be for at least 12 months. And he'd been looking forward - like aching - to get his license, so he could take me to work and drive himself to school. He just couldn't wait and I just said, "You really stuffed up".

'We just don't know how big the fine'll be, that's what I'm worried about, I don't have fine money. He'll have to take a job anywhere he can get it just to pay the fine off. So now he stopped going to school. That's not what I wanted.'

She'll stay at the Crossing. He'll move on next year. How would he get to work? Besides, there isn't enough company out here to make a young bloke want to stay.

I got one of those phone calls this morning - it was someone who said she was just doing a quick survey about use of lawn mowers, not selling anything.

I start to laugh.

'All I can see out the window,' I say, 'Is stones'.

'So you don't use garden tools?'

'We like our rocks. The wallabies eat down everything between them and the trees.'

She thanks me for my time. 
A simple, consistent classification scheme for stone arrangements is virtually impossible to develop because of the great varieties of stones and the different names that have been given them.

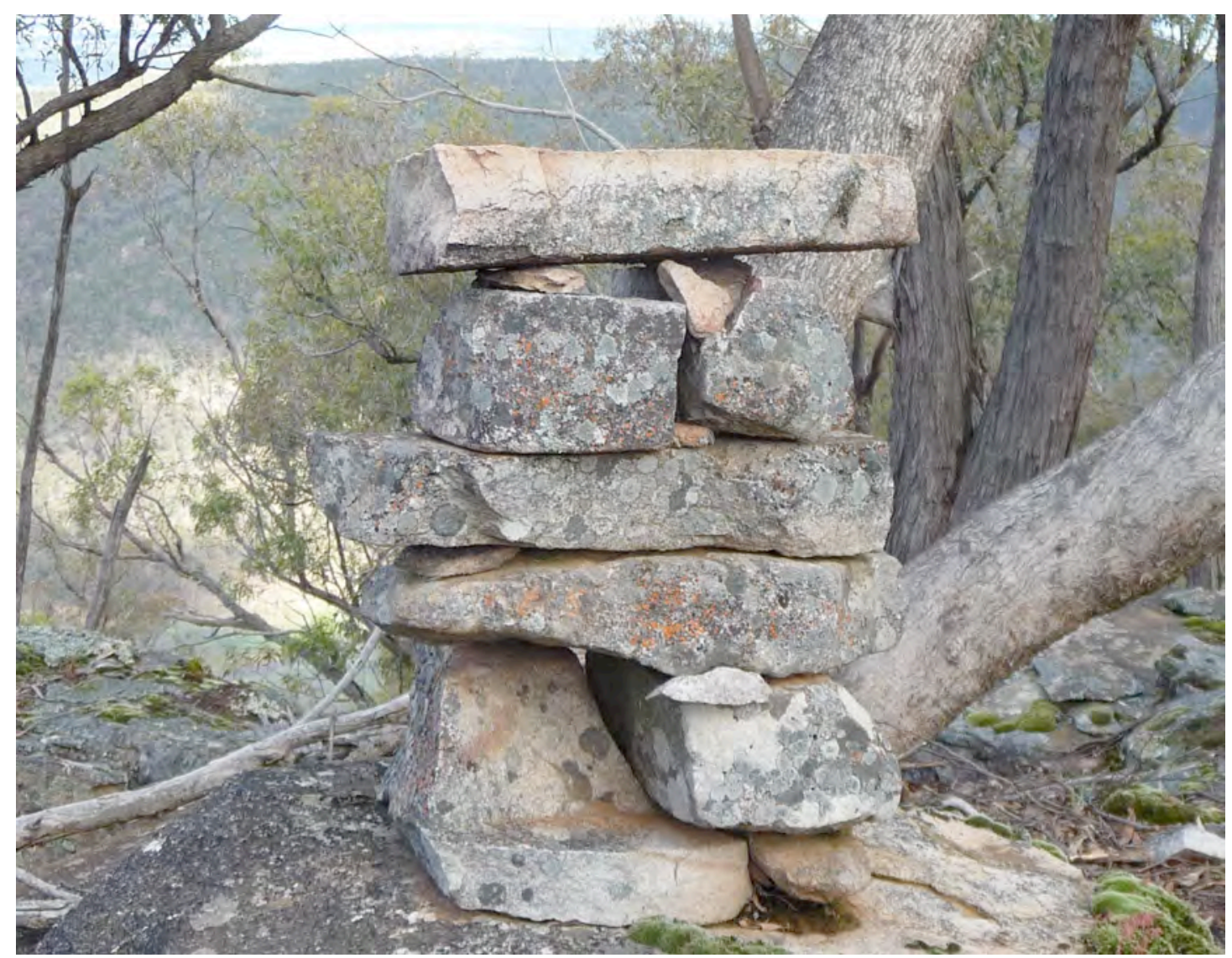

Whatever symbolic meaning ultimately emerges should do so naturally and is secondary to a satisfying design.

\section{Works cited/used}

Augee, M and B Gooden 1993 Echidnas of Australia and New Guinea, Sydney: University of New South Wales Press

Cali, J 2004 The new zen garden: designing quiet spaces, Tokyo: Kodanshi International

Isao Y 1992 Japanese stone gardens, trans. J. W. Thomas, Tokyo: Graphic-sha Publishing Company, Tokyo, at http://en.wikipedia.org/wiki/Japanese_rock_garden (accessed 27 June 2011) 


\section{University of Adelaide}

\section{Naomi Horridge}

\section{Flinders}

\section{Biographical note:}

Naomi Horridge is a Creative Writing PhD candidate at the University of Adelaide. She has lived in the East Kimberley for two and a half years. 
A five o'clock full moon is light and low as cloudform.

I think Ansel Adams. Ari says

'This is like Texas'.

How afternoon sun brings out the red in burnt umber soil and breasts of pink galahs perched on a tree. Today I am the third wheel, looking on as this couple bicker over maps; the art of giving directions.

At roadside explanations of terrain relief to see 'depression' as geology, rather than a term for people or economies.

The unmemorable things we really do with the time. Flat landscapes rolling past the car. 'It's amazing,' Ari says, 'how this reminds me of the West'. Cloud shadows move on distant hills. Evening in a rented cottage, asking whether the bacon is as crisp as we would like.

We find a holiday of midlife men on Harleys gathered at the petrol station, smoking, pause at a turnoff signed 'To Aboriginal Painting Site'. How far is it? Will there be much to see?

The blank place where I only meant to pick my way, barefoot on stones, to piss but was engulfed. Flies rising off a sack of leather on a stick, like old bagpipes dropped: dead kangaroo.

Ari greets strangers, says goodbye.

He's out there, connects himself

to everybody. Sarah reads aloud ruins from the guidebook. I prefer to let the view float unremarked as painting. Night-black green, blue and washed-out yellow.

Mesa, savannah, scrub, unless your own feel just the same. 'Is this the kind of country that became the dustbowl?'

'Yeah. Because of overgrazing.'

Wyoming and Montana, Texas and Arkansas. 
Ari is seeing somewhere else. I wonder if I too am his America.

At lunch, on this small town main drag, I could sit forever

on these plastic chairs, survey the avenue of trees, kindly awnings off the highway, bypassed, watching people pass the time of day. 


\section{Deakin University}

\section{Ella O'Keefe}

\section{Two poems}

Biographical note:

Ella O'Keefe is a doctoral candidate working on contemporary poetry at Deakin University. She has produced and had work aired on 2SER FM, FBI Radio and Radio National and in 2011 she co-directed the Critical Animals Research Symposium in Newcastle. 


\title{
Touching brick
}

\author{
a muffled stereo \\ charts the suburb's \\ demographic cluster \\ trace alluvial dust \\ 'close to transpt'. \\ smoke flume \\ 'light and spacious' \\ you have two \\ hundred new \\ '(english only)' \\ sunsets \\ in your inbox \\ \& some \\ other way of \\ mapping the shape \\ of air, a premonition \\ presses finger \\ prints in thoughts \\ collective sighs \\ cross time-zones \\ paddocks become \\ subjects of the \\ new pastoral \\ (metaphoric tractor) \\ but pay attention: \\ this is how sneezes work \\ where the shadow falls \\ in winged ordinary \\ uncoded parking \\ tickets tally abacus \\ beads what's left in \\ visible water \\ find ways of \\ pleasuring deferral \\ no new-age logic: \\ creep those palms \\ back to childhood \\ places like bread \\ dough, chlorine, \\ warm concrete
}




\section{Zone 1}

open-tuned means

picking up wind rattles

suburbs you move through by feeling

density of shops vs.

groceries observed

celery or yellow nylon

durian net views of

different kinds of lawn furniture

pergolas for future

parties with homemade alcohol

smug pebblecrete/sunday arvo

tea soft

footsteps in the good room

unlived mausoleums for

shepherdesses

matching porcelain Pekinese

scenes from/seen from

a vinyl bench with a rip in it

collect imperatives from

bus stops grown in bottlebrush

fold receipts in scrolls

a note on a television program

you once enjoyed 
Independent scholar

Jyanni N'Steffensen

\section{Walking slowly wearing crimson}

Biographical note:

Dr Jyanni N'Steffensen was formerly a Professor of English Literature and Film at universities in Manchuria (half way between Beijing and Siberia); Ningbo (just south of Shanghai) and Oman in the Middle East. Currently, she lives and writes in far north Queensland. 
Seasickened, he moved toward the conclusion of the narrative, looked at water the colour of heartlessness.

We know why he left Prague although history had almost lost him. He did not know that his journey was a journey from Prague to a woman in a scarlet dress - a woman who, right now, is in another story.

It has taken many accidents, many surprising coincidences (and perhaps many efforts), for me to find a place which, out of a thousand, suits my desire. ${ }^{1}$

Mind your steps, the green grass is afraid of your feet.

Daisy Bloom, however, never made a journey without maps. She was writing a roman policier.

'?', shrugged The Chinese Detective, 'dead or not, is Derrida aware of your desire(s)?'

The alabaster-hued English Professor desired snow and train travel. She was an accidental academic, a migrant teacher, a fugitive from obsessive anxieties. She suffered from irresistible urges to include mad footnotes in her research.

I am in a condition of perpetual departure, of journeying. The other is motionless, nailed to the spot, motionless, at hand, in expectation - like a package in some forgotten corner of a railway station ${ }^{2}$

vagabond $n$ wanderer or vagrant, esp. an idle or dishonest one ${ }^{3}$

The Chinese Detective incorporated the image of the woman in the scarlet dress into the design of a series of postcards. At the Shanghai railway terminus, she posted one to Daisy Bloom. On it she inscribed nothing. For Li LiLi the story had already taken place.

According to the critic, the structural confusion of the narrative is generally regarded as its main stylistically weakness; yet he insists that its charm lies precisely in its rather bizarre arrangement in which a list of 'awful things', for example, is followed by an account of a Yuenu swordswoman teaching the Imperial Army, after which comes an apparently unrelated incident about the Czech refugee crossing Siberia sixty years ago (Are you following me?) and then a short, lyrical description of a thin fall of snow.

Disassembled by desire, Li LiLi laughed, her raucous ghost laugh. She dogged the characters who most loved reading texts by Hanif Kureishi and Kazuo Ishiguro.

114 It is delightful when there has been a thin fall of snow

It is delightful when there has been a thin fall of snow; or again when it has piled up very high and in the evening we sit round a brazier at the edge of the verandah with a few congenial friends, chatting until darkness falls. There is no need for the lamp, since the snow itself reflects a clear light. Raking the ashes in the brazier with a pair of fire-tongs, we discuss all sorts of moving and amusing things. ${ }^{4}$ 


\section{The train}

All life's serious journeys involve a railway terminus. ${ }^{5}$

The train was already in motion. Ignoring the perversities of railroad travel, Li LiLi departed Shanghai. Other passengers suspected that she was not really Chinese at all. She was no amateur detective. She smoked cigarettes and searched for traces of Eugene Kafka. (You might scoff, but now that I have your attention, where do you think this train is going?).

The narrator followed a man she met on a boat. She disguised herself and followed him around the $\operatorname{deck}(\mathrm{s})$. Sometimes she followed complete strangers. Li LiLi once photographed writing and objects in a hotel room in Beijing. The room had been momentarily unoccupied by Sophie Calle. If you think that you are being misled, I assure you that I am utterly trustworthy.

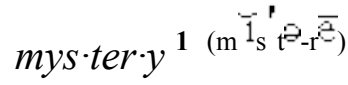

1. One that is not fully understood or that baffles or eludes the understanding; an enigma: How he got into the plot is a mystery.

2. One whose identity is unknown and who arouses curiosity: The scarlet woman in the photograph is a mystery.

Daisy Bloom wrote that she thought that she (Li LiLi) was skating on thin ice.

Li LiLi responded, 'You are fictional.'

Neatly folded on the top of the case was a thin scarlet silk kimono embroidered with dragons. ${ }^{6}$

Daisy Bloom went to the market to buy more silk, lots more silk. ${ }^{7}$

The younger girls are soaking the cocoons in boiling water until the silk threads loosen. It's one of the most important jobs here. They have to find the main thread from which the entire web of silk is unravelled. ${ }^{8}$

In one of Li LiLi's photographs, Daisy Bloom is seated in the university boardroom below a portrait of Marx. She is wearing Armani sunglasses. Opposite her, the Chief of Police is seated under Lenin. The chair under Stalin is left vacant. The Chancellor is seated in front of the window. Daisy Bloom's whiteness is ghostly. The photograph became lost in the digital ether, sent but never received. The Chinese Detective was preoccupied, leaping the barriers between art and history. 


\section{Star-crossed lovers}

'When I love, I am very exclusive,' Freud says. Barthes takes Freud here to be the paragon of normality. Who am I to argue?

At times, Daisy Bloom felt that she was in a critical theory nightmare. She compiled a List of star cross'd lover on film. She thought that there were ice-skating scenes in both Pushkin's Onegin and Tolstoy's Anna Karenina.

language $n 1$ (U) system of sounds, words, patterns, etc. used by humans to communicate thoughts and feelings. 2 (C) form of language used by a particular group, nation etc.

The Students continued to create their own language: Her feet covered many cocoons; He stood there, dumb as a wooden duck; bookhouse (library); epidermis (the exterior of the Freud Museum); waterdown (waterfall). At the Buddhist temple, Li LiLi lit a cigarette and photographed the signs that demanded No Burning (No Smoking) and No Photoing. One of The Students described her family to Daisy Bloom as 'fragrant.' Daisy Bloom desired this adorable language. She proved unable to learn it. Outside the train station, she sat down in the thin snow and wept.

$\mathrm{Li}$ LiLi rode downtown on the gong gong qiche past the barber shops where the prostitutes peered from behind lace curtains. She played mah jong with the ancient Mr. Wang. She was West and he was East. She tried to concentrate on the little ivory tiles. Mr. Wang curated the (former) Ohel Moishe Synagogue, north of Suzhou Creek. He had been expecting her.

From time to time Daisy Bloom forgot about the roman policier. Li LiLi photographed the hotel rooms of absent guests in the wildly art deco Guojin Fandian Hotel. She did not consider life as a narrative, but more as a putting of accidents in order. She had not lived according to some comprehensive plot.

\section{Tobogganing without snow}

In Anna Karenina ${ }^{9}$ the tragically shy Levin went to the pond in the Zoological Gardens in Moscow where Kitty was skating. He wanted to propose to her, but speechless or not, it did him no good. He was, however, an excellent skater.

So, it is rumoured, was Lenin. He forced himself not to be distracted by his twin passions for night skating and Latin.

\section{November St Petersburg 1891}

Horse-drawn sleighs are skimming along the glassy highway of the Neva, today the busiest thoroughfare in all (St) Peter(sburg) .... With my skates on, I have been able to move from one end of the capital to the other at the speed that only a steam locomotive could exceed. ${ }^{10}$ 
In another of Li LiLi's images a man is walking a dog along Green Street in Soho, New York. It is snowing heavily. In the foreground two people are walking, leaning forward, arms crossed, heads bowed into the wind.

One day, when the snow lay thick on the ground and was still coming down heavily, I saw a woman in a red qipao who had a fresh complexion and a pleasant, youthful look. Her beautiful, crimson- purple coloured coat, which she wore over the scarlet costume, brushed the ground as she walked. The dark purple garment stood out startlingly against the white snow. I could see her under-jackets, dyed scarlet and a beautiful rose-yellow. She had opened her umbrella, but since it was very windy the snow came at her from the side and she bent forward slightly as she walked. The sparkling white snow covered her feet all the way to the tips of her lacquered leather shoes.

Daisy Bloom began reading Anna Karenina again from the beginning without skipping the characters who appealed to her least.

Li LiLi photographed objects in the Gongti Hotel. In Room 204 she accidently shot a body.

\section{The swordswoman of Gongti}

We saw swordswomen jump over houses from a standstill; they didn't even need a running start. ${ }^{11}$

Li LiLi practised a form of gong $f u$ sword called Yuenu. It was invented by a woman who was also called Yuenu.

When I could point at the sky and make a sword appear, a silver bolt of sunlight, and control its slashing with my mind, the old people said I was ready to leave. ${ }^{12}$

By the stone bridge Li LiLi learned Spinning Sword, Parrying Sword, Resting Sword (thrust), Raised Sword, Hacking Sword, Uppercutting, Intercepting (left and right), Tilting Sword, Upward Chop, Spin Sword and Sweeping Sword. She practised thrusting until her heart hurt.

\section{The art of stories $^{13}$}

'The art of the catastrophe calms me down. ${ }^{14}$

\section{Cryptic crossword clues}

Clue: depressed as a duck after preening. Answer: down in the mouth. ${ }^{15}$

Clue: it turns into a different story. Answer: spiral staircase. ${ }^{16}$

Clue: $(1,6,1,4)$ Answer: I haven't a clue. ${ }^{17}$ 


\section{The poetics of Chinese pharmacology}

The vendors also came, one after another, old women with herbs that could cure any ailment, from the physical to the emotional. They carried everything in glass jars, and measured the dark twigs and dried leaves into white pieces of paper folded neatly into perfect squares. ${ }^{18}$

The instructions on the packet of capsules that Daisy Bloom acquired from the well lighted pharmacy in Jiefang Lu sugested that: 'To take the capsule can nourish blood, moisturize yin, and nourish heart and quiet spirit. Distinct effects for neutral nervous system in repressing, calming, pain-settling and anti-fright reversal. The medicine can settle the following symptoms:

- insufficiency of yin-blood, insomnia and

- over-dreamingWeakening memory, heart

- palpitation Vexing heart in five hearts,

- night sweating and tinitus.'

'That's it,' thought Daisy Bloom, 'anti-fright reversal is what I need'.

Li LiLi steals the letter of the body, leaving another in its place. Lacan is puzzled.

From where does this terrible fearfulness come? If, as Freud says, my symptom speaks, then what is it trying to say?

\section{Desire}

In spite of it all, Sei Shonagon insisted that when a woman lives alone, her house should be extremely dilapidated, the mud wall should be falling to pieces, and if there is a pond, it should be overgrown with water-plants. It is not essential that the garden be covered with sage-brush, but weeds should be growing through the sand in patches, for this gives the place a poignantly desolate look.

She was fond of telling both Li LiLi and Daisy Bloom that she greatly disliked a woman's house when it was clear that she had scurried about with a knowing look on her face, arranging everything just as it should be, and when the gate was kept tightly shut.

The art of stories calmed Daisy Bloom.

Li LiLi always thinks of Marco Polo as 'the Italian Interlocutor' but is always misheard as saying 'Italian Interloper.'

Daisy Bloom began A list of Chinese culinary moments.

Mao apparently studied at night under a street lamp.

\section{From the skies}

Two people fell from an Air France jet (a Boeing 777) as it was preparing to land at Pudong airport. The two falling bodies crashed into a small village in Nanhui District, 
one in an orchard and one through the roof of a house. 'It's so frightening. I could not fall asleep,' said Ding Xiaolin, 80, who was cooking in her kitchen when a body fell through the roof and landed beside her. ${ }^{19}$

non-sequitur $n$ (Latin) statement that does not follow logically from the previous statement(s) or argument(s).

\section{The most splendid thing}

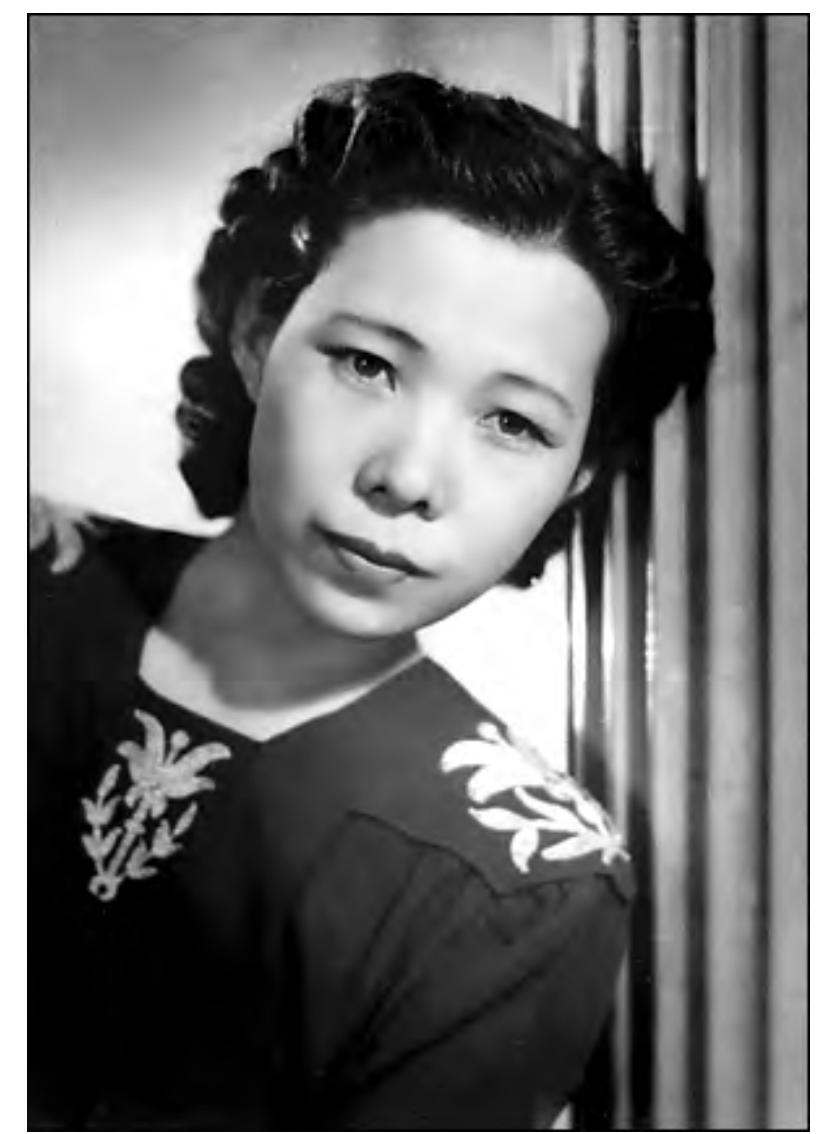

Yukiko

Li LiLi always slept soundly.

\section{Endnotes}

1 Rewritten from Barthes, Roland 1978 A lover's discourse, New York: Hill and Wang, The Noonday Press, 20. (Somewhere between Lacan and Proust)

2 A lover's discourse, 13 (A wilful misquotation)

3 Oxford advanced learner's English-Chinese dictionary 1989 (4 $4^{\text {th }}$ Edition), Oxford: Oxford University Press/The Commercial Press, 1677

4 Shonagon, Sei 1986 The pillow book [around 1000], Ivan Morris (trans and ed) Middlesex, New York, Auckland, Ontario, Ringwood: Penguin Classics, 184 
5 Wilde, Oscar (played by Stephen Fry) to Lord Alfred 'Bosie' Douglas (Jude Law) in Wilde (dir Brian Gilbert, 1997)

6 Christie, Agatha 1994 Murder on the Orient Express, Beijing: Beijing Foreign Languages Press (Not for sale outside the People's Republic of China)

\section{The story of silk}

It began with the difference between Japanese and Chinese gardens or the problem of how to add colour to shade. It is also the story of how Marco Polo left Venice and mysteriously found himself in Suzhou.

\section{Marco Polo comes to Suzhou.}

One of his travel companions - a botanist - meets a beautiful Chinese woman in one of the gardens of Suzhou. They have a daughter who is rejected by the Chinese community. Polo and the horticulturist return to Italy - Polo to Venice and the horticulturist to Florence. The daughter, whose name means 'silk', becomes a concubine and has a daughter also. Female descendants of the botanist's daughter become 1) a female banker in Shanghai and 2) a revolutionary.

A female descendant of the Florentine botanist migrates to Australia in 1945 and settles in Adelaide. Her daughter becomes and academic and writer who moves to China. Here she meets a successful female silk merchant who lives in Shanghai but who was born in Suzhou.

\section{Peony}

The silk merchant's name was Peony. She had travelled the world selling her silk. As a younger woman she had studied textiles in New York even though the United States did not, she felt, understand silk. It is the touch that counts, the lightness and texture of the cloth. She fingered her forehead frequently, kneading it furtively when stressed or worried.

8 Tsukiyama, Gail 1991 Women of the silk: a novel. New York: St. Martin's Press, 37

9 Tolstoy, Leo 1960 Anna Karenina, Joel Carmichael (trans), Toronto, New York, London, Sydney: Bantam Books

10 Brien, Alan 1987 Lenin: the novel, London: Secker \& Warburg, 74

11 Hong Kingston, Maxine 1989 The warrior woman, New York: Random House, 19

12 The warrior woman, 33

13 Hypotext/hypertext: The pillow book (the film), Peter Greenaway (1996)

The pillow book (the film) begins with a Japanese mother reading to her daughter Nagiko who is in bed. On Nagiko's face is a 'birthday greeting' written by her father. Her father has written her name on her face and his signature on the nape of her neck. Her mother reads to her Section 150 of Sei Shonagon's The pillow book (the book).

'The Empress wore a robe of green Chinese silk. Beneath a Chinese jacket were five unlined robes. She also wore a skirt of ceremonial elephant-eye silk. I felt that nothing in the world would compare with her beauty.'

She says,' I will make you a List of Elegant Things'.

Chinese silk. Duck eggs. Shaved ice in a silver bowl. Wisteria blossoms. Plum blossoms covered in snow. A child eating strawberries. (Nagiko is seen eating a bowl of strawberries) Things that make one's heart beat faster (Nagiko has peered through a gap between the sliding paper doors at her father being fucked by his publisher). To sleep in a room where incense is burning.

Nagiko develops a lifelong passion for being written upon.

The grown Nagiko (played by Vivian Wu) says:

'I would fill [my book] with all manner of observations just like Sei Shonagon. Perhaps one day, like her, I will fill it with accounts of all my lovers.' 
Her mother continues to read Sei Shonagon's List of splendid things: Chinese brocade. An imperial procession led by the Empress. A large garden covered in snow. Indigo coloured silk. Anything coloured indigo is splendid. Indigo coloured flowers. Indigo thread and especially indigo paper.

Later in the film, Jerome (Ewan McGregor), one of Nagiko's lover's says, 'Write on me. Treat me like the pages of a book'. His publisher (who was also Nagiko's father's publisher) is impressed. He says, 'Copy that text'. In her List of Body parts she lists penises as 'pickled gerkins'.

He (Jerome) wrote on Nagiko in English, Hebrew, Japanese and Latin. She said, 'I would like to honour my father by becoming a writer'. 'I can help', he replied.

Nagiko writes on Jerome in gold ink.

14 A lover's discourse, 143

15 The cryptic crossword clue is Nancy Sibtain's all-time favourite. Quoted from Fiona Harari 'The Clue Room', The weekend Australian, 13-14 October, 2001, Review, 12

16 Will Shortz's favourite clue. He is crossword editor of The New York times

17 Taffy Davies, a former cryptic compiler for The daily telegraph, Sydney

18 Tsukiyama, Gail 1991 Women of the silk: a novel. New York: St. Martin's Press, 107

19 Zhu Yanyan, Zhu and Yi, Zhang 2003 'Air France deaths still a mystery.' Shanghai daily, SaturdaySunday 25-26 Januar, 1 


\section{University of Western Sydney}

\section{Gillian Barlow}

\section{Ruby}

Biographical note:

Gillian is a writer and architect living in Sydney. She recently submitted her $\mathrm{PhD}$ thesis which is a multi-disciplinary exploration of space/place anchored in her work as an architect working in the area of Aboriginal housing. She has just finished writing Ageing, Disability and Home Care's guidelines for designing group homes: accommodation for people who require up to 24-hour supported care. 
Let a picture of Ruby arise!

Ruby the DJ. Ruby who is slightly wild. Ruby, always rushing from place to place. Ruby, always with her finger on the pulse. Ruby with her wise intelligence. Ruby who, through the goodness of her soul, finally allowed me to be forgiven. Ruby who, having yelled and screamed at me, came and gave me a hug. Ruby who I used as an example in my less-than-wise years, in my desire to have someone else understand, in my rush to attempt to be a good boss.

I meant no harm, but that is, of course, a weak excuse.

I will need to live to an extremely ripe old age if I am ever to understand things, and things being as they are, time is not on my side. I am getting old. I am not that well. It is unlikely that I will understand much more so the few things I do know I feel compelled to write down.

These are parallel strands I will to plait together for you. Everything is interconnected. Housing begat health begat education begat employment begat ...

But let us begin at the beginning as I sit in my office, drifts of papers around me. Memos and memorandums and briefs. All marked CONFIDENTIAL. All accompanied by a pink cover sheet with explicit instructions on them. I have to task the people around me to remove these papers and to accomplish what is spelled out on the pink sheet. It is not for me to do the jobs anymore but for them. I find this hard because sometimes it seems to take them so long to finish what it is I want done, and I wonder if it is not better to do it all myself instead. I must resist. I am expected to have others do these things and for them to reap the rewards of doing this.

Each day I carry this and other thoughts home with me and then back to work the next morning. Sometimes miraculously overnight, just like the cobbler's elves, a solution comes to me. Suddenly, I know what to do or so it seems - or seemed.

I have done those things which ought not to be done and I have left undone those things that ought to be done and there is no health in us. But thou, oh Lord, have mercy upon us miserable offenders, spare thou them that confess their faults.

I am hoping that the mere act of confessing will buy me the indulgences I would so like, to free me from this guilt and shame. But it is a gamble. I cannot take the high and mighty ground. ${ }^{1}$ I have no excuses. It is mine alone. ${ }^{2}$

I did say it. I did say it about someone else. Ruby. Let's call her Ruby and in a way that is her name. As I said it, I waved my hand and said, 'So, let's take - ahhh, say Ruby'. And in that wave of the arm, I made my unmaking. The woman seated in front of me started a little. Or is it that I see her start now as I think back on things. Her attention pricked up at least and she settled back into her seat. She adjusted her hands in her lap. They no longer lay open. Snap. She shut them tightly. Snap. She had me or so she hoped. The corners of her mouth twitched. Listen now. Listen. She said it to herself internally, but, in looking back now, I see her lean in ever so slightly.

'It is not that it is bad as such ...', I was saying, but I was thinking, 'It's awful. Your writing is awful. I don't know how or why we got you to do this. It is clearly above, beyond, you. You are way out of your depth'. And while I was saying the one thing and thinking the other, I was failing to think about what it was I was wanting to say. I 
need to remember this for future. I joke, but mean, that I have a slow IQ not a low IQ, but in explaining my guilt, and hence shame, I am also demonstrating here what it is I mean by this statement.

'It is not that it is bad as such ... but it is very ....'. And the words failed me. I was still thinking that it was awful and my mind was racing around banging into things trying to move them aside so I could get to the one that would best explain to her what my problem with her writing was. Was the problem even with her writing or what it was she was saying? My mind was racing around too fast for me to even note with any precision what it was that I was trying to do. Mainly my mind kept grabbing at something I don't even believe in, but it must have some sort of resonance with me since it was still lodged in there. Mainly my mind kept bumping into 'Show, don't tell. Show. Don't tell'.

Meanwhile she, and this 'she' is not the Ruby I have mentioned at the beginning here, she, and perhaps we should call her Theresa, because although that is not her name she seems to me like a Theresa, meanwhile Theresa had run with my hesitation and said somewhat breathlessly, 'Yes, yes, I am used to writing for university and I did find this type of writing hard. I get very good marks on my university essays and things. I get only HDs'.

My heart fell for just a moment for now I was stuck on a number of fronts. I now had in the mix that I needed to alert her to the fact that I had a number of degrees, including higher degrees including a whole lot more education than her and I needed her in her place. I had way more things than she could ever do. I was feigning humbleness and retiring, but I could do superior as well if that's what she wanted. This dimwit who couldn't write was boasting to me about how great she was. How the university (which one??) thought she wrote well. What sort of faculty was she in that could think that what she wrote even made any sense? She didn't even get it. I had asked her numerous times to do this report and here it was (again) the tenth time and it still made no sense whatsoever. How could I ever get her to get it?

And so here it comes, I said, 'So let's take Ruby. Let's write this as though it were for Ruby. She's a good one to take because, although she's not stupid by any count, this isn't her area of expertise. She knows nothing about this. You will have to keep it simple. Simple not simplistic'.

Smug. I felt smug. I felt I had explained everything extremely well. I had been clear. I had 'shown' not 'told'. I hadn't let my centre go and say what it was I had achieved and gained. I had been quietly superior. I had shown her alright.

Theresa rose from the seat, picked up her ridiculous unreadable report and left my office. If I hadn't been revelling in my smugness, in my superiority, I would have noticed that she left with a slight skip - a lightness in her step that, if I had been noticing anything at all except my sense of righteousness, would have alerted me to things. I was seemingly oblivious, but uneasy. ${ }^{3}$

A hush and calm, always an indication of something awful about to happen, now occurred. The office hummed on as it ought to with people busying themselves at their desks. The sounds of computer keyboards being tapped. Quiet conversations between comrades. A printer's whirr. I had things to do. From my office, I watched 
the general office busyness on the other side of the glass wall partition. I was glad that I had had removed the large masculine painting that once hung in the middle of the main wall. I no longer felt so crowded in.

At an early age before my youngest brother was born, my other brother and I had been left in a beach house for a bit by ourselves while our mother picked up our father who was arriving by train from the city. We were playing to see who could stay the longest in the small wooden wardrobe before having to get out. My brother had stayed in for the count of one hundred and seventy six before beating on the flimsy door to let him out. It was now my turn again and I stood in the small dark place counting out loud for both me and him because his counting was more erratic than mine.

I easily reached and then passed two hundred. 'Now!', I called and banged on the door for him to let me out. I could hear fumbling at the lock. Then it stopped. 'Let me out now,' I called. Again there was fumbling at the lock, a scrapping of metal against metal. 'NOW', I shouted, asserting some authority, for my time was way over his by far. 'Let me out NOW. NOW.' The darkness moved one step darker and closer. 'Let me out. I want to get out.' I started pounding on the door. Maybe he hadn't heard. 'Let me out. Get me out.' My panic infectious. The sound of the key in the lock turning this way and that, wobbling of the key, some further wiggling of both the key and the door. 'Let me out. I wanna get out.'

Finally my brother answered in a small voice, and he KNEW this was against the rules of the game, that he had locked the door. Somehow now the key wouldn't work any more. He knew this wasn't right. We had agreed at the beginning of the game, as soon as mum stepped out the front door, that we would play but you weren't meant to turn the key at all.

Now I was panicked and angry. 'We promised not to turn the key. You said you wouldn't. Let me out NOW. I'm going to die I haven't enough air. Get me out.'

My brother, too, was panicked but quiet. We'd both agreed that we wouldn't turn the key. It was our favourite game, yet mum had not wanted us to play it. She wasn't at home, which is why we could play.

She's going to die. Oh my god, she was going to die. The key slipped loose in the lock. He wobbled it up and down. Inside the cupboard his sister was jumping around like a lunatic shouting and screaming, crying, bashing on the door, the walls, jumping up and down inside the locked cupboard. Mum would never be home. When she did get back, whoa, would he be in trouble. What should he do? He could run away. He could pretend that she had gone out somewhere - but it was mighty difficult to pretend there was no-one else here, with all the bashing on the cupboard doors, the screaming, the crying. Maybe she would stop soon. What was he going to do? How could he get out of all this. Oh my god. If she would only stop for a bit, he would get a chance to think about it. Perhaps it was the wrong key. He took it out and looked at it again, turned it around the other way, slipped it in, wobbled it up and down. Oh my god. Took it out, noticed the key on the other side of the cupboard, swapped them over - nothing working, screeching and crying, bashing of head against the inside of the door, 'Let me out, let me out. I'm going to die. I'm dying'. 
The cupboard was almost leaving the ground with the force with which she was jumping around inside.

He could leave, there was still time to leave. Would anyone notice? The key didn't work. The key couldn't work. He could take the key out and walk away. He wondered for a second.

For the rest of his life he would do just that. When the situation got to too desperate, he would take the key out of the lock, stride across the room, drop the key in the garbage bin, walk to the door, take a quick look around, then close the door and walk on, never even hearing the bashing from inside. Not the screams. Not the crying. Not the splintering of wood.

I, on the other hand, found it impossible to sit for any time in places where I couldn't see out, where there was no obvious means of escape. Even in traffic, sitting behind a large vehicle, I begin to feel edgy, have an urge to overtake and get out from behind the situation. It doesn't matter that I might be taking a risk, anything is better than not being able to see fully what is in front of me.

So I had the painting, which had been hung smack bang in the middle of the glazed partition in order to stop straying eyes and protect my privacy, removed. I had hated it when it was there, but then later admired it when it was hung in someone else's office. With it gone, I could look up from my computer screen or from written material on my desk at regular intervals as prescribed by any ergonomic guidelines and focus on some distant object and rest my eyes for a bit.

And me in the cupboard?

My mother and father returned eventually. Cheerful, as they entered the house, they were propelled into action when they heard banging and crashing coming from the small second bedroom at the back of the fibro beach house they had rented for summer holidays. My father dropped his overnight suitcase at the front door and raced out the back. Asking no questions, he turned the key in the lock, knowing how to engage its strange shape in the old lock as required. He did it with comparative ease and opened the door.

I stepped out. We continued our holiday at the beach. We never played the game again, never placed anything in the cupboard for any reason, never spoke of what happened. I have never liked being enclosed in any confined space and I don't know how I might behave if I was to find myself in similar circumstances again. ${ }^{4}$

I sat now in my office with nothing much to do. A hush came over the place. The director entered my office, holding a typed piece of paper. She sat down. She is an incredibly beautiful woman, daunting in her elegance. Her skirt fell around her crossed knees like only an expensive well-cut garment can do. Her shoes were almost new and clean and polished.

'I'm afraid ...', she said and then looked nervously away. 'I'm afraid there is a claim of racism against you and you will have to go to mediation. Don't worry', she followed up quickly, 'this happened to me once'.

Nothing else can now be heard. There is a clanging of the universe, a ringing. I am standing within the bell itself. The whole world is vibrating. Golden metal surrounds 
me. I am small and timid within its confines. The tower of London. The tower of Babel. There is nothing else. I am in there enclosed, unable to get out, beating on the door, crying, screaming.

'Go and wash your mouth out with soap.'

There is nothing more. I am too small to be seen. ${ }^{5}$

I used to be a contender. I used to feel I knew what I was doing. I used to believe that maybe somewhere somehow I belonged. And then I didn't.

It speeds up from here. Next Ruby is pounding the desk in my office, shouting at me. 'How dare you! How dare you!'

I am trying to explain, but there is no-one around to listen, even if they would.

Then I am sobbing at my desk. I can close my door, but not everyone else can, and it means nothing to them. No-one turns to look at where the sound comes from. Everything is as usual out in the office, as they all busy around doing what they ought.

Everything as usual, everyone doing as they usually do, except the thin, scrawny one. Suddenly she is in my office with me, her arm around me saying she believes me, she believes in me. It can't be so bad. What is it? What can be so bad?

And I am explaining to her and saying again and again, 'I didn't mean it'.

Saying, 'I chose my words carefully'.

Saying, "I said "simple" not "simplistic".

And she is nodding and ah-ha-ing and taking it all in. She leaves and returns with a box of tissues and a cup of tea.

'Sit down', she says, she is saying.

'I do the records, you know that', she says, is saying. 'The records for the Stolen Generations.' She is wiping my tears and nodding as she tells me this.

'Do you know what word they used time and time again about each child as she or he was assessed, having been ripped away from their mother and family and all the world that knew?'

'I know you were trying to say something particular. I know you didn't mean anything more than what you were saying. But to others, to Ruby, to me, it means so much more. There is a history stretching back to the first invasion with that word. People locked away. People shot. People stolen from their families - because they didn't speak the same language, didn't value the same things as the strangers who had moved in, because they chose not to be so materialistic and didn't invest in all those materialistic things. We don't take those words so easily.'

\section{Endnotes}

1. ' 1 said, "All along I have been wondering how you got to be the way you are. Just how it was that you got to be the way you are."” (Kincaid 1990: 41) 
2. 'I said it again. I said "How do you get to be that way?" The anguish on her face almost broke my heart, but I would not bend. It was hollow, my triumph, I could feel that, but I held onto it just the same.' (Kincaid 1990: 41)

3. The whole thing had an air of untruth about it all; they didn't mean to do what they were doing at all. It was a show - not for anyone else's benefit, but a show for each other. And how did I know this? I just could tell - that it was a show and not something to be trusted. (Kincaid 1990: 47)

4. I was lying there in a state of no state, almost as if under ether, thinking nothing, feeling nothing. It is a bad way to be - your spirit feels the void and will summon something to come in, usually bad. (Kincaid 1990: 121)

5. One day I was a child and then I was not. ...One day I was living silently in a personal hell, without anyone to tell what I felt, without even knowing that the feelings I had were possible to have...' (Kincaid 1990: 136)

\section{Works cited}

Kincaid, Jamaica 1990 Lucy, Farrar, Straus and Giroux, New York. 


\section{University of Sydney}

\section{Robyn Ferrell}

\section{Whitefella worship}

Biographical note:

Robyn Ferrell is a Sydney writer and philosopher. Her most recent book Sacred Exchanges: Images in global context was published with Columbia University Press in 2012. She is the author of several books of philosophy and creative writing, including The Real Desire (Indra Press, Melbourne, 2004) which was shortlisted for the 2005 NSW Premier's Award. She is a research associate in the Department of Gender and Cultural Studies at the University of Sydney. 
Four old Warlpiri women artists, and their daughter, granddaughter and greatgranddaughter, came down to Sydney from Lajamanu on the edge of the Tanami desert, for a workshop to paint their jukurrpa.

We set them up in a studio on the top floor of the College of Fine Arts, with a deep balcony and a view to the harbour. They had yards of Belgian linen, litre bottles of acrylic paint, brushes and bamboo skewers with which to make dots. They were paid by the hour and the resulting paintings they retain as a collection.

This research project invited them to share some women's business though painting some of their traditional designs for our instruction. This idealism was perhaps honoured more in the breach. My enduring lesson from this intercultural event was how we turned out to be whitefellas, with all the complicated responsibility and shame that should bring home.

How little I got to know them. I know they like chicken and chips, but not the trendy Portuguese type - 'Too spicy, Napaljarri!' - and lemon soft drink, and they did repeatedly ask to go shopping. Not an unnatural request when you're in the Big Smoke and you've just been paid.

I took them shopping to Bondi Junction, but the mall was overwhelming, with its five floors of fashion stores and a tower of moving escalators in the atrium. Myra wouldn't chance them, she remained marooned on the top floor and we had to rescue her via the lifts, which were out the back. Then we spent fifteen minutes, out on the street, waiting for a taxi that would pick up blackfellas.

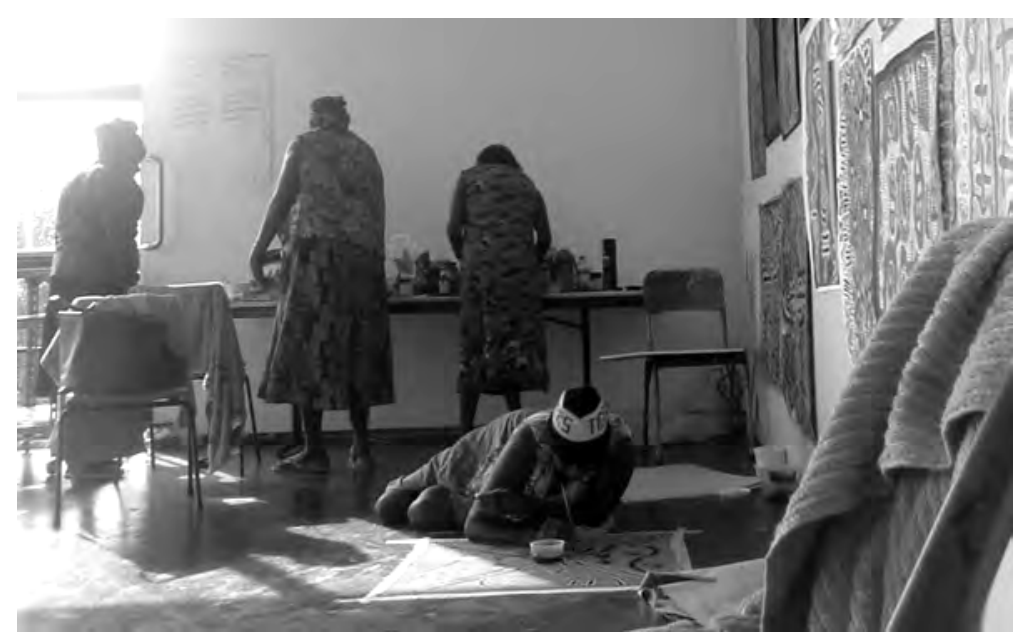


The studio space of concrete and glass took on a little of the look of a desert camp, with paintings unfinished being walked across on the floor, and tea brewed in a billy, and the quiet intentness of concentration going on in the middle of a parade of people walking in and out - to use the urn or the sink, to have a smoke on the balcony - and the tide of other obligations - to pick up the school-age children or pacify the toddler or move the cars so they wouldn't get booked.

We had plenty of kids, but no dogs, which I gathered was a short-coming. Lily told me about her dogs over lunch of chicken and chips, and she showed me on her tiny spindly calf how they would bite. She and Rosie told me about lots of other things that lunch time, but most of them in Warlpiri, and I repeated, as my contribution, 'I'm sorry I don't speak Warlpiri. I'm afraid I don't really understand'. Lynette said later: 'Them old ladies, they really funny. They been hit over the head too many times'. She said it with a classical Aboriginal dryness that makes me laugh.

We were given skin names to smooth the interaction with the Aboriginal group, names given by the old ladies. They called me Napaljarri, making me a grandaughter to Lynnette, an aunty-niece with Myra and Lily, and mother-daughter with Molly and Rosie.

My son was given the Warlpiri name Jupurrurla. His English name was, coincidentally, kumanjai - that is, shared by a relative who had recently died and was thereby subject to the Aboriginal mourning practice that the names of the dead not be pronounced. Protocol required he not be called by his 'real' name in the hearing of the Aboriginal people, because it may give offence.

This edict hurt me in an explicit but surprising way. I found myself cut off from a vocalising that expresses my special connection to this child, and which carries the practice of love. The effect was the feeling that my son and I were being separated, and I resented it viscerally. My hurt showed up in my inability to adequately pronounce 'Jupurrurla'. While I learned to say many other Warlpiri words, I could never say Jupurrurla without stumbling over it. This became an embarrassment, as I stumbled and Lynnette begged me to use his English name: 'Don't worry!', she cried.

This small experience hurt more than I would have credited. So I feel dreadful when I hear stories of the stolen children, who had their names changed so they would forget their mothers. They didn't. Instead, they cried themselves to sleep in dormitories at missions like the one at Moore River.

My son picked up on my affect, and complained that he didn't like 'that silly name', and didn't want to be called that. I tried hard to persuade him it was a cool thing, and a special honour, to have been given a real Aboriginal name, but he wasn't convinced.

It may have been the right thing nevertheless to insist on customary lore in this exchange, even though it hurt my feelings. Giving offence, or taking it, is a necessary risk when cultures meet. 
About many of my responses at the time of the painting workshop, I now feel unsure. We are used to taking our feelings as indicators of some kind of truth. This is an axiom, especially of feminist thinking, that I had previously inhabited comfortably.

But the workshop made me profoundly uneasy. Perhaps I had not expected to recognize all the feelings displayed by the artists, but I had expected to go on using the compass of my own.

In the event, I felt comfortable with the way Lynette and the others occasionally remarked on how they felt. Their affection, generously proffered, was easy to reciprocate.

But I couldn't account for my anxiety at what seemed to be extraneous and peripheral stresses. The heat bothered me, the tasks of amusing children while hanging out in the studio as a 'Chief Investigator'. I was uncomfortable 'in my skin', as they say.

Which is, on reflection, the most expressive I could have been. I felt uneasy in my white skin, for the many small ways in which the workshop, and our larger project, as an emblematic whitefella activity (knowledge acquisition) collided with 'the Indigenous Other'. Politely, thoughtlessly, self-servingly, well-meaningly.

And I was squirming in shame for all the ordinary white middle class habits that have made my body a white body in a postcolonial country.

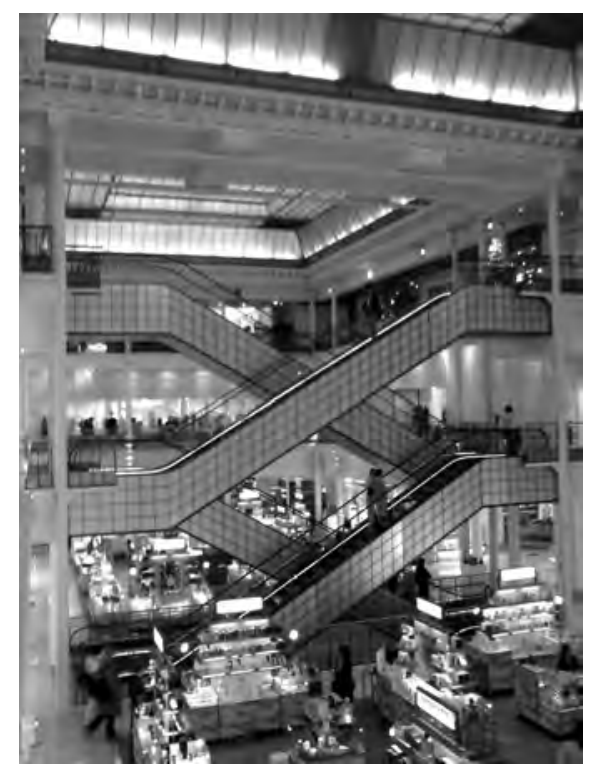

The department store is the Real World. In the department store I come up against what matters.

Those items that appear to me as desirable, even indispensable - the lipsticks, the clothes, the household accessories - define a world in which I am 'truly myself'; hence the urge to buy them and complete myself, express myself, satisfy myself. Not only what I want, but what I can become, if I only will hand over one bit of plastic for 
another. Not only can I put on a delicate shade of shell pink or a vibrant scarlet on lips or nails, but in doing so I can become the fashion-conscious urban woman that these practices signify.

I can buy 'my colours' at Bon Marché on Paris's Left Bank, and then go to marvel at other styles of living down the river at the Musée du Quai Branly. This is where 'cultures speak', according to the Musée's slogan.

I can't buy, at the Lancome counter, shades of ochre for my bare breasts, or white to paint lines on my brow. Make up is the real world, but body-painting is culture.

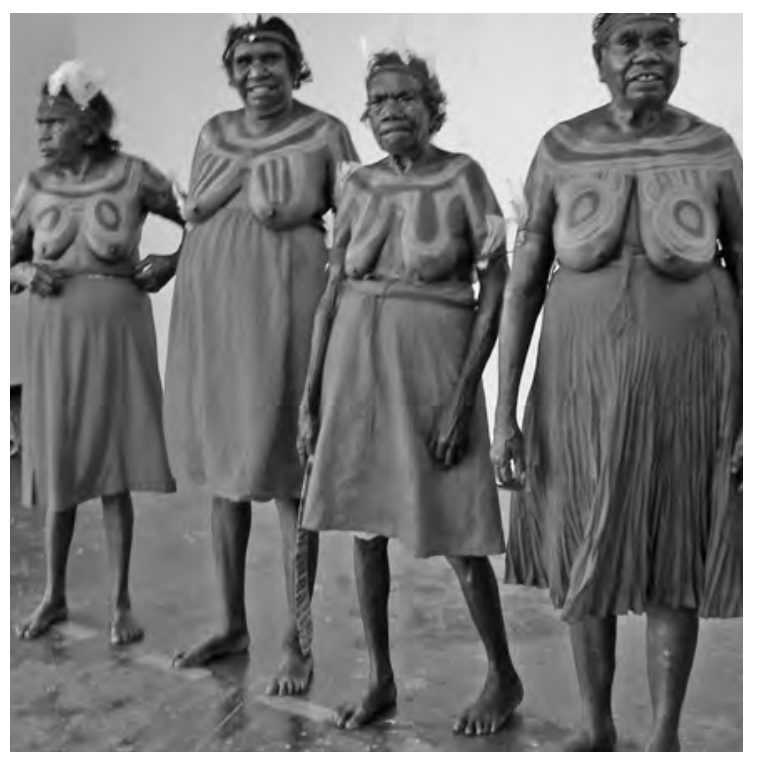

There is a setting where ochres on bodies can command a reality, and produce a world. In Aboriginal Australia, these things are full of meaning, they are 'being bearing meaning', as philosopher Julia Kristeva defines the sacred. Paradoxically, we don't find this hard to believe - the other is the sacred, cultures are other people's.

It's harder to perceive the process, of 'being bearing meaning', in ourselves. That's because it is the Real World that is the domain of the sacred, a literal worship of materialism that denies belief in any other world beyond it.

Despite the heat wave, the old women felt the cold, and they wore woollen hats the whole time they were painting. I wanted to give them a present that said a warm informal thank you, in keeping with their own relaxed reserve. I bought them each a beret at the department store where we went shopping that day, a perfectly absurd gesture marked somehow by the Indigenous art museum that had recently opened in Paris, and had made such a feature of Aboriginal work.

The old women wore them and seemed pleased, but I don't know what they thought of this gesture; whether they thought 'Eurocentric' or 'naïve' or 'that girl mad' or 'a handy hat'. I didn't find out whether they wanted hats, or cared about appearance or felt they had ever been given a choice in these matters. I don't know what exigencies govern 
their wardrobe as they do mine (nothing that needs ironing, nothing that makes me look fat etc).

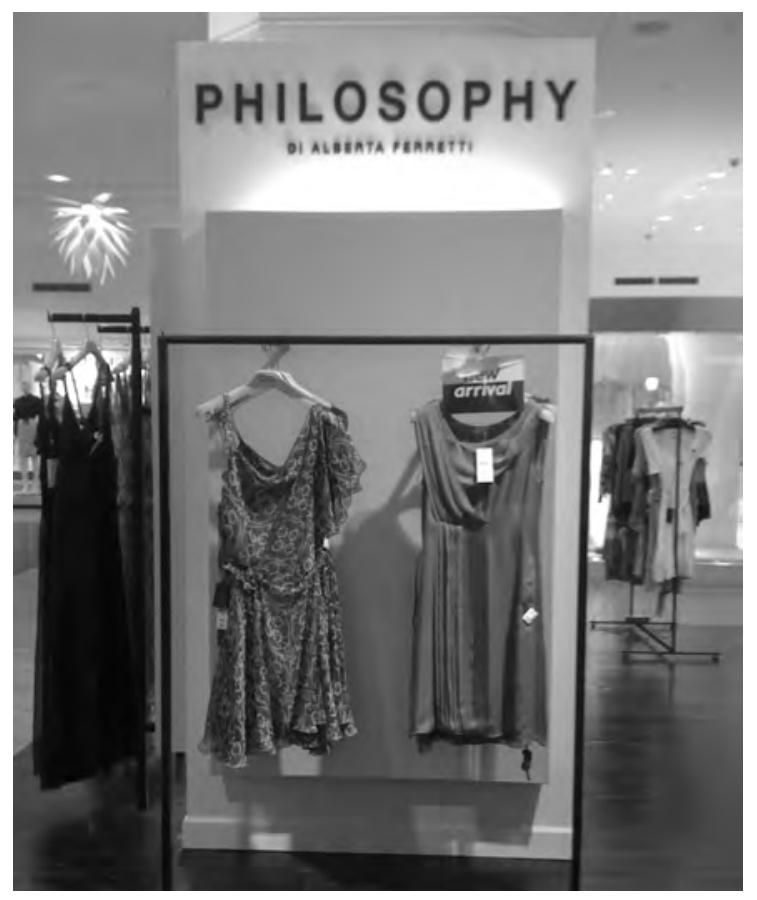

At Balgo, a remote Aboriginal community in the Western desert in North Western Australia, a group of young girls showed us their photographic exhibition, portraits of members of their family, mounted on the walls of the Cultural Centre.

Older Aboriginal people resist photographic images being taken of people, because of the way photos keep the dead hanging around. But the kids don't seem to feel like that. The Cultural Co-ordinator, a fashionable young woman fresh from a Melbourne art school, really had these girls engaged with photography and they were keen to photograph us, too.

They live as we all do in a world of magazine photographs and TV pictures, and if they feel part of the world beyond the small and troubled settlement of Balgo, it is because they are connected to it by images.

I arrived on an 'air art tour'. We had a professional photographer with us, too, who had come with the commission to photograph the Art Centre, and those of the painters who would agree, for a magazine article. The girls hung around holding the equipment and making up part of the scene, playing with the photographer's reflector between shots.

The image takes her momentarily out of the remote Indigenous world and into the world of fashion where her face is suddenly not shy but frankly beautiful, highlighted by the reflections of her impromptu hat. 


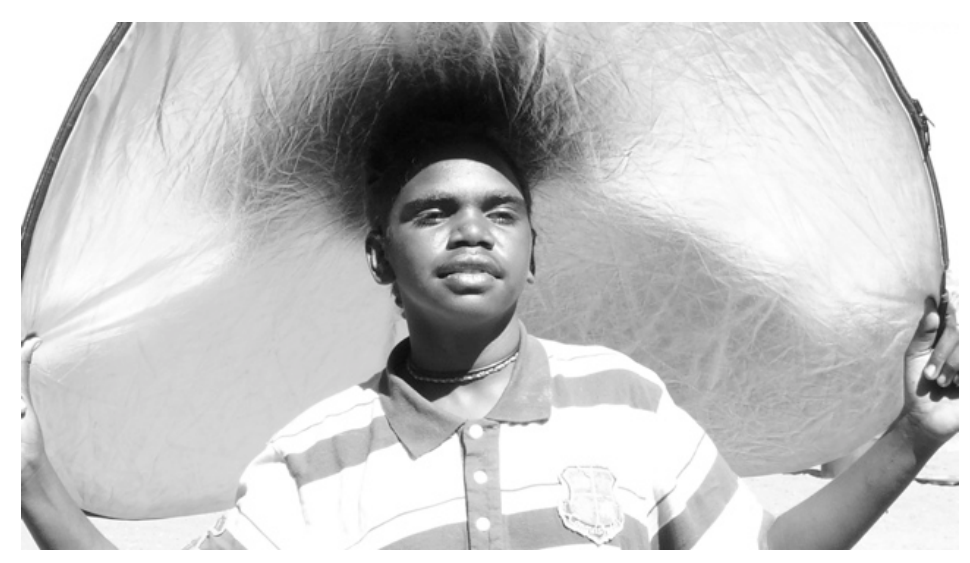

In Selfridges, I meet with philosophy. 'Buy me I'll change your life' says the billboard. 'I shop therefore I am'. I photograph them with my mobile phone, but I am aghast at having my inner life broadcast on signs hanging from the ceiling.

It is where I am least self-conscious that I am where things matter most. Where else can I 'lose myself for hours?' in pleasurable contemplation but when I am shopping? Unless it is when I'm watching the news on television, which scene I am wholly immersed in, believing it to be real.

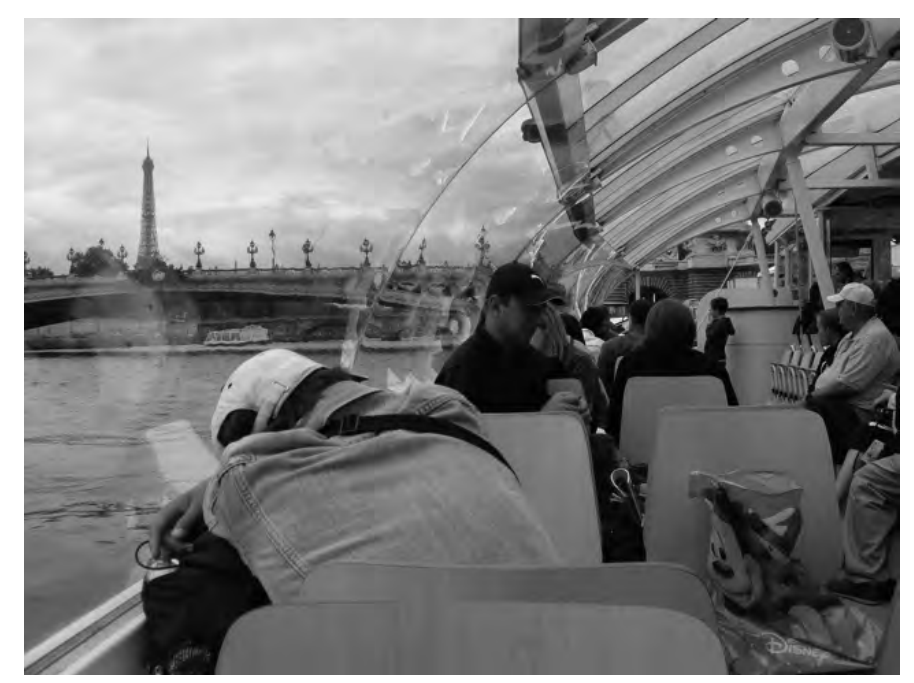

Cultural tourism is the Real World. The city of Paris is visible through the wavy glass of the Batobus. We are going down the Seine on the way to the Musée du quai Branly. The fatigued tourist, plastic Disney bag on the seat beside him, sleeps as the Tour Eiffel slides into view.

Paris acknowledges its place as a cultural curiosity in its tourism, where it plays the exotic other in a pan-American globalism. It's one commodity among many, but one that sells well. 
A 'river' runs through the musée, too; a concrete monstrosity in earth colours. The curation informs us that it refers to the flow of time. 'Vitesse le temps l'autre' flows ... the musée, the Seine, the Batobus, the flood of tourists 'hopping on and hopping off' all the way to Il de la Cité.

The trip ends near to the point of the embarkation of the 'martyrs', the Nazi victims who were crowded onto boats and shipped off to the camps. But they were not sightseers.

The Musee du quai Branly others the others, the third world or the first nations, as they are more politely known (but do we have a definition for the first world, second world and who is in each?)

You are either 'us' or 'them' in this scene. The French themselves feel othered, as their language is covered in an effluvial tide of Franglais from iPod to Barbie ${ }^{\circledR}$.

Perhaps this explains the remarkable muddle of this museum, its lack of cohesion, located where the imagination fails, where the image falls into - to quote Susan Sontag - sentiment, cliché or shock.

The musée advances a weird temporality that seems to miss any distinction between past and present cultures, and has no ear for what it translates. The signage addresses us in English, French and Spanish, although the museum is replete the day I visit with Japanese tourists, and is deaf particularly to the ticklish question of conquest, i.e. which cultures are no longer practiced because of colonisation (invariably Western).

If colonialism were to be imagined as 'The Empire games', then France came second, and the 'rest of the world' probably lost. The museum's booty is the French consolation prize.

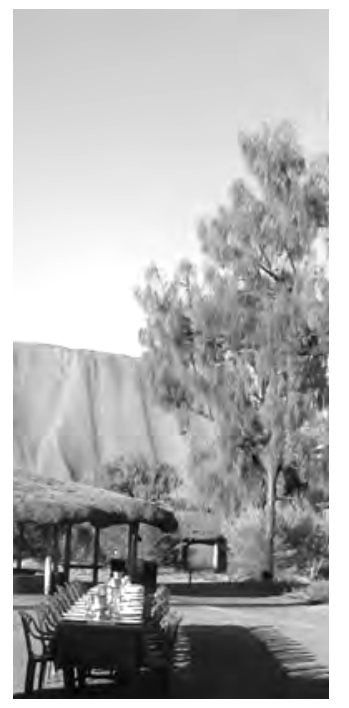


If you want a text for this, start at the Yulara resort at Uluru. The whole white worship is laid out with religious conviction, in the plan of accommodation. 'Desert Garden' for the upper middle class, 'the lost camel' for campers and backpackers.

Everyone flocks at sunset, like the devout to a shrine, to see the Rock. All around the country is implacable, and, left to their own devices, the tourists would have no chance against it, given the heat and the scarcity of surface water. The more you learn of how a culture has endured in the harsh exacting conditions there, the more you must admire its rigour and precision.

Repetition is its essence: to make an eye for detail and pattern the basis of survival. Everything is legible to those who know the signs, even though to the untrained eye the country seems monotonous, its forms of life inarticulate and mute.

The desert around Uluru, even if only seen from a minibus, is daunting. It's intimidating to think we could only survive there at $\$ 400$ a day ... The people who live there, and their ancestors, have slept on the ground and walked the distances that survival mandates in order to find foods in certain seasons, or water. Their 'dreaming' is rigorous, strenuous; quite literally a body of knowledge. And things about getting by in that world are known through memories of treks and songs, imprinted on the body by immersion in the country.

This is a landscape that is quite probably uninhabitable to a body like mine; if I were lost there, and thrown onto my own resources, I could not stay alive. The knowledge is communal, the memory a collective one. It is nowhere written down.

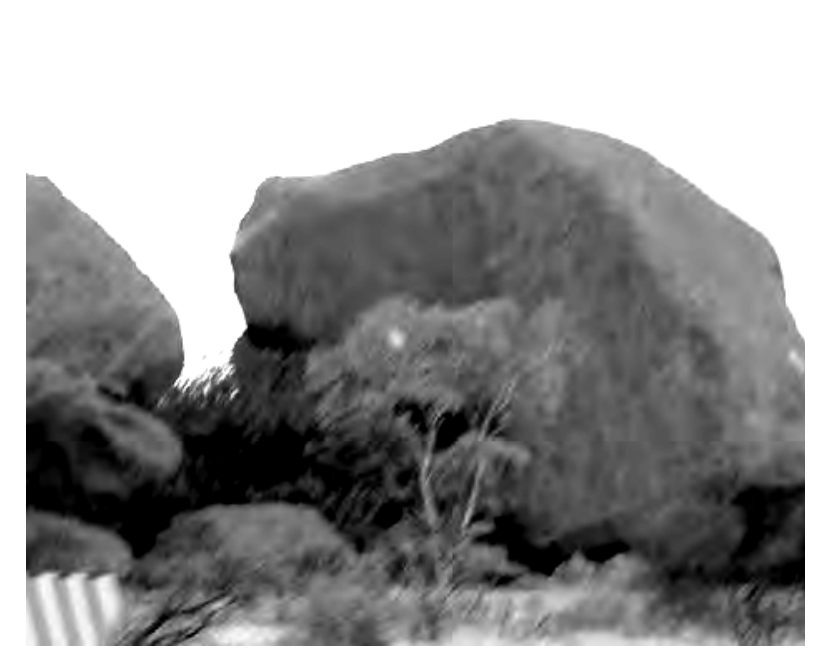

Around the base of the rock, there is a cave that is sacred to women, we are told. It is a birth site, apparently. 'The women love their dogs', says the guide, pointing to the rock that bears an uncanny resemblance to a dog's head, guarding the mouth of the cave. 
'But you don't get to hear much about it,' he says. 'Women's business really is secret', he puzzles, as though he has forgotten he is male and white, and that we are not in the vicinity of liberal individualism.

Uluru is a 'family place' he says, with six sacred sites around it, some for men and boys, some for women. The Anangu people respectfully request tourists not to climb the rock, but $65 \%$ do anyway.

Watching a movie in the cultural centre, I see an Elder woman dancing a traditional dance with breasts painted up. The audience, of ordinary Aussie blokes, snicker and mumble obscenities to each other. Of course, they have happened upon one of their deepest taboos, one of their sacred sites, sex and the breast.

In the cultural centre they encounter cultural difference and they can't help themselves, they have to jeer and ridicule because this is men's business. Their girlfriends sit watching the film in embarrassed silence, also in keeping with their custom.

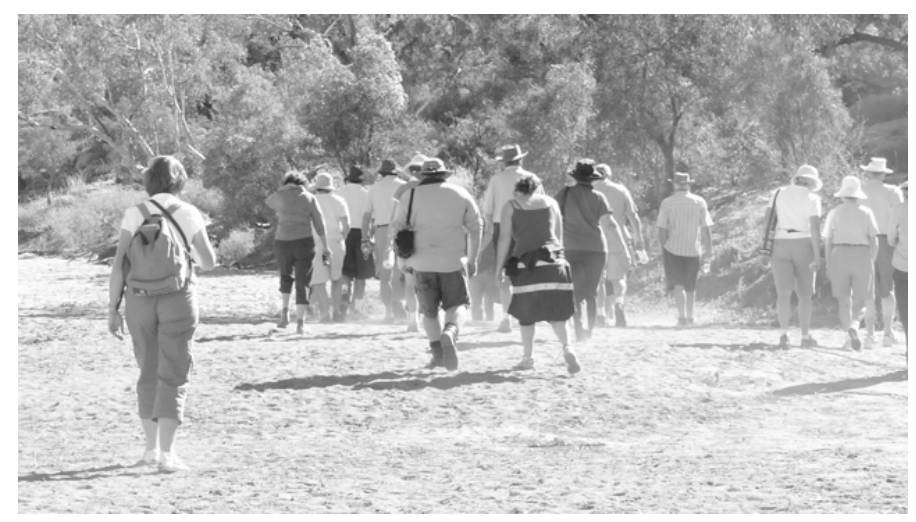

The modern urban subject desires to save wilderness, respect other cultures and know something about art, going to galleries, buying 'fairtrade' and voting green. The three belong together in a secular landscape, denuded of other forms of sacrament. Ecotourism is whitefella worship.

This mob are off to see bush tucker with Gus, the Aboriginal guide. His group, the Bunuba, own the business that steers tourists down the Fitzroy Gorge, in the Kimberleys, past the freshwater crocodiles, to alight on the river beach and struggle up this hill.

It's a warm day and some of the women have worn the wrong shoes. It's not comfortable, but it's required of you when you're a tourist, to submit to this discipline, including the bad mother-in-law jokes peppering the commentary. Gus tries to make Indigenous kinship practices relate to modern suburban life by equating men's business and women's business with the lore of the garage and the kitchen.

Sexual difference is different in every culture, but in Fitzroy Crossing it is epitomised in the dilemma of alcohol. The Aboriginal women there petitioned the government to 
restrict the sale of take-away booze. It caused a dramatic decrease in the number of local Aboriginal men incarcerated.

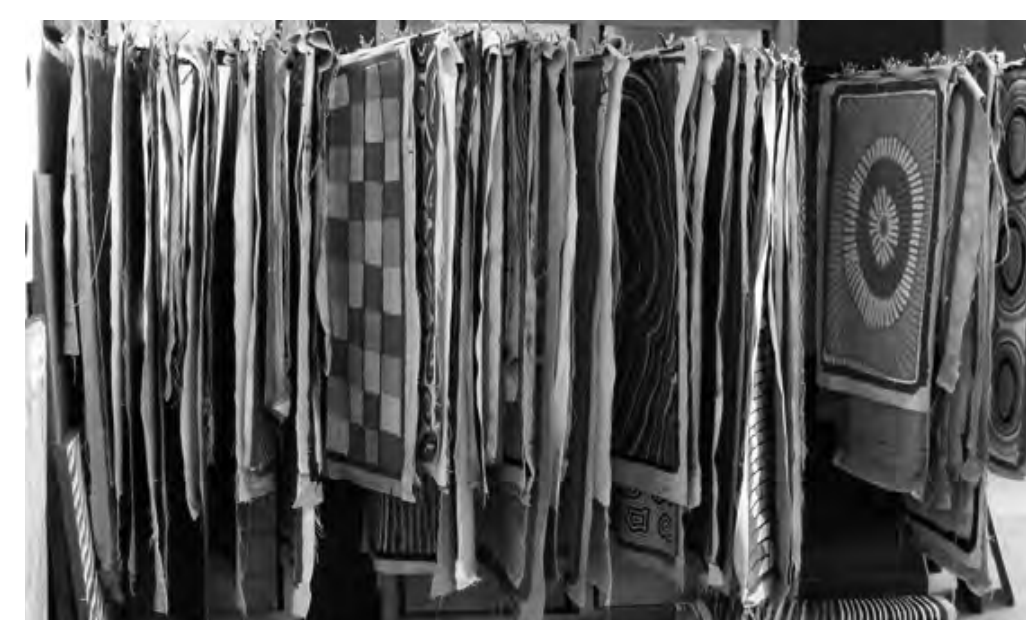

According to anthropologist Jennifer Biddle, the point of Desert women's painting is to 'make a mark' - a physical pressure or imprint on canvas, in the same way that the kuruwarri designs were traditionally made on skin. In doing so, the signs evoke the imprint on country of the ancestors' actions; the fires, the dancing, the food, the fighting.

The marks of these paintings are designed to produce the experience of being in that ceremony in that country, keeping the continuity of the Dreaming acting in the present. And this matters now, more than ever, with the exile of the traditional owners of the country, their care confined to canvas where before they would have been 'looking after country' in the flesh.

For the women, there is a specifically 'breasted' way in which to view their attachment to country; the ceremonies that the kuruwarri refer to are dances in which breasts are painted up and move in rhythm, conjuring the attachment of all to the land like a suckled child attached to its mother. This is a very different view of culture and place from the Western model of land ownership, but through the painting, there can be a magical extension of the Aboriginal world.

'Country' is evoked for the viewer, even for the uninformed, by the vivacity of the surface itself. The spectator can enter country not so much by viewing, as by touching with the eye, its rhythm, colour, texture and contour.

The sacred nature of these canvasses is embedded in the experience of viewing them. This is why Emily Kame Kngwarreye, when pressed by Christopher Hodges to describe what a canvas depicts, replied: 'You know'. The Dreaming is communicated directly in the feeling for the work. 
'A building, a Greek temple, portrays nothing', philosopher Martin Heidegger tells us in The Origin of the Work of Art, and yet it 'encloses the figure of the God ...'

Heidegger describes the fabrication of the world as an inherently aesthetic event. He draws on architecture, and not painting, to illustrate the idea:

By means of the temple, the God is present in the temple ... It is the temple-work that first fits together and at the same time gathers around itself the unity of those paths and relations in which birth and death, disaster and blessing, victory and disgrace, endurance and decline acquire the shape of destiny for human being.

This truth-making is also a world-making; truth takes place in a meeting of 'earth' and 'world' and turns on the vitality that experience gives to knowledge and understanding. I know something as I know my kin, by intimate acquaintance. Familiarity is a staging - of sensation, their affects, the values rising from them. This is the way that the ordinary repetitive familiarity (of, say, going to Mass or going to work) will take shape by means of a temple, and come to 'acquire the shape of destiny'.

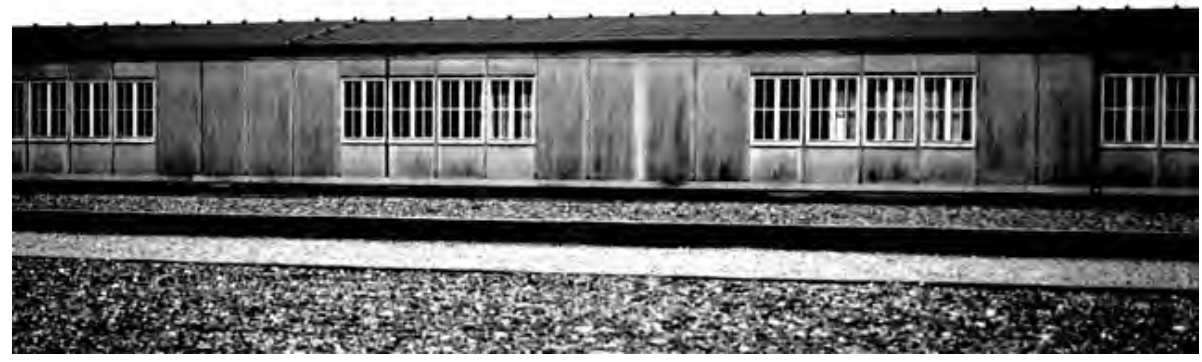

But the artlessness of cultural tourism comes to something of a halt at Dachau. Literally, at the railway station called that, which is just one stop on a suburban Munich line. These days it's known as 'dark tourism', the organized inspection of the sites of atrocities and tragedies, as well as of treasures and marvels.

In the wake of the Jewish holocaust, philosopher Hannah Arendt wrote of the banality of evil. The concentration camp at Dachau is a terrible spectacle, not least because of the impermanent look of its buildings, the temporary and undistinguished huts in which hideous suffering was made commonplace. These places can hardly bear the weight of the scrutiny they must now receive from history. The most solid thing about Dachau seems to have been the motto, cast in iron, over the gate: 'Work makes us free'.

Likewise the pious tone in Heidegger's essay, too, disguises the menace latent in his account of the temple-work. In the setting-up of a space in which experience can come to pass, the temple and the concentration camp equally do their work, their temple-work and their concentration-camp-work.

If truth is present in the work, it is in virtue of the values derived from what was felt and known in the experience. Truth is not an antidote of evil. It can only withdraw 
into world-withdrawal and world-decay. And: 'World-withdrawal and world-decay can never be undone'.

It is not falsified. But as it came to pass, so it can pass. The concentration camp-work, as the staging of the values knows intimately as Nazism, for example, revealed a truth that was, in Heidegger's prophetic words, lived between 'disaster and blessing, victory and disgrace'. Which did not save him from falling for the myth, and disgracing his philosophy by his ambition in accepting a commission from the Third Reich to become Rector of his university.

Truth, as the production of experiences of knowing through the staging of them, is always coming about, as Heidegger says. In the account given of temple-work, truth (and not necessarily 'the truth of') works in the work. But it may also be said to play about a figure, as a shadow flickers, or as a trick of the light. What is understood thereby cannot be guaranteed.

Dark tourism provokes a perverse understanding. The ancient god may no longer be present for us in the temple, nor the Honey Ant Dreamings in the outback landscape. But we still have an absolute faith in the gods of the laboratory, the television and the bourse.

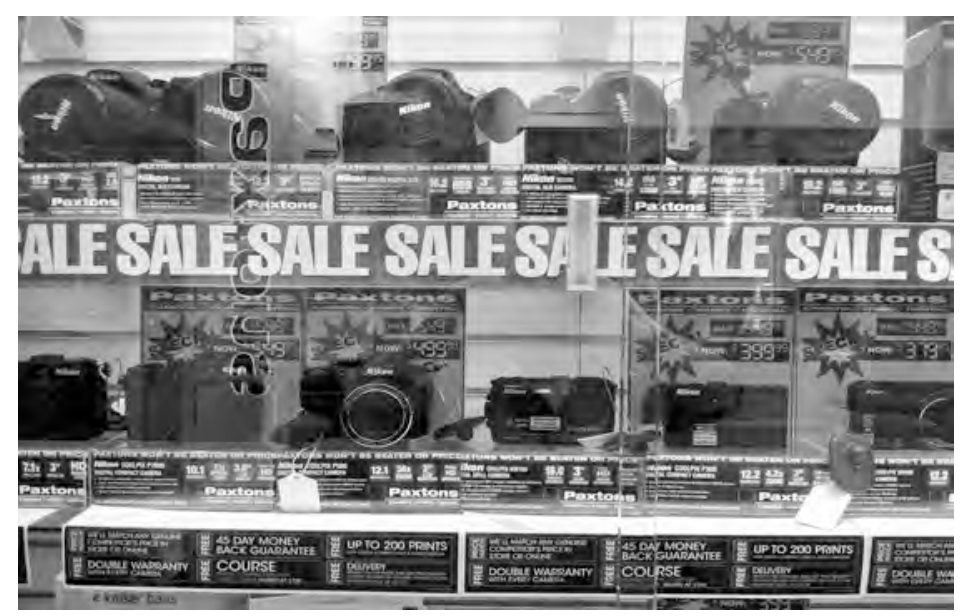

The best is now.

I have two earlier models of these cameras - a Fuji Finepix and a SONY cybershot. They are both perfectly functioning digital cameras, purchased within the last five years, but that was then! Where are they now? At best, they are the 'before' shot in a 'before-and-after' shot.

The point is not so much what these ads sell, but what they market generically. They teach us the consumer way of thinking.

The dollar sign attached to each individual object serves to link them in a series of equivalent commodities. Buy this - or this - or this. Good - Better - Best. On whatever basis the series is constructed - price, features, currency or brand name - it 
is grounded in similarity. The series connects terms, not through narrative, historical, causal or logical consequences, but through likeness (and predominantly visual likeness) that can be played on forward or rewind.

What produces the meaning of these objects is their similarity. The sequence protects, supports and promotes their differences into an intelligible whole. The concern is not with causes but with effects, an emphasis of surface over depth. In the overwhelming stream of images, the really different becomes radically invisible.

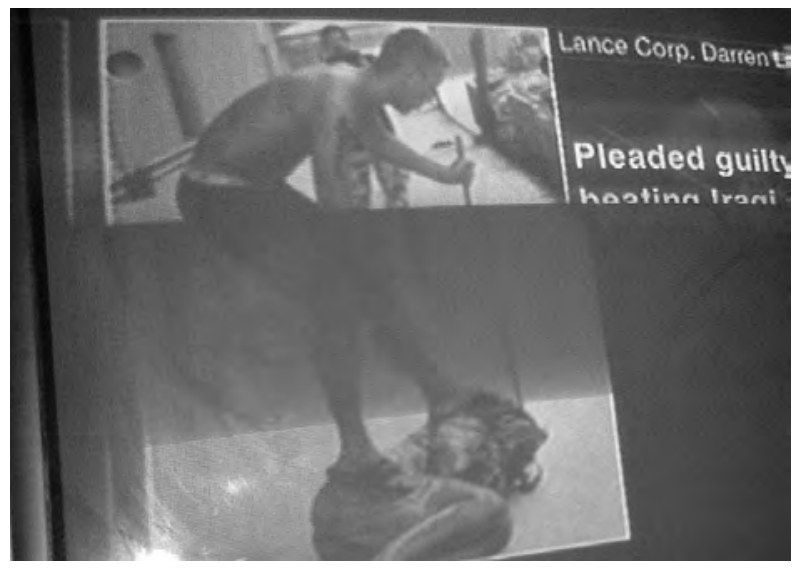

The press photograph proposes an unmediated reality. But of course, however realistic it appears, the photograph remains an image.

'What does the photograph transmit? By definition, the scene itself, the literal reality', in the words of philosopher Roland Barthes.

The press photograph professes to be 'a mechanical analogue of reality', and likewise photojournalism a true presentation of reality. Appearances deceive. We infer from our own general knowledge that the newspaper photograph has been chosen, composed, constructed and treated according to professional, aesthetic, or ideological norms. And it is read, connected more or less consciously by the public that consumes it, to a traditional stock of signs.

The objectivity of the photograph is 'mythical', in the sense that it harbours a belief that gives meaning to other cultural signs. Of course, photojournalism would be regarded in common sense as the antithesis of the sacred, but this only shows how deeply held the myth of the photograph as a record of the real is.

The inherent religiosity invested in the famous image of the twin towers burning on September 11 makes the point. With its iconography of crucifixion, and the surrounding rhetoric of the axis of evil and the sanctity of American life, a reality sprung out of the image of apocalyptic change, and: 'the world will never be the same'.

In more ways than many, this 'media event' raises knowingness of the production of the real through images; for example, many have remarked on how this photo (and the 
video of the same events) are 'like a disaster movie', its spectacular capture creating an iconic 'photo-opportunity'.

The myth of the separation of reality and image is paradoxically so strong that most viewers have no trouble identifying the press photograph as a depiction of what happened. It is as it purports to be. But aliveness to this mythical meaning structuring our view might come from considering the myths of others.

Aboriginal painting of the Central Desert also presents a reality. Anthropologist Eric Michaels has written: 'These paintings make the claim that the landscape does speak and that it speaks directly to the initiated, and explains not only its own occurrence, but the order of the world.' And the same action is also attributed to the Byzantine icon, bringing the devotee into direct communication with the sacred. These possibilities are dismissed today as mere myth or superstition.

Yet the press photograph makes the same claim; that reality speaks directly to the initiated in the image, explaining its own occurrence and the order of the world.

In the photographs of 9/11, we see not only the burning skyscrapers, which we accept as factual and not simulated in a movie sequence. At the same time, we see the sequence as apocalyptic, in the manner of the disaster movie genre. We see sacrilege and historical forces at work, in the transmission of pixels to a screen, of dots to a page.

The belief in the reality of the photograph betrays its religiosity when it claims not only that it is a record of reality, but also that it is the only (real) one.

'Modern man is losing his soul,' writes Julia Kristeva, but he does not know it, for 'that darkroom needs repair.'

On this metaphor, the mind is an apparatus like a darkroom, a process by which light (and other sense impressions) are developed into something meaningful. Kristeva writes in several places of the mystery of life and meaning that is joined in the sacred.

But now in our time, on Kristeva's diagnosis, the body conquers the invisible territory of the soul... 'You are overwhelmed with images, they carry you away, they replace you, you are dreaming...' she writes. The body, or at least a particular secular version of it depicted in neuroscience and biology, has called into question the function of the mind. 'If drugs do not take over your life, your wounds are 'healed' with images, and before you can speak about your states of the soul, you drown them in the world of mass media.'

The question shifts from 'To be or not to be?' to 'To take a pill or to talk?' What do we get from the idea of a 'darkroom of the soul'? Is it a modern version of the so-called primitive anxiety that the photograph will capture your soul? Is the photograph, in its verisimilitude and its ubiquity, actually producing a new kind of self? 
The sacred for Kristeva is 'the mystery of the emergence of meaning (and its celebration)' and 'the impossible and nevertheless sustained connection between life and meaning'. Kristeva distinguishes this mystery from the technocratic 'life without questions', the totalitarianism that seeks to destroy life, or leave life in the domain of the purely instrumental.

But even the darkroom is more mysterious than a mere instrument. When she likens the soul to the darkroom, it is picturing a head-space of images that reach back into childhood, where the word is first an aural image, and where that image is charged with affect for the child as the voice of its mother. The association of ideas, according to Kristeva, is a corporeal process - this is not a body separate from its ideas, but a body that motivates its ideas, and that strings them together according to the movement of bodily energy.

The way pleasures of the body transfer in Western life onto essential cultural operations like literacy, numeracy and citizenship has been explored through the psychoanalysis of children. This is one way in which meaning and being are imagined as joined in each of us.

The maternal has a special place in the sacred, as generative of meaning and being. Its effects move outward in a double action, into real bodies and into the language used by those bodies. When Kristeva talks of life bearing meaning she conjures this extraordinary matrix of feeling and images.

The Circuit Court was sitting the day we came to Turkey Creek. Warmun artist Mabel Juli is a traditional custodian of the Moon and Stars Dreaming, which could be plainly seen in the sky that evening. But she was in court as a mother with other mothers, supporting their adolescent sons on various charges, trying to keep them out of jail.

We were there in the week after the Federal Government declared there was a 'crisis' of child sexual and other abuse in these remote communities and sent in police and doctors over the heads of the autonomous Indigenous councils. It followed from a disturbing Northern Territory report released in the weeks before, titled 'Little Children Are Sacred', citing alcohol and social breakdown as major causes of the routine neglect and abuse of Aboriginal children.

Children are sacred - they are a leading case of the sacred. In Western culture, childhood is invested with all our sentiments, affects and visions that fall outside adult, rational consciousness. This includes, and is exemplified by, the mystery of maternal love that is the miraculous exception to modern economies of exchange.

In the religious icon, communion is offered with the Mother of God; that is, with the image of mother and child as the necessary precursor to becoming a rational citizen. When Julie Dowling frames the child's black face in her painting, 'Icon for a Stolen Child', she animates not only the pain of Aboriginal children taken from their mothers, but also of a generation growing up without their culture and language. The 
'Stolen Generation' was an attempt at genocide, however unconscious and unacknowledged, since it was an attempt to supplant the body signs of an Aboriginal maternal/matrix with the manufactured seeming of colonial lore.

In Dowling's icon, we are solicited to make direct communication again with this loss, and with this 'sacred' connection between word and flesh. When the stolen children were told to forget their Aboriginal names and use only their White ones, it was from this chora that they were cast out. But although imbued with pathos in the Dowling image, this chora is not nostalgia. It is mystery, for it joins meaning and being, the inside to the outside of the culture.

Children are sacred, in the technical sense that their conception represents life bearing meaning, and is the literal product of social laws that mandate some copulations and forbid others. Reproduction of physical beings is primary to the continuation of a culture, race or species, as evidenced by its murderous contradiction, genocide.

They are sacred in that their physical embodiment, growing up around others of their group, means they acquire the meanings of the group as ways of being, and of being embodied. Growing up as a process of acquiring bodily meanings was acknowledged by the removal of children from their families throughout the colonial world, aimed at erasing that sensibility.

Children are sacred in that damage to sensibility - through violence, sexual abuse, racism, nutrition, lack of education - desecrates a culture, weakening its inherent viability.

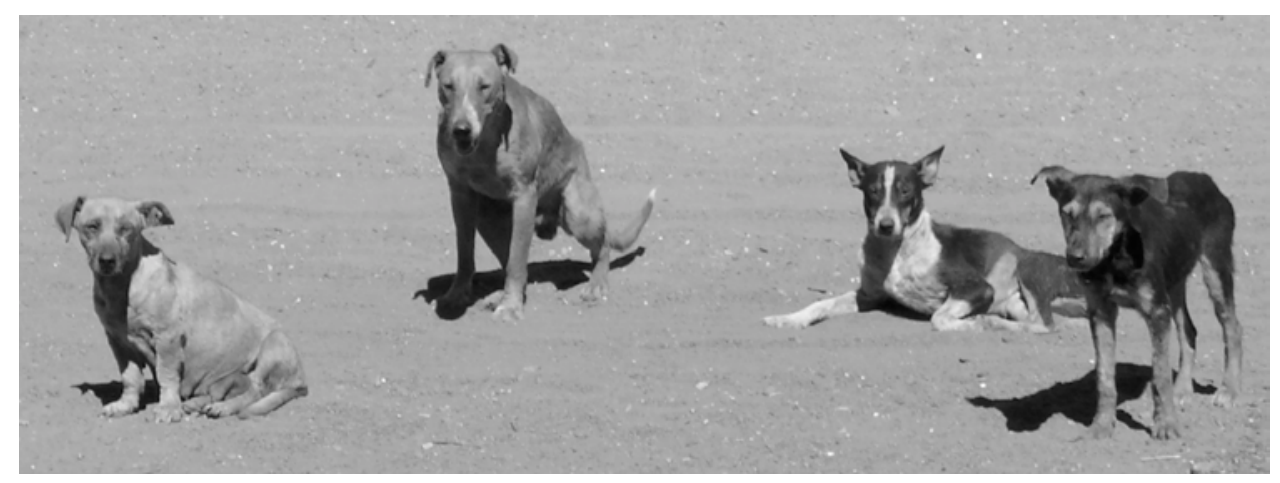

It's a monumental world for the two year old, even though we diminish it as adults. Mother leaves the room, and panic ensues, the realization that the child cannot command the figure that keeps body and soul together. The child cries inconsolably.

'Woof-woof' says the dog, and all animals become 'woof-woof', Kristeva writes.

In 'woof-woof', an object has been identified, separated out from the world. A fragment from the world has become a sign. And then all animals become 'woofwoof' - the sign is generalized, becomes abstracted, the inaugurating of a word, and even of a concept. 
A friend of mine related this 'woof-woof' to the comfort the innocence of childhood can offer us in the face of a cruelly ambivalent world. She wrote about a child she knew: 'When I returned to Australia after 9/11 he welcomed me with open arms and with a smile as big as the world. Aged two, as he was then, he was touched enough by others to welcome; not yet self-possessed or defensive enough to fear the response.'

'But, like all welcomes, his was conditional - I had to sit down and join with him in naming the animals in his picture book.' The apocalypse of terror was challenged by the sanctity of a child's language-game.

'While I continued to call a snake a snake, he was open enough to call a zebra a dog and make me laugh, not at his mistake, but at the rigidity of my own force of law and the ordering of meaning it involves.'

How do we dare hope for things to change? The renewal is promised, paradoxically, by the enduring nature of the sacred: the new joining of meaning and being in every new human life.

Each generation will find the world for themselves, and kinds of good and evil will be redistributed, the body re-ordered. 'If he can be open enough to the strangeness of others and to a different order of things, then so can we all.' 


\section{Independent author}

\section{Gig Ryan}

\section{Two poems}

\section{Biographical note:}

New and selected poems (Giramondo, Australia, 2011); Selected poems (Bloodaxe, UK, 2012); all songs on the CDs Six goodbyes (1988) with the band Disband, and Real estate (1999) and Travel (2006) with the band Driving Past; Poetry Editor at The age newspaper (Melbourne), and freelance reviewer. 


\section{Rally}

I marry at your feet, but only you can move me

$\mathrm{Nu}$ Folk dangles from a deck

My ekphrastic breastplate speaks to the abstruse courtier

Who would think I was one of fourteen?

Your Eleanor, my Isobel, whose slippers in the grate

tarry, but true empathy is kept for this

I make history in the Tower,

fleece the rent to peruse a commentary

time hovels through days' dreamt tyrant

To choir would sully this grasp

Two Americas checked off, one Ireland picked,

all these wrappings.

Hived in insignia your enchained horse canters

as entreaties whistle up a kingdom

I would push my galleons to charge for you

blowy and stern

And here I decipher some longing, the flowered verse

not sent returns to oak.

But let's walk, diplomacy can stick it

Pennants beam into air, and all trials you meant and break, twinned princes not annul but stayed

\section{Central locking}

The bullet-point poem wades benignly

to the artist's pronunciation of its shell, relaxed in a rockpool

Presiding bright spark tweets the newest joy

sing the museum from the dream's props basket's

ill-fitting mask of comedy, and grin

You were one of the great pleasures of the pageant

holding a banner of rights

as Twinkle Toes accosts the mourning ensemble

Imagination shimmers through hotel windows

at the Bathware car to the outskirts

one word would end. The costume pales air

and a suggestion of

He slips his pennyfarthing to an ipad

Where do you stand on coriander?

Liquorland Pure Blonde stuffed in your armpit

Reversing frays the line, avanti the rehearsal's

bundled aspiring. 
Dull sums rest on a screen

as the Euro wallows and Facebook shares skimp

a churlish moon audits supply

and demand, as if either functioned (the narcissists exclaim)

as Autumn steers the footpath's

old newspapers into the leaf-blower's muffed Sisyphus

behind the Sale sign 


\title{
University of South Australia
}

\author{
Kathleen Mary Fallon
}

\section{Spirit of France - a biography}

\section{Kaye Nine}

Biographical note:

Kathleen Mary Fallon holds a Masters from Murdoch University and is working on a $\mathrm{PhD}$ through the Hawke Research Institute, focusing on the Australian South Sea Islander community. She was co-ordinator and lecturer in Creative Writing at the University of Melbourne for eight years and was a Senior Editor at Allen and Unwin. Amongst her major works is a three-part project - a novel, Paydirt (UWAPress), a play, Buyback, and a feature film, Call me Mum (short-listed for the NSW Premier's Prize and an AWGI, nominated for three AFI Awards, winning for Best Female Support Actress). Her novel, Working hot, won a Victoria Premier's Prize and her opera, Matricide - the musical, with the composer Elena Kats-Chernin, was produced by Chamber Made Opera. 
In the empty bar of the Maroubra Hotel, scraping a place for the chairs in the cigarette butts and ash, looking out through the drizzle at the Warning High Pollution Levels Swimming Prohibited beach Tres Bien saw Kaye Nine was sizing her up. Turning her drink on the sopping cardboard coaster, fitting it in and out of sticky concentric circles on the dirty plastic tabletop, Kaye Nine told her something about herself. Something she had judged Tres Bien was ready to hear. She told her about a dog.

She said, 'I tell you this now because I think you will not feel sorry for me. I believe you will take it in the spirit in which it is intended. You will grieve with me, for the $\mathrm{dog}$, and a little bit for the child I was. You won't think of me now as a Poorkid asking for donations and for more understanding in some gauche current affair appealathon program. My sister Marie-Marie and I were on TV one Christmas with a lot of other Poorkids in an appealathon. Viewers were asked to send in Christmas presents for us and in return they each received a lost dog from the Pound. I remember very well that some viewer sent in a xylophone for me. I used to tell my stories all the time. At first I was forced to, to social workers, priests, directors of institutions, counsellors, doctors, psychologists, teachers. I knew they were just wanting to compare what I told them to what they had in front of them on my file. Later I told my stories to friends, lovers, acquaintances, neighbours, people on trains, whoever I could buttonhole for a few hours. I knew I would get sympathy, attention, Poorkid love. People would be kind to me, try to love me and give me what I had missed out on as a Poorkid. Then they'd find a new hobby, a new charitycause, get tired of my stubborn refusals, my failuretothrive under their lovingcare. I do not want that type of attention anymore. I do not want to sing that victim's lament. You understand.' Then she told me about her dog, Mick.

\section{'Make a party story out of this then. You Australians can make a party story out of anything.'}

'Mick. A farmer found him and his brother as puppies running wild and hungry in the forest so he took them home. The farmer wanted to keep Mick's brother because Mick was pretty little and pathetic, so he said, "Take that one". Mick came home with me to the village, running after my bike, tied with a piece of rope, and we loved eachother right away but he kept running back to the farmer and his brother and I'd ride out and fetch him back with a leash tied to the back of the bike. After the third time, when I had to go back to get him I was crying and crying and I said, "Don't you like me Mick. If you run back again I won't come to get you. If you don't want to live with me I won't force you." He followed me home that time without a leash and he never went back to the farm or the farmer or his brother again. His brother died a little while later when he ran straight into a wall. They do that sometimes, dogs. I don't know why. From then on we were together all the time. I'd take my bike and my dog and go into the forest and watch him for hours and hours. He was so happy. And it told me something about happiness - that happiness, it does exist. I was so hard and sad then and that dog gave me a lot, a lot.'

'That year, as usual, my sister, Marie-Marie, and I were sent away for the summer to a holiday camp for Poorkids and at the end of the camp we were not sent home as we 
expected. No one told us why or where we were going. We were sent off to another institution where our father, who we hadn't seen for many years, came to pick us up. All he said was, "You're coming to live with me now".'

'That was after my mother had killed herself and I was so relieved and I was living with my father. After a while, I told him about Mick and we went back to the village to look for him. I asked everyone. I went to the Arab family I'd been friendly with and they said he'd come back for months and months looking for me but hadn't been seen for quite a while now. Before my mother died she was mad, mad and my brother came home one week-end and heard a noise coming from a cupboard. My mother had locked Mick in and forgotten him when she was so out of it. Who knows how long he must have been in there? My brother said he was almost dead and crazy, really crazy. He said he just flew out of the cupboard and out of the house. '

'The ranger hated him. He told me he would shoot him one day and that is probably what happened. My dog was free, roaming in the forest and the ranger hated him.'

'In the Chateau, one of the institutions where my sister Marie-Marie and I were sent, I was mad to get out, grow up, light upon some obsession that could really save me. Something to nail, fixed, to the stark wall of my mind. When I saw Jacques Cousteau in the ocean on television, shush-shush-shushing the other Poorkids running wild in the TV room, "What's that?" I asked the nurse looking after us that day.'

"That's the ocean."

"How do I get there?"

"Well, you become a fisherman or a fisherman's wife, a tour guide, a taxi driver ..." '

\section{Kaye Nine teaches Tres Bien the meaning of the word 'pathos'}

\section{Lesson one - a Leunig cartoon image}

Her first year at Lille University, Kaye Nine lived in a high rise amidst many others on campus. One of these new universities built, after the riots of '68, on the outskirts of regional cities - self-contained, so that the students didn't have to have anything to do with the life of the cities or villages.

'Sometimes you'd have to queue for an hour at the canteen to get your horrible cafeteria food and then have ten minutes to bolt it down. At the weekend or on holidays everyone would leave the campus because it closed down and there was nothing to do there. But I didn't have anywhere to go or any money to go with so I stayed. Often my light was the only one on in my tower and often the only one on the whole campus and I'd sit at my little window, gazing for hours through the dark, abandoned towers, watching the traffic lights far away on the Lille/Paris freeway.'

Pathos! She taught Tres Bien the meaning of the word 'pathos'. That is, she taught her that it existed on the verge of being derived from the same root as pathetic but what stopped it toppling was the fact that it was a word with pride and spirit attached. 


\section{Pathos - lesson two}

'When I was working as an observer on the Russian fishing vessels, one of the sailors asked me if next time I went ashore I would try to sell a little plastic souvenir ashtray with a Mary transfer on it. They weren't allowed to go ashore in case they jumped ship. He explained in his Russian, his broken English and French that they hadn't been paid for months and he wanted to buy a stamp to send a letter home to his wife and kids.'

Pathos has a political dimension. It implicates you; it allows you to act, it makes you empathise.

\section{Pathos - lesson three}

\section{I've left toys behind / I always keep my suitcase packet}

After my sister (well half-sister) Marie-Marie had turned eighteen and been released, she found the institution I was in and came to visit me. She brought me a beautiful doll. It was porcelain or china, something like that. It was so beautiful. One of the guards locked it in a cupboard for safekeeping. When he came on duty he'd unlock the cupboard and give me the doll to play with. But one night a social worker arrived unexpectedly and told me to pack my suitcase because I was being sent to another institution. But the guard who had the key had gone home and I had to leave my doll behind. I cried and cried and they said they'd send it but they never did of course. I still dream about that doll, locked in that cupboard, I still dream that she's waiting for me there still. Still. Still. I know it's ridiculous but sometimes I want to go back to that dark old place, that grim chateau on the edge of that pine forest, I want to go back and look in that cupboard. Of course I know that she won't be there, of course I know that but still. Still. Still.

\section{Mozart, Chopin, Tchaikovsky}

'My mother's vast dreamoflife had reduced to Marie-Marie becoming a concert pianist. We had no furniture, no food, no clothes, all we had in the two room flat where we all lived was wooden boxes, a pile of blankets and a baby grand that my mother Lidia forced Marie-Marie to practice on day and night. We moved many times because we couldn't pay the rent or to avoid the debt collectors. We had nothing but the piano which would have to be lowered over balconies, dismantled to get through doors. And my mother screaming orders and instructions at the removalists. When Marie-Marie went away and my mother's dreams rotted and suppurated in sinks and buckets and under our feet, us kids used the piano lid as a slippery slide, as a table. We had no beds so we slept cosily under the lid on the wires. Turning and tuning the strings all night, parodyplaying Mozartchopintchaishostakovsky as we turned in our sleep. My mother was, by this stage beyond caring or trying - screaming for the rotten chicken in the shower recess, for her enema, her medication, her injection, her abortion, her young lover, her children to help her, any one of her husbands to help 
her, Saint Bernadette of Lourdes to intercede for her, Mother Mary to succour her, just screaming.' Kaye Nine

When Kaye Nine shut the door on her madmother, Lidia, snoring in her drugged sleep, Marie-Marie playing Mozartchopintchaishostakovsky at the baby grand, the suppurating chicken in the shower recess, the murky green slime of the plastic Marybottles of holywater from Lourdes, 'Now I will be happy all day,' she'd say as she closed the door, reciting this magic ritual part of her childhood modus operandi of survival. 'Mary weeps when little girls whistle - sss s s s ss ss sss s s s ss s' she'd sing.

\section{Survival (or an aestheticisation of poverty?)}

\section{'Make a story out of this then. You writers can make a story out of anything.'}

Kaye Nine running all over the cities of the France she lived in. Chasing buses with the right names and numbers on the front, trying to follow them home. Checking in the slots of all the telephones, the food, drink and cigarette dispensers in the Metro, for change.

In those last days Kaye Nine came home one night to find Lidia gone. Days later she returned weighed down by heavy shopping bags, some had burst, their contents long lost, others bulged over. It was the very last time Lidia had that manicsaved joy in her eye. She'd been to Lourdes and blown her whole month's pension cheque on blueheaded Marybottles of holywater, blessed candles, holy knickknacks, the praying of Special Masses, Popeashtrays, rosaries or holycharm bracelets for each of the kids, saintly tracts, illustrated prayer bookmarks and a tiny plastic statue of Mary in a halo of minuscule flashing red bulbs, so many angryswollen gangrenous teats. With these she set up an altar on the lid of the piano, forcing capfuls of holywater through the clenched teeth of her children each day until the water went putrid, until Kaye Nine eventually caught her refilling from the kitchen tap, crossing herself and mumbling some sort of farceprayer as she did so.

\section{Tres Bien reminisces}

Cleaning the laundry in the new house, thinking of that Poorkid, Kaye Nine, fixing the washing machine. Thinking of her respect for and love of the material, useful world. How happy she was when we got the refrigerator, the vacuum cleaner; restored something broken to utility. Her mother, Lidia, enduring the coat-hanger abortions, performed by her husband, on the kitchen table. (France is a Catholic country after all.) Kaye Nine should have been one of them but she hung on with both hands to her mother's rib cage crying a defiant 'no' into those uterine waters. Lidia making Kaye Nine give her enemas, injections in the buttock. Kaye Nine forcing herself to practice on a pillow. Kaye Nine slivering and cutting the callus under Lidia's foot, the corns on her toes, till she hit raw flesh. 'She was very brave,' she said. 'She didn't make a sound.' Kaye Nine down on her hands and knees at eight years of age scrubbing the floor, washing the clothes, learning to wash herself as she'd seen someone do on TV. 'So that's how they get clean,' thought Miss Smelly, as the kids at school called her. 
Over the basin she sponged her face, her arms, her stomach, her legs ... her bottom. 'My bottom? No, leave that till later, till I'm sure about it. That's enough for now.' And Lidia watching, screaming from her serapax sick-bed, 'Who do you think you are Miss High-and-Mighty?'

\section{Making it last}

'Every Sunday morning they'd walk us in a line from the Chateau to the church three kilometres away. If we had some money we were allowed to buy lollies from the shop next door to the church after the service. I'd always buy a chocolate bear and I learnt how to make it last all the way so that I'd be eating the left ear by the time we went back through the gates of the Chateau. I could only make it last like that during winter though.' Kaye Nine

\section{Song of Lidia's daughter Kaye Nine}

\section{A song from the high lake of lamentation}

Most women can't believe that there's not this weak, squashy, longing, whining, whingeing space 'inside' you that you so pitifully, arrogantly, defensively think of as 'yourself,' your 'identity'. They believe that being 'nice,' 'kind,' 'supportive' means revealing this sickening neediness to eachother. (As a dying woman once showed me what had drained into her colostomy bag during the night. As a dying woman once showed me the cancercanker of her breast after breakfast.) They can't seem to conceive that another woman could be different than that. Not contain, veil, mollycoddle this. That someone, say myself for instance, might be able to see right through it to the underdog savagery snarling in the heart of every victim.

\section{Lidia}

'Au succour! Au succour!' she cries into the mal aires decayrotten cavity of the mouth of her night. Her children, still hearing this wail in the winds of the world, turn in their sleep. Turning and tuning the wires of the baby grand. 'Children?' she'd wail 'Dischords!' Her dreams of musical excellence long blasted in the abrasive screech of her voice.

Lidia, that old dero-licked woman, said to me, 'Ever been so low and lonely you rang Life Line just to hear someone say your name, so skin hungry for affection you tried to get a dog to fuck you, a cat to lick you'.

After Lidia died, Kaye Nine found an ancient clock, all face, no hands, ticking away under her bed. She'd felt silly about it but, every night, before she went to sleep, she'd take the clock out and wind it 'so that when I wake up during the night I'll know I'm in my bed not in my grave'. The clock had been given to her by her mother over half a century before. 


\section{Folie a deux (not to mention deja vu) of two too exigent souls}

the other conjured into existence through the mediation of speech

well tended

\section{Tres Bien eavesdrops Kaye Nine's 'Lament of the neutered'}

I have scrubbed out my body

no lover can read it

can't read a blessed thing in it

there is no shadow

there are no shadowy untended places

not the shadow of a stain

there are black out lines

she says she's sick of colouring them in

why can't she be more of a minimalist

Tres Bien says there is a feral child she catches

in the corner of the eye of her blind spot

she wants me to deliver that child over

she says we are twotoo sad children - orphaned children

that that child makes her cry and there's no sex in that

she says she wants us to be twotoo wild feral children

find at last the other half of the pain, the pleasure

at least find a pack to run with

or a flock to fly with

when she says that I only remember the kid with the fork stuck in its cheek in the institution, in the Chateau

or I remember my mother, Lidia

food rotting all over the house

the rancid chicken in the shower recess for instance

the smell of clothes suppurating in buckets in the kitchen

I remember trying to learn to wash myself (but leaving the bottom till another time) and my mother watching me from her bed and screaming 'Who do you think you are, Miss Princess, washing yourself hahaha'.

But most of all I think about Jacques Cousteau flying his chopper into a wilderness, over a desert, over a jungle. I think of the four faces of the terrified feral women who ran in mad circles around eachother in their own panicdust under the whirring silver blades. 'The last survivors of an extinct tribe,' he called them, hailing them through his megaphone. I'm afraid her voice above me in bed chops into the air, is unnaturally loud, is somehow augmented and magnified by her trumpeting heart, her trumpeting sex. Her cargocult hands are held, full up, with promises and presents, she says.

\section{Two too tooserious children}

\section{Two too toosad children}


I learnt all I know from dirty dogs in the backstreets of all the dirtycities of my childhood country France in the National Estate forests and the Private Trespassers Prosecuted forests amongst the cultivated fields where I took them to play

learnt fleshy physicality, boom-or-bust funjoy, catch-as-catch-can friendship, bosombuddy companionship, when-thieves-fall-out manners, DO-NOT-CROSS-THETRACKS-WHEN-THE-BOOM-AND-BELL-ARE-IN-OPERATION

survivalinstincts, sheep-dog mastery, wet-nose-in-crack eroticism, do-doggy sex learnt the sniff and the smell

learnt the growl and the howl well well into the night - full moon or no moon learnt dog-concentration through the simple pleasure of holding the bone learnt to simply exist in mysenses, myviscera, myskin learnt loyalty and nobility and toughness learnt stealth and clevercunning learnt to run with the pack with the scent in my nostrils learnt the ways and the time it takes to tame the abused cur (she wants me running back and forth across the landscape of her body, sniff out her sex, run it to ground, dig up that worry-wish bone)

... but though those two are buried at opposite ends of the earth, one dog will find them both. Djuna Barnes 